ORNL/TM-2015/414

\title{
Optimized properties on base metal and thin-walled tube of Generation II ATF FeCrAl
}

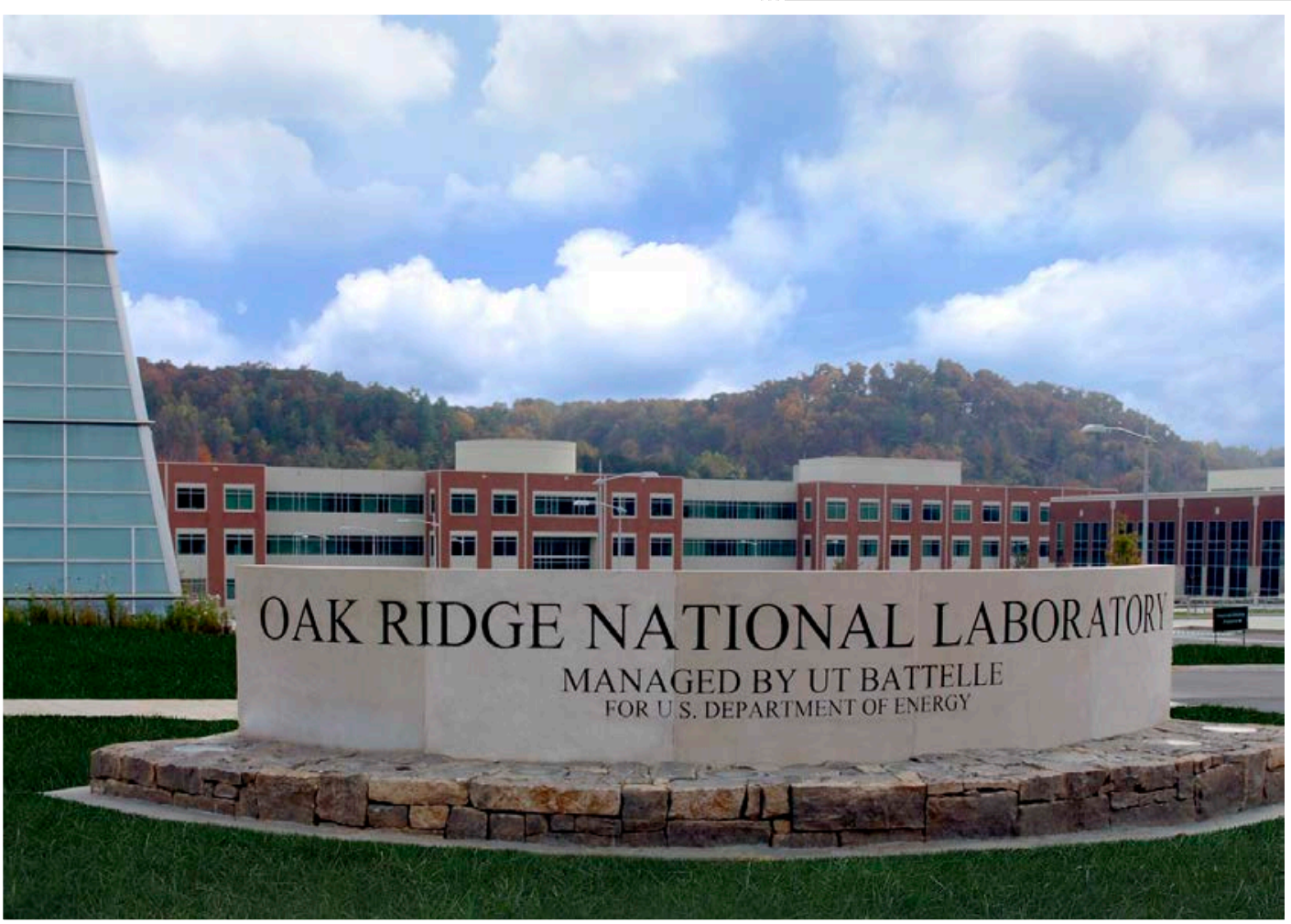

Approved for public release; distribution is unlimited.
Yukinori Yamamoto Maxim N. Gussev Byoungkoo Kim Thak Sang Byun

August 14, 2015 


\title{
DOCUMENT AVAILABILITY
}

Reports produced after January 1, 1996, are generally available free via US Department of Energy (DOE) SciTech Connect.

Website http://www.osti.gov/scitech/

Reports produced before January 1, 1996, may be purchased by members of the public from the following source:

\author{
National Technical Information Service \\ 5285 Port Royal Road \\ Springfield, VA 22161 \\ Telephone 703-605-6000 (1-800-553-6847) \\ TDD 703-487-4639 \\ Fax 703-605-6900 \\ E-mail info@ntis.gov \\ Website http://www.ntis.gov/help/ordermethods.aspx
}

Reports are available to DOE employees, DOE contractors, Energy Technology Data Exchange representatives, and International Nuclear Information System representatives from the following source:

Office of Scientific and Technical Information

PO Box 62

Oak Ridge, TN 37831

Telephone 865-576-8401

Fax 865-576-5728

E-mail reports@osti.gov

Website http://www.osti.gov/contact.html

This report was prepared as an account of work sponsored by an agency of the United States Government. Neither the United States Government nor any agency thereof, nor any of their employees, makes any warranty, express or implied, or assumes any legal liability or responsibility for the accuracy, completeness, or usefulness of any information, apparatus, product, or process disclosed, or represents that its use would not infringe privately owned rights. Reference herein to any specific commercial product, process, or service by trade name, trademark, manufacturer, or otherwise, does not necessarily constitute or imply its endorsement, recommendation, or favoring by the United States Government or any agency thereof. The views and opinions of authors expressed herein do not necessarily state or reflect those of the United States Government or any agency thereof. 


\title{
Optimized properties on base metal and thin-walled tube of Generation II ATF FeCrAl
}

\author{
Yukinori Yamamoto ${ }^{1}$, Maxim N. Gussev ${ }^{1}$, Byoungkoo Kim ${ }^{1}$, Thak Sang Byun ${ }^{2}$ \\ ${ }^{1}$ Oak Ridge National Laboratory \\ ${ }^{2}$ Pacific Northwest National Laboratory (formerly at Oak Ridge National Laboratory)
}

Date Published: August 14, 2015

\section{Work Package Title: Thin walled Tube Development and Testing \\ Work Package \#: FT-15OR020229 \\ Work Package Manager: Yukinori Yamamoto \\ Milestone \#: M2FT-15OR0202291}

Prepared under the direction of the

U.S. Department of Energy

Office of Nuclear Energy

Fuel Cycle Research and Development

Advanced LWR Fuels

Prepared by

OAK RIDGE NATIONAL LABORATORY

Oak Ridge, Tennessee 37831-6285

Managed by

UT-BATTELLE, LLC

for the

U.S. DEPARTMENT OF ENERGY

under contract DE-AC05-00OR22725 
This page intentionally left blank 


\section{CONTENTS}

Page

$\begin{array}{ll}\text { LIST OF FIGURES } & 7\end{array}$

LIST OF TABLES

ACKNOWLEDGEMENTS $\quad 11$

1. EXECUTIVE SUMMARY 12

2. INTRODUCTION 14

3. MATERIAL PROCUREMENTS 16

3.1. Alloy COMPOSITIONS AND THERMO-MECHANICAL TREATMENTS 16

3.2. MicrostruCtURE AND BASIC PROPERTIES 18

3.3. THIN-WALL FABRICATION 20

3.4. TUBE BuRST TESTING $\quad 22$

4. BASE ALLOY PROPERTIES AND THIN-WALL TUBE FABRICATIONS 23

4.1. EFFECT OF Alloying AdDitions on Tensile Properties 23

4.1.1. $\quad$ Effect of $\mathrm{Cr}$ and Al additions on Phase I alloys 23

4.1.2. $\quad$ Effect of Al, Mo, and $\mathrm{Nb}$ additions on Phase I and Phase II alloys 24

4.2. Tube Manufacturing With COMMERCiAl MANUFACTURERS 27

5. TUBE BURST TESTING WITH IN SITU MEASUREMENTS 29

5.1. MATERIALS AND SPECIMEN GEOMETRY 29

5.2. OPTICS PRINCIPLE USED FOR High TEMPERATURE MEASUREMENTS 31

5.3. EQUIPMENT AND SOFTWARE

5.4. CUSTOM-BUILT FURNACE AND SPECIMEN HOLDER 32

5.5. TEMPERATURE MEASUREMENT DETAILS 33

5.6. RESULTS AND DISCUSSION 35

5.6.1. Deformation and burst behavior of candidate alloys 35

5.7. CALCUlation OF HoOP STRAin VAlues 41

5.7.1. $\quad$ Maximum diameter and hoop strain 41

5.7.2. Internal pressure and true hoop stress 43

5.7.3. High-temperature plastic (creep) deformation behavior 45

5.7.4. $\quad$ Rupture temperature versus hoop stress with database 47

6. POST-TEST STRUCTURE CHARACTERIZATION 49

6.1. SPECIMENS TO BE CHARACTERIZED 49

6.2. EXPERIMENTAL METHODS 49

6.3. StRUCTURE EVOLUTION DURING High-TEMPERATURE TEST 50

6.3.1. Optical microscope analysis $\quad 50$ 
6.3.2. Electron microscope analysis 53

7. THE CONCEPT AND DESIGN OF THE ADVANCED IN SITU TESTING 55

7.1. $\quad$ LiMitation OF EXISTING TEST METHOD 55

7.2. CONCEPT AND DESIGN OF ADVANCED TEST SYSTEM

8. SUMMARY AND CONCLUSIONS

9. REFERENCES $\quad 62$ 


\section{LIST OF FIGURES}

\section{Page}

Figure 1. (a) A hot-rolled and annealed FeCrAl alloy with a thickness of $\sim 0.7 \mathrm{~mm}$, (b) a hotforged and annealed FeCrAl alloy bar, and (c) hot-extruded FeCrAl bars with 32 mm diameter

Figure 2. Optical micrographs of Phase I alloy sheet specimens after hot-rolling and annealing; (a) B055Y, (b) B108Y, (c) B136Y, and (d) B137Y 19

Figure 3. Optical micrographs of cross-section and longitudinal section of the hot-forged $\mathrm{FeCrAl}$ alloys; (a) C35M2, (b) C36M, and (c) C35MZ ..... .20

Figure 4. Optical micrographs of Phase II alloy sheet specimens after hot-rolling and annealing; (a) C35MN, HR@1200C, (b) C35MN, HR@800C, and (c) C35M, HR800C. 20

Figure 5. Preparation steps of C35MN6 master tubes to be tube-drawn; (a) annealed cast FeCrAl billets, (b) extruded master tubes by using a mandrel, and (c) the master tubes after cleaning both outer and inner surfaces .21

Figure 6. Preparation steps of C35M3, C36M2, and C37M master tubes to be tube-drawn; (a) extruded master bars, and (c) the master tubes after gun-drilling and cleaning .22

Figure 7. Tube burst test specimen made of the drawn C35M3, before (a) and after weld (b)22

Figure 8. RT tensile properties of Phase I alloys plotted as a function of Al (a, b) and $\mathrm{Cr}$ (c, d). 24

Figure 9. Stress-strain curves of Phase I and Phase II alloys tested at RT, showing the effect of (a) the $\mathrm{Al}$ and $\mathrm{Cr}$ additions and (b) the Mo and $\mathrm{Nb}$ additions on the properties. .25

Figure 10. Temperature dependence of tensile properties of Phase II alloys, showing the effect of (a-c) the $\mathrm{Al}$ addition and (d-f) the $\mathrm{Nb}$ and $\mathrm{Zr}$ additions on the properties .26

Figure 11. A C35MN6 drawn tube failed during drawing process. 27

Figure 12. Drawn tubes after several passes; (a) C37M, failed, (b) C36M2, failed, (c) C35M3, no failure, and (d) C35M3 after further drawing, partially failed. 28

Figure 13. As-received C35M3 drawn tubes with $9.5 \mathrm{~mm}$ diameter and $<0.40 \mathrm{~mm}$ wall thickness .28

Figure 14. A drawing of tube specimen holder .33

Figure 15. Setup of specimen and holder in the furnace, in which four thermocouples are installed: TC2 and TC4 touching at specimen surface and TC1 and TC3 embedded in holder top and bottom bars (the width of the horizontal support plate is $60 \mathrm{~mm}$ ).

Figure 16. The configuration of camera-light source unit. Main components are one camera (C), one lens (L), two light sources (L), and two fans (F) .34

Figure 17. An alloy A-T35Y2 specimen prior (top) and after (bottom) burst test. .36

Figure 18. Two alloy T35Y specimens showing deformation and burst. Note that the cracks with openings (or holes) are marked by white arrows and the deformation of endcaps by black arrows. 
Figure 19. C35M3 alloy specimen before and after the test. Top temperature $~ 1007^{\circ} \mathrm{C} \ldots \ldots . .38$

Figure 20. Diametral change versus temperature curves in the specimens without significant deformation. Note that all of these materials are $2^{\text {nd }}$ generation FeCrAl alloys. .39

Figure 21. Materials with pronounced ( $>2 \%$ ) diameter change. Alloy C35MN5C (which did not demonstrate plastic deformation) is given for comparison. The curves are given for the area with the largest diameter increase.

Figure 22. Temperature dependence of outer diameter converted from optical measurements, i.e., the number of pixels through the specimen diameter.

Figure 23. Temperature dependence of hoop strain. The true strain values were calculated from the outer diameters of specimens.

Figure 24. Internal pressure versus temperature curves. The internal pressure is almost purely dependent on the thermal expansion of helium gas filled in the tubular specimen. The curves deviating from linear lines are because of the ballooning or internal volume expansion of the pressurized tubular specimens.

Figure 25. Temperature dependence of hoop stress in the wall of tubular specimen. The differences in wall thickness and diameter resulted in significantly different hoop stresses. .45

Figure 26. Creep rate versus temperature curves for relatively soft FeCrAl alloys: T35Y, Kanthal-AF, and A-T35Y2.

Figure 27. Comparison of rupture temperature versus hoop stress data. The Zircaloy database is from the reference [21] which integrates the results of tube burst tests by international institutes.

Figure 28. Tested specimens and the scheme of their cutting; (a) T35Y, \#1, and (b) A-T35Y2, \#1

Figure 29. Mounted and polished samples of (a) T35Y, \#1, and (b) A-T35Y2, \#1;. Left, middle: transverse direction; right: longitudinal direction. .50

Figure 30. Optic images of the specimen microstructure. 1-5: different locations along the tube specimen length. (a) T35Y\#1 and (b) A-T35Y2,\#1. .51

Figure 31 Microstructure at different locations. Position \#4 corresponds to the neck location. (a) T35Y, \#1, and (b) A-T35Y2, \#1 .52

Figure 32 SEM image depending on distance from necking location, (a) T35Y\#1 and (b) AT35Y2,\#1.

Figure 33. The scheme (at the left) and a general view of the first furnace offered by the vendor. .56

Figure 34. The general view of the modified furnace. The black arrow points the optic port. The design and geometry followed the light furnace used in the current test station. .57

Figure 35. Modified furnace. 1 - light optic heater. 2 - water cooling channels. .57

Figure 36. The final inspection of the furnace body (the image provided by the vendor). .....58

Figure 37. A picture showing the test run of new furnace installed in the test station .59 


\section{LIST OF TABLES}

Page

Table 1. Nominal and analyzed compositions of Phase I alloys.........................................16

Table 2. Nominal and analyzed compositions of Phase II alloys ......................................17

Table 3. RT tensile properties of Phase I alloys ..............................................................23

Table 4. Chemistry and final processes for candidate cladding materials; the highlighted materials were prepared under the current program via machining (blue) or tube processing (red)

Table 5. Summary on the dimensional changes and temperature parameters .......................35

Table 6. Hoop stress data at initial and final moments in deformation-burst tests .................40

Table 7. Specimen weight changes before and after deformation-burst test .........................41

Table 8. Summary of creep parameters .....................................................................47

Table 9. Average wall thickness of the tubes before and after testing (in micrometer) ..........52

Table 10. Average grain size of the tubes before and after testing (in micrometer)...............54 
This page intentionally left blank 


\section{ACKNOWLEDGEMENTS}

The authors are grateful to Kurt Terrani, Bruce Pint, and Mary Snead of Oak Ridge National Laboratory (ORNL) for their helpful discussions, and Mike Howell and Tom Geer for their technical supports. The time spent by Kevin Field of ORNL in reviewing this report is also greatly appreciated.

This research was funded by the U.S. Department of Energy's Office of Nuclear Energy, Advanced Fuel Campaign of the Fuel Cycle R\&D program. 


\section{EXECUTIVE SUMMARY}

There are two objectives in this milestone report: one is to report the optimization effort of the

$2^{\text {nd }}$ generation ATF FeCrAl alloys to date, with a specific focus on the mechanical properties of both Phase I and Phase II alloys (model alloys and modified alloys, respectively) under the optimization process. The other objective is to evaluate the high-temperature behavior of various FeCrAl alloys via in situ deformation measurements.

In the context on reporting the optimization efforts, the effect of the $\mathrm{Al}, \mathrm{Mo}, \mathrm{Nb}$, and $\mathrm{Zr}$ additions on the properties has been evaluated, and the FeCrAl alloy processbility has been discussed which aims to support the thin-wall tube fabrication through commercial manufacturing processes. It includes actual thin-wall tube fabrication efforts of the selected 2nd generation ATF FeCrAl alloys with a commercial tube-drawing company.

Room temperature tensile properties of hot-rolled Phase I alloys were evaluated, and compared as a function of the $\mathrm{Cr}$ and $\mathrm{Al}$ additions in a nominal composition range of Fe-(0-18)Cr-(3-8)Al$\mathrm{Y}$, in weight percent. It was found the tensile strength increased with increasing the $\mathrm{Al}$ content with a rate of 35-100 MPa/\% Al at a given Cr content. The $\mathrm{Cr}$ addition also increased the tensile strength, although the increasing rate was less than one third of the $\mathrm{Al}$ addition. It was also found that the effect of the $\mathrm{Al}$ addition on the properties was minimized above $700^{\circ} \mathrm{C}$. Property evaluation of hot-processed Phase II alloys with minor alloying additions of $\mathrm{Mo}, \mathrm{Nb}$, and $\mathrm{Zr}$ indicated that nearly 50\% improvement of tensile strength compared to the Phase I alloy could be obtained by combining with the proper process condition (e.g. 2 wt.\% Mo $+0.3 \% \mathrm{Zr}$ additions, hot-forged at $650^{\circ} \mathrm{C}$ ). The key factor for improving high-temperature tensile properties is the thermal stability of the deformed microstructure consisting of sub-grains, and it requires further investigation to understand the mechanism of the thermal stability improvement.

Thin-wall tube fabrication has been initiated with support from commercial manufacturers. The C35M3 (Fe-13Cr-5.2Al-2Mo-0.2Si-0.03Y) alloy was successfully drawn to be a thin-wall tube with $9.5 \mathrm{~mm}$ diameter and $<0.4 \mathrm{~mm}$ wall thickness through tube-drawing process with a mandrel at $320^{\circ} \mathrm{C}$. However, it was found that the property improvement from the $\mathrm{Al}$ or $\mathrm{Nb}$ additions actually poisoned the processbility of tube-drawing because such alloying additions made the materials being susceptible to work hardening and more difficult to be deformed at the process temperature, which limited the range of the alloy compositions that can be drawn.

To address the second objective of this report, an advanced in situ deformation and burst testing method has been developed to provide in situ data on material behavior at high temperature under simulated loss of coolant accident (LOCA) scenario. Shortened tube specimens were sealed by laser welding in a pressurized atmosphere. The measurement method was based on visual imaging and allowed for the analysis of plastic strain behavior, creep properties, hoop stress and strain up to $1050^{\circ} \mathrm{C}$. A number of candidate materials were tested including Phase II $\mathrm{FeCrAl}$ alloys and $\mathrm{FeCrAl}$ alloys with oxide dispersions (otherwise known as oxide dispersion strengthened (ODS) demonstrating the advantages of the in situ analysis.

However, since a usual electric resistance furnace was employed, the developed method had definite limitations on the environment, temperature ramp rates, and internal specimen pressure. 
To overcome these limitations, new furnace with an optic port was designed and manufactured to be used together with an already operational test rig for LOCA testing house at ORNL, known as the LOCA test station. The advanced system, as expected, will allow for in situ specimen dimension measurements under a wide range of temperature and internal pressure conditions. The installation of the newly designed optical furnace with windows has been completed, and the test run to heat up to $1000^{\circ} \mathrm{C}$ without tube specimens was successfully conducted.

Additionally, the detailed microstructure characterization of the tube burst tested specimens (T35Y, \#1 and A-T35Y2) was conducted, and compared with the as-received tube samples. Asreceived tubes consisted of uniform grain structure with around $70 \mu \mathrm{m}$ size, together with globular yttrium-rich oxides $(5 \sim 10 \mu \mathrm{m})$ dispersed in the grain interior and on the grain boundaries. Dynamically recrystallized grains as well as the creep voids were observed near the rupture area in the burst-tested specimens. Large plastic deformation was also observed at the necking area. Both inter-granular and trans-granular cracks were found at the ends of specimens. From the microstructure characterization, the localized plastic deformation seems to be a dominant factor of the tube burst, rather than the brittle fracture. 


\section{INTRODUCTION}

The development of nuclear-grade enhanced accident tolerant fuel cladding alloys targets a new, metal-base structural material for nuclear fuel cladding, substituting for zirconium alloys, that exhibits greatly improved accident tolerance, including good mechanical properties in a wide temperature range as well as oxidation and irradiation resistance under normal and transient operating conditions. FeCrAl alloys were selected based on their excellent oxidation resistance in high temperature steam environments up to $1475^{\circ} \mathrm{C}$ (provided by the sufficient amounts of $\mathrm{Cr}$ and $\mathrm{Al}$ additions), compared to the industry standard zirconium alloys which would not have such high temperature tolerances $[1,2,3,4]$. This is the key for enhancing safety margins under severe accident conditions by limiting the heat and hydrogen production, which occurs when the fuel cladding reacts with steam during a severe accident [5]. With superior high temperature strength compared to zirconium alloys, utilization of this class of alloys is expected to enhance burst margins during design basis accident scenarios and potentially for conditions extending beyond those limits.

The deployed design strategy for the ATF FeCrAl alloys at Oak Ridge National Laboratory (ORNL) includes improving strength while maintaining high temperature oxidation resistance of $\mathrm{FeCrAl}$ alloy(s) resulting in excellent structural and environmental performance under normal operation $\left(\sim 320^{\circ} \mathrm{C}\right)$ and potential accident conditions (up to $\left.\sim 1300-1400^{\circ} \mathrm{C}\right)$. The ATF FeCrAl alloys should also have a good fabricability since the final cladding tube products will need to be fabricated through conventional industrial equipment (extrusion, drawing, etc.) in commercial manufacturers to keep the ATF cladding option cost effective with current Zr-based cladding options. This is another key factor for successful development of the ATF FeCrAl, and the efforts are currently in progress [6]. The ATF FeCrAl development projects were initiated in FY2013 under the Fuel Cycle Research and Development program [7]. It consisted of two phases; in Phase I, it was targeted to find base Fe-Cr-Al-Y alloy compositions of the nucleargrade $\mathrm{FeCrAl}$ alloys for LWR fuel cladding with accident tolerance, through the evaluation of fundamental properties, such as the tensile properties, oxidation resistance, fabricability, and weldability, as a function of the major alloying elements. It was found that the higher Cr addition would be better for corrosion or oxidation resistance to support the stability of alumina-scale in a wide temperature range, although it would increase potential embrittlement of the materials at relatively lower temperatures due to the formation of $\sigma$-FeCr or $\alpha$-Cr phases [8]. Irradiation effect on microstructure evolution, such as acceleration of $\alpha-\mathrm{Cr}$ formation or the formation of dislocation loops, has been evaluated and discussed under the same program [9]. The higher Al addition was found to be beneficial for the oxidation resistance, especially at elevated temperatures, but it may raise the ductile-brittle transition temperature (DBTT) which could affect the room temperature fabricability [10].

Based on the results in Phase I, a candidate base FeCrAl alloy composition, Fe-13Cr-4.5Al$0.05 \mathrm{Y}$ in weight percent, was downselected for further optimization under the second phase of the development program. Variants of the Fe-13Cr-4.5Al-0.05Y are otherwise called " 2 "nd generation ATF FeCrAl alloys”. Minor alloying additions were applied through guidance from computational thermodynamics for improved strengths together with sufficient oxidation 
resistance at elevated temperatures, as well as a good fabricability for potential commercial tube fabrication. Laboratory heats as well as commercially fabricated heats were used for the property evaluation as a function of not only the alloy compositions but also the fabrication processes. Trial thin-wall tube fabrication of the selected $2^{\text {nd }}$ generation ATF FeCrAl alloys was also initiated with support of commercial manufacturers who provided the large size FeCrAl alloy cast ingots and the tube-drawing process to make thin-wall tube products. The details and the efforts to date of the thin-wall tube fabrication are being summarized elsewhere [6].

In parallel to the ATF FeCrAl alloy development, the evaluation of tube burst characteristics was also conducted by using pre-pressurized FeCrAl tubes and in situ tube deformation observation during continuous heating. The development of evaluation methodology was summarized in the previous report $[11,12]$. It was concluded that the rupture temperatures of Phase I alloys at a given hoop stress were comparable to commercial zirconium alloys. Terrani et al. [13] also reported the tube burst behavior under simulated LOCA conditions, and the results exhibited the advantage of FeCrAl alloy (Phase I) compared to the zirconium alloys in steam environments. Since the design strategy of $2^{\text {nd }}$ generation ATF FeCrAl alloys focused on the improved high temperature properties, better performance of the tube burst resistance can be expected in the Phase II alloys.

There are two objectives in this milestone report; one is to report the optimization effort of the 2nd generation ATF FeCrAl alloys to date, especially focusing on the mechanical properties of both Phase I and Phase II alloys under the optimization process. The effect of the $\mathrm{Al}, \mathrm{Mo}, \mathrm{Nb}$, and $\mathrm{Zr}$ additions on the properties has been evaluated, and the FeCrAl alloy processbility has been discussed which aims to support the thin-wall tube fabrication through commercial manufacturing processes. It includes actual thin-wall tube fabrication efforts of the selected 2nd generation ATF FeCrAl alloys with a commercial tube-drawing company. The other is to summarize the evaluation of the tube burst behavior of various FeCrAl alloys via in situ deformation and burst observation captured by a high-temperature, high-speed digital camera. This part compares the creep deformation of the tubes among the commercial alloys and the developed FeCrAl alloys under the program. Microstructure characterization of the burst tubes was also conducted. The new test furnace installation for in situ tube burst characterization at the current LOCA test station has also been initiated. The design strategy as well as the current status of the installation is summarized. 


\section{MATERIAL PROCUREMENTS}

\subsection{Alloy Compositions and Thermo-mechanical Treatments}

Table 1 summarizes the nominal and analyzed compositions of the Phase I alloys in the range of $0-17.51$ wt. $\%$ Cr, $4.44-7.80 \% \mathrm{Al}$, and $0.003-0.120 \%$ Y, with balanced Fe. They were selected to investigate the effect of the $\mathrm{Cr}$ and $\mathrm{Al}$ additions of various properties including oxidation resistance and tensile properties. The oxidation resistance of the alloys is being reported or has been reported elsewhere [2,14]. The alloys were cast by arc-melting in a back-filled argon gas atmosphere with pure element feedstock and pre-alloyed Al-Y to make button ingots. The ingots were then drop-cast to a water-cooled copper mold with a size of $13 \times 25 \times 125 \mathrm{~mm}(\sim 500 \mathrm{~g})$ to make bar-shape ingots, or $36 \mathrm{~mm}$ diameter $\times 100 \mathrm{~mm}$ length to make a columnar ingot. The ingots were homogenized at $1200^{\circ} \mathrm{C}$ for more than $2 \mathrm{~h}$, and then thermo-mechanically processed by using hot-forging at $1200^{\circ} \mathrm{C}$, followed by rolling at $700^{\circ} \mathrm{C}$ to make plate specimens with a final nominal sheet thickness of 0.7-0.85 mm. Some of the cast ingots were hot-rolled without pre-forging. Subsequent annealing in a temperature range from $700-750^{\circ} \mathrm{C}$ after the rolling process was applied to control the recrystallized grain structure with a size range of 30-80 $\mu \mathrm{m}$. Note that T35Y2 was prepared by a vacuum induction melting to make a $\sim 7 \mathrm{~kg}$ ingot through Sophisticated Alloys, Inc., Butler, PA, followed by hot-extrusion process at $1050^{\circ} \mathrm{C}$ and annealing at $700^{\circ} \mathrm{C}$ (designated as "HE+Ann" in the latter part of this report) at ORNL, which resulted in the equi-axed grain structure similar to the other Phase I alloys.

Table 1. Nominal and analyzed compositions of Phase I alloys

\begin{tabular}{ccccccccc}
\hline \multirow{2}{*}{ ID } & \multicolumn{9}{c}{ Nominal, wt $\%$} & \multicolumn{3}{c}{ Composition, wt\% } \\
\cline { 2 - 9 } & Fe & Cr & Al & Y & Fe & Cr & Al & Y \\
\hline B055Y & 89.95 & 5 & 5 & 0.05 & 90.09 & 5.04 & 4.81 & 0.032 \\
\hline B058Y & 86.95 & 5 & 8 & 0.05 & 87.16 & 5.04 & 7.73 & 0.037 \\
\hline B085Y & 86.95 & 8 & 5 & 0.05 & 87 & 8.05 & 4.87 & 0.064 \\
\hline B086Y & 85.95 & 8 & 6 & 0.05 & 86.06 & 8.07 & 5.81 & 0.035 \\
\hline B087Y & 84.95 & 8 & 7 & 0.05 & 85.17 & 8.04 & 6.76 & 0.010 \\
\hline B088Y & 83.95 & 8 & 8 & 0.05 & 84.01 & 8.13 & 7.81 & 0.036 \\
\hline B106Y & 83.95 & 10 & 6 & 0.05 & 83.98 & 10.06 & 5.93 & 0.003 \\
\hline B107Y & 82.95 & 10 & 7 & 0.05 & 83.1 & 9.98 & 6.87 & 0.039 \\
\hline B108Y & 81.95 & 10 & 8 & 0.05 & 82.17 & 10.00 & 7.80 & 0.019 \\
\hline T35Y & 82.35 & 13 & 4.5 & 0.15 & 82.26 & 13.18 & 4.44 & 0.070 \\
\hline T35Y2 & 82.35 & 13 & 4.5 & 0.15 & 82.26 & 13.15 & 4.44 & 0.120 \\
\hline B136Y & 80.95 & 13 & 6 & 0.05 & 80.85 & 12.99 & 6.14 & 0.003 \\
\hline B137Y & 79.95 & 13 & 7 & 0.05 & 80.00 & 13.00 & 6.98 & 0.003 \\
\hline B154Y-a & 80.85 & 15 & 4 & 0.15 & 80.99 & 15.03 & 3.92 & 0.035 \\
\hline B155Y-a & 79.85 & 15 & 5 & 0.15 & 79.88 & 15.21 & 4.83 & 0.063 \\
\hline B183Y-a & 79.35 & 17.5 & 3 & 0.15 & 79.52 & 17.51 & 2.93 & 0.017 \\
\hline B184Y-a & 78.35 & 17.5 & 4 & 0.15 & 78.39 & 17.51 & 3.91 & 0.043 \\
\hline
\end{tabular}


Table 2 summarizes the nominal and analyzed compositions of Phase II alloys. The base alloy composition, Fe-13Cr-4.5Al-Y, was selected based on the property evaluation of the model $\mathrm{FeCrAl}$ alloys in the previous efforts [7], and minor alloying additions such as Mo, Nb, Zr, Si, and $\mathrm{Al}$ were made in order to expect the improved properties at elevated temperatures. The alloys were cast by arc-melting and drop casting to make laboratory scale heats with $~ 500 \mathrm{~g}$ at ORNL, or a vacuum induction melting (VIM) to make $20 \mathrm{~kg}$ ingots through Sophisticated Alloys, Inc. (corresponding to the alloys with "*” in the table). The alloys C35MN and C35N were hot-rolled and annealed at 1200 and $800^{\circ} \mathrm{C}$ which would be designated as "HR@1200C" and "HR800C", respectively, in the latter part of the report. The alloys C35MZ, C35M2, and C36M were hot-forged and annealed at $650^{\circ} \mathrm{C}$ which would be designated as “HF@650C”. The alloys C35MN5/6, C35M3, C36M2, and C37M were hot-extruded and annealed at 800 or $1150^{\circ} \mathrm{C}$ which would be designated as “HE@800C” or “HE@1150C”, respectively.

Table 2. Nominal and analyzed compositions of Phase II alloys

\begin{tabular}{|c|c|c|c|c|c|c|c|c|c|c|}
\hline \multirow{2}{*}{\multicolumn{2}{|c|}{ ID }} & \multicolumn{8}{|c|}{ Composition, wt $\%$} & \multirow{2}{*}{ Remarks } \\
\hline & & $\mathrm{Fe}$ & $\mathrm{Cr}$ & $\mathrm{Al}$ & $\mathrm{Y}$ & Mo & $\mathrm{Si}$ & $\mathrm{Nb}$ & $\mathrm{Zr}$ & \\
\hline \multirow{2}{*}{ C35MN } & Target & 79.25 & 13 & 4.5 & 0.05 & 2 & 0.2 & 1 & & \multirow{2}{*}{ Hot-rolled, 4.2Al alloy } \\
\hline & Analyzed & 79.96 & 12.77 & 4.22 & 0.032 & 1.94 & 0.21 & 0.81 & & \\
\hline \multirow{2}{*}{ C35MN5* } & Target & 78.55 & 13 & 5.2 & 0.05 & 2 & 0.2 & 1 & & \multirow{2}{*}{$\begin{array}{l}\text { Extruded, for tube burst } \\
\text { testing (by gun-drilling) }\end{array}$} \\
\hline & Analyzed & 78.68 & 13.02 & 5.08 & 0.032 & 1.99 & 0.21 & 0.97 & & \\
\hline \multirow{2}{*}{ C35MN6* } & Target & 78.55 & 13 & 5.2 & 0.05 & 2 & 0.2 & 1 & & \multirow{2}{*}{ Extruded, for tube-drawing } \\
\hline & Analyzed & 78.7 & 13 & 5.11 & 0.044 & 1.99 & 0.18 & 0.96 & & \\
\hline \multirow{2}{*}{ C35MZ } & Target & 79.55 & 13 & 5.2 & 0.05 & 2 & 0.2 & & 0.3 & \multirow{2}{*}{ Hot-forged } \\
\hline & Analyzed & 79.34 & 13.02 & 5.16 & 0.01 & 1.97 & 0.18 & & 0.29 & \\
\hline \multirow{2}{*}{ C35M } & Target & 80.25 & 13 & 4.5 & 0.05 & 2 & 0.2 & & & \multirow{2}{*}{ Hot-rolled, 4.2Al alloy } \\
\hline & Analyzed & 80.88 & 12.68 & 4.22 & 0.031 & 1.92 & 0.20 & & & \\
\hline \multirow{2}{*}{ C35M2 } & Target & 79.55 & 13 & 5.2 & 0.05 & 2 & 0.2 & & & \multirow{2}{*}{ Hot-forged } \\
\hline & Analyzed & 79.67 & 13.06 & 5.15 & 0.01 & 1.97 & 0.12 & & & \\
\hline \multirow{2}{*}{ C35M3* } & Target & 79.55 & 13 & 5.2 & 0.05 & 2 & 0.2 & & & \multirow{2}{*}{$\begin{array}{l}\text { Extruded, for tube-drawing } \\
\text { and burst testing }\end{array}$} \\
\hline & Analyzed & 79.43 & 13.06 & 5.31 & 0.053 & 2 & 0.13 & & & \\
\hline \multirow{2}{*}{ C36M } & Target & 78.75 & 13 & 6 & 0.05 & 2 & 0.2 & & & \multirow{2}{*}{ Hot-forged } \\
\hline & Analyzed & 79.03 & 12.91 & 5.93 & 0.01 & 1.97 & 0.13 & & & \\
\hline \multirow{2}{*}{ С36M2* } & Target & 78.75 & 13 & 6 & 0.05 & 2 & 0.2 & & & \multirow{2}{*}{-Extruded, for tube-drawing } \\
\hline & Analyzed & 78.4 & 13 & 6.29 & 0.059 & 1.99 & 0.2 & & & \\
\hline \multirow{2}{*}{ C37M* } & Target & 77.75 & 13 & 7 & 0.05 & 2 & 0.2 & & & \multirow{2}{*}{-Extruded, for tube-drawing } \\
\hline & Analyzed & 77.49 & 13.01 & 7.22 & 0.081 & 1.99 & 0.19 & & & \\
\hline
\end{tabular}

Typical images of the FeCrAl alloy samples after thermo-mechanical treatments are shown in Figure 1, such as hot-rolled plates, hot-forged bar, and hot-extruded bars. Microstructure observation was conducted typically from the longitudinal section (the transverse direction) of the samples, and occasionally from the cross section (the longitudinal direction). Sub-sized dogbone shape sheet specimens (SS-3) with $0.7 \mathrm{~mm}$ thickness, $1.5 \mathrm{~mm}$ width, and $7.6 \mathrm{~mm}$ length at the gage portion were machined from these plate/bar samples, in which the tensile axis was always parallel to the longitudinal axis of the plate/bar samples. The tensile test was conducted in 
the range from room temperature to $900^{\circ} \mathrm{C}$ in a laboratory air with the cross-head control and the nominal deformation rate of $10^{-3} \mathrm{~mm} / \mathrm{mm} / \mathrm{s}$.

(a) A hot-rolled plate

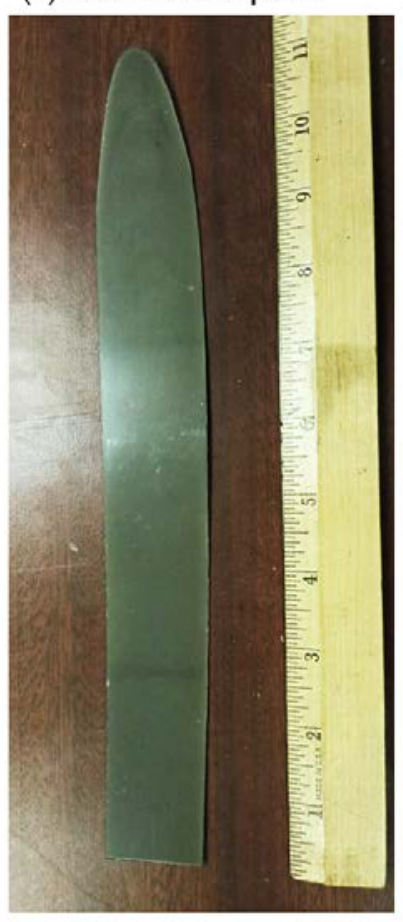

(b) A hot-forged bar

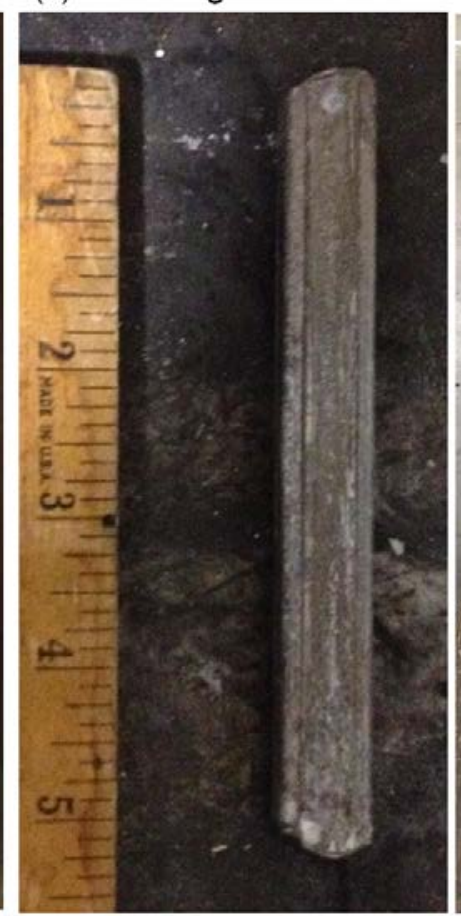

(c) Hot-extruded bars

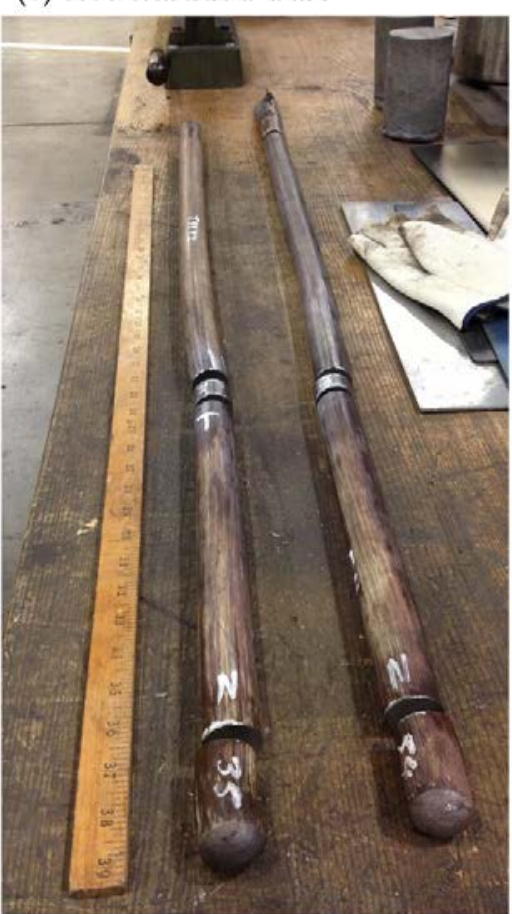

Figure 1. (a) A hot-rolled and annealed FeCrAl alloy with a thickness of $\sim 0.7 \mathrm{~mm}$, (b) a hotforged and annealed FeCrAl alloy bar, and (c) hot-extruded FeCrAl bars with 32 mm diameter

\subsection{Microstructure and Basic Properties}

Figure 2 represents typical longitudinal sectional microstructure of the Phase I alloys after hotrolling and annealing. All of them showed mostly recrystallized grain structure with the size range of $\sim 30-80 \mu \mathrm{m}$. The hot-rolling temperature and the amount of thickness reduction were selected to control the grain size through "hot-deformation" and "recrystallization" [7], although it sometime failed to make a fully recrystallized state and the non-recrystallized, elongated grains would remain as shown in Figure 2b. However, the volume of this elongated grains were typically very small so that such grains are ignored when the average grain size was measured. The average grain size seems decreasing with increasing the Y content. The B055Y showed 30$50 \mu \mathrm{m}$ grain size with $0.032 \mathrm{wt} . \% \mathrm{Y}$ (Figure $2 \mathrm{a}$ ), and the B136Y showed $\sim 80 \mu \mathrm{m}$ grain size with 0.003 wt.\% Y (Figure 2c). This was attributed to the formation of yttrium-rich oxide or intermetallic particles in the matrix which would pin the grain boundary slowing down the grain coarsening during/after recrystallization, and the larger Y contents resulted in more amounts of the particles due to the low solubility of $\mathrm{Y}$ in the Fe matrix. 

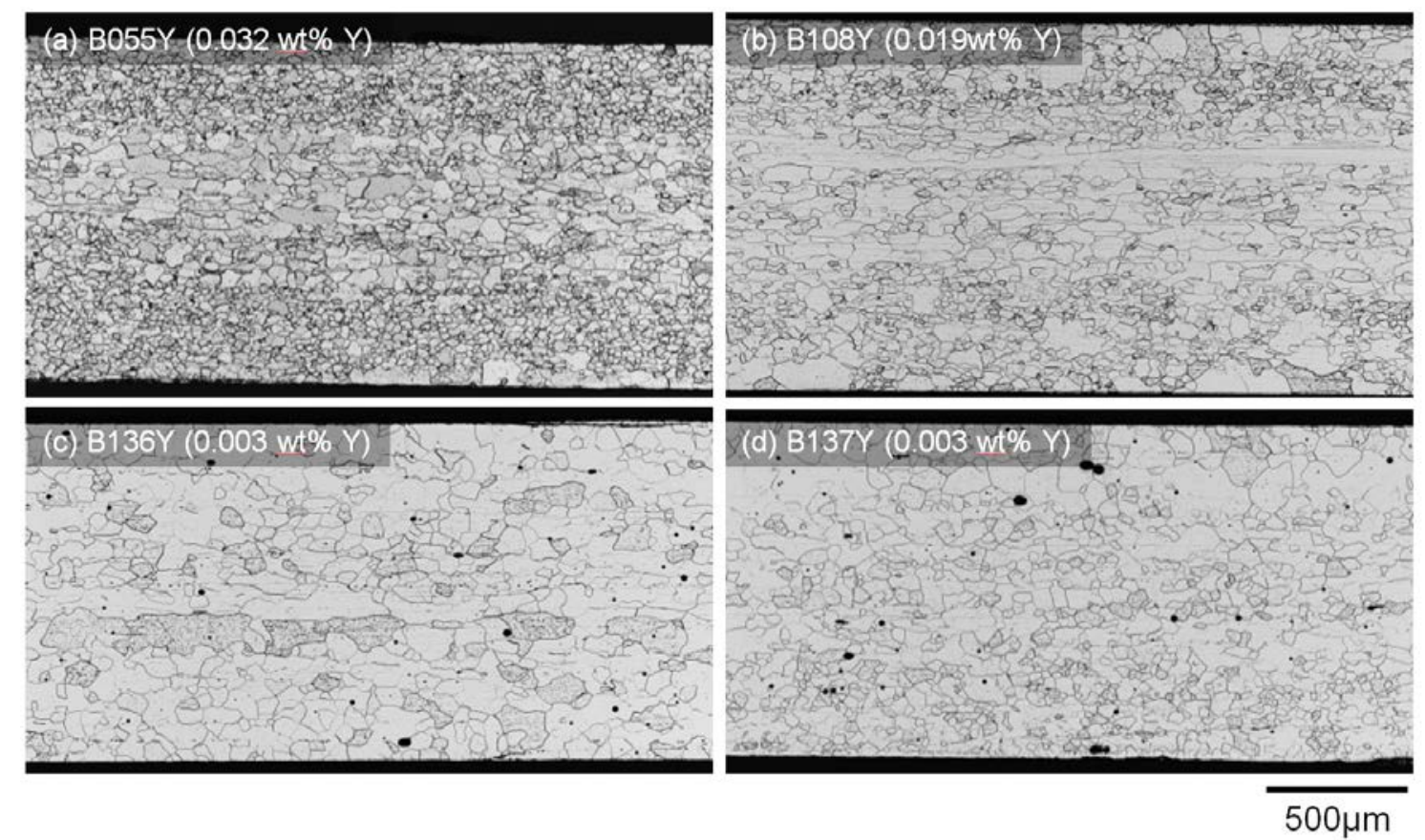

Figure 2. Optical micrographs of Phase I alloy sheet specimens after hot-rolling and annealing; (a) B055Y, (b) B108Y, (c) B136Y, and (d) B137Y

Figure 3 shows the cross-sectional and the longitudinal-sectional OM pictures of the hot-forged FeCrAl alloys, reported previously [15]. The forging and annealing temperature was $650^{\circ} \mathrm{C}$ which was not sufficient for the alloys to be recrystallized during the processes, so that only the deformed microstructure can be observed. Detailed characterization indicated that the microstructure consisted of sub-grain structure with $\sim 3-5 \mu$ m sized sub grains. It should be noted that the high $\mathrm{Al}$ alloy (C36M) and the $\mathrm{Zr}$ containing alloy (C35MZ) showed more severe deformed features compared to the C35M2 alloy. It is correlated to the third element effects on the deformation resistance (e.g. increasing work hardenability), which will be discussed in the next chapter.

Figure 4 illustrates temperature and composition dependences of the microstructure of the hotrolled Phase II alloys. As reported previously [7,15], C35MN exhibited quite different microstructure between two different hot-rolling temperatures, 1200 and $800^{\circ} \mathrm{C}$. The C35MNHR@1200C showed equi-axed grain structure with 100 $\mu$ m grain size, whereas the HR@800C resulted in non-recrystallized, deformed microstructure which consisted of sub-grain structure with 1 $\mu \mathrm{m}$ size of sub grains. On the other hand, the C35M-HR@800C sample showed recrystallized grain structure with 50 $\mu \mathrm{m}$ grain size. The C35MN-HR@800C sample showed more than 25\% improvement of room temperature tensile properties compared to the C35MHR@800C sample. These results indicate that the Nb addition drastically increased the thermal stability of such deformed microstructure, and supported to improve mechanical properties, as discussed previously $[7,15]$. Note that the hot-extruded C35MN5/6 at $800^{\circ} \mathrm{C}$ also showed similar microstructure to the C35MN-HR@800C. 
(a) $\mathrm{C} 35 \mathrm{M} 2(5.2 \mathrm{Al})$

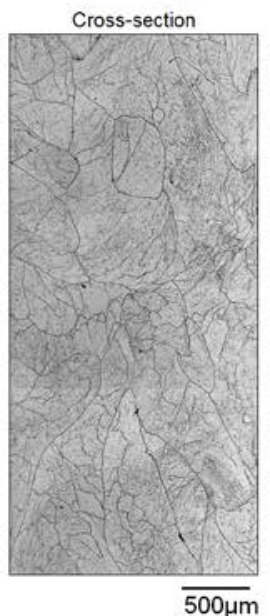

(b) C36M (6Al)

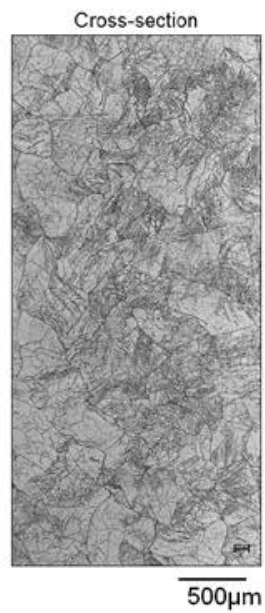

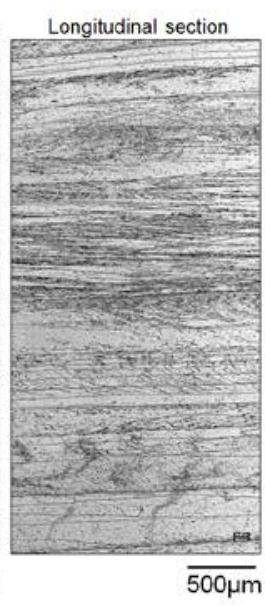

(c) $\mathrm{C} 35 \mathrm{MZ}(5.2 \mathrm{Al}+0.3 \mathrm{Zr})$
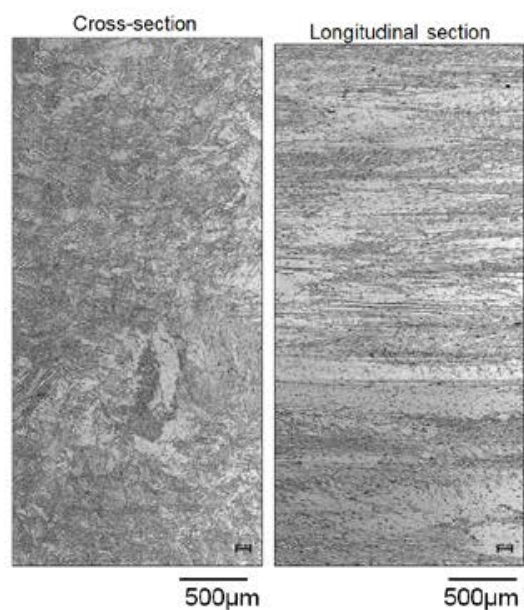

Figure 3. Optical micrographs of cross-section and longitudinal section of the hot-forged FeCrAl alloys; (a) C35M2, (b) C36M, and (c) C35MZ

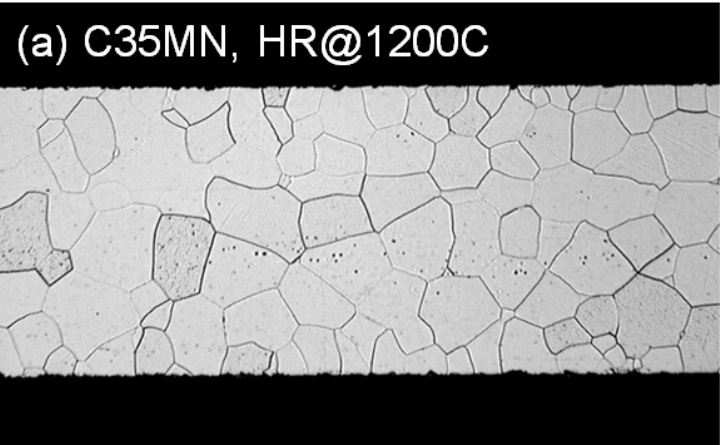

\section{(b) C35MN, HR@800C}

\section{(c) C35M, HR@800C}
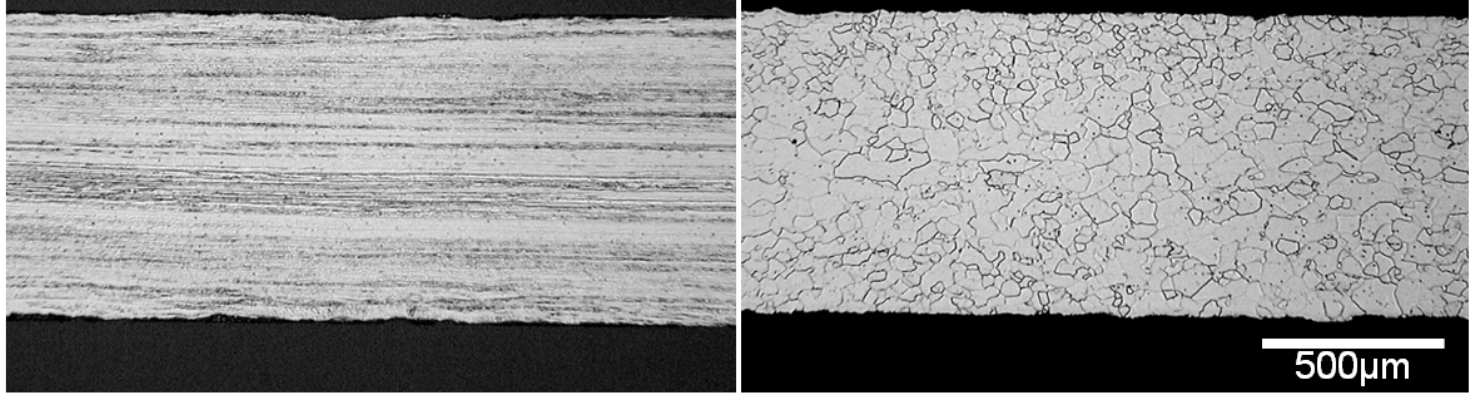

Figure 4. Optical micrographs of Phase II alloy sheet specimens after hot-rolling and annealing; (a) C35MN, HR@1200C, (b) C35MN, HR@800C, and (c) C35M, HR800C

\subsection{Thin-wall Fabrication}

The C35MN6 alloy was selected for the first trial tube fabrication via commercial manufacturers, because of its strength when the microstructure was controlled with sub-grain structure [7], as 
well as the thermal stability as described in the previous section. The vacuum induction melt ingot with 3.4” diameter x 18” length was prepared by Sophisticated Alloys, Inc. The ingot was homogenized at $1200^{\circ} \mathrm{C}$, and then machined into two billets with a hole, and then hot-extruded with a mandrel at $1150^{\circ} \mathrm{C}$ to make master tubes with 1.5 ” outer diameter (OD) x 0.3 ” wall thickness (WT) x 38-40" length, processed at ORNL (Figure 5). The master tubes were sent to Rhenium Alloys, Inc., North Ridgeville, $\mathrm{OH}$, for surface machining prior to the drawing process, and then they were pre-annealed for solution heat treatment. The master tubes with a size of 1.25” OD x 0.125 ” WT were then warm-drawn by using a mandrel and a steel die. The detailed tube drawing process is proprietary; therefore the process steps will only be discussed qualitatively in the next chapter.
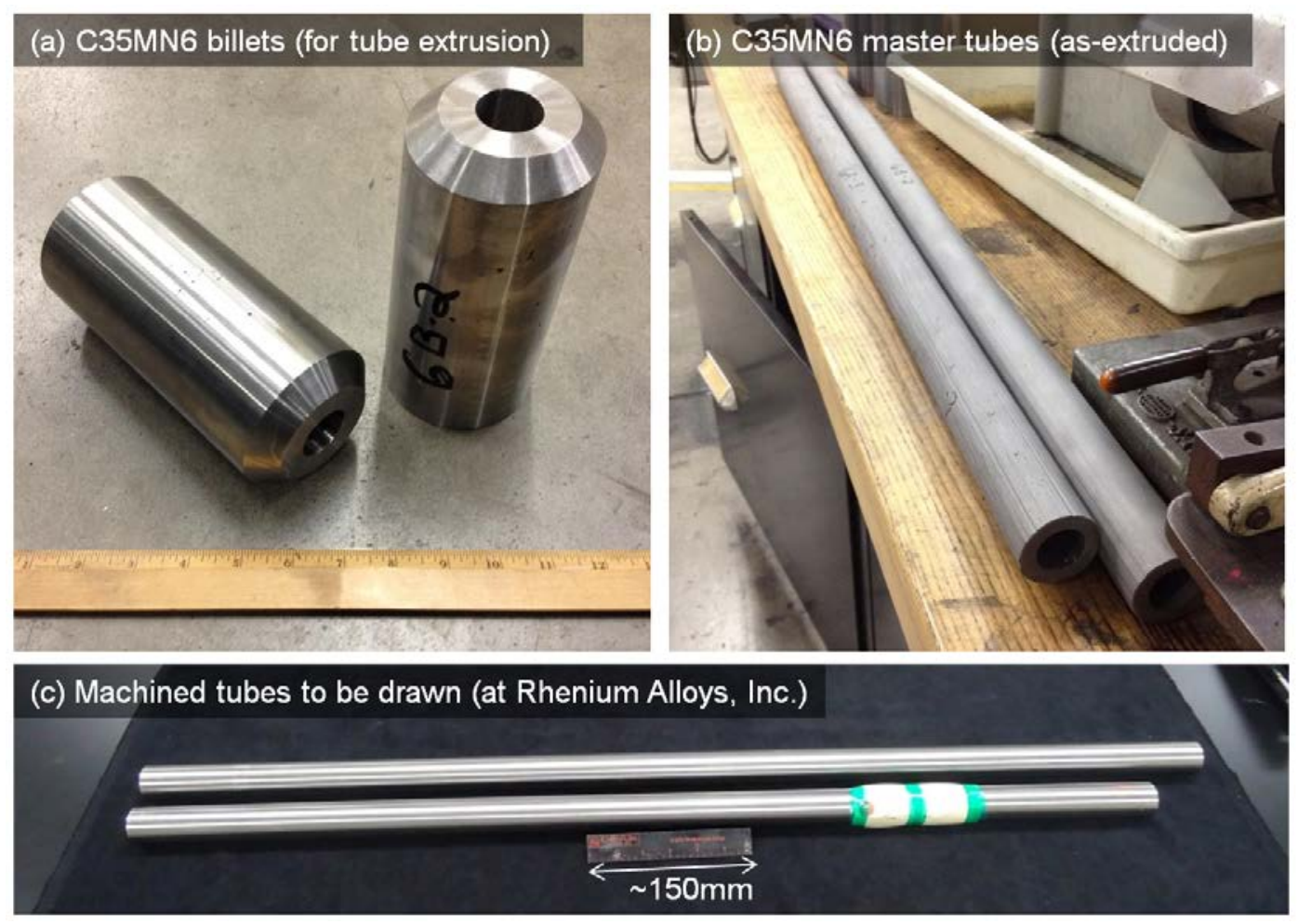

Figure 5. Preparation steps of C35MN6 master tubes to be tube-drawn; (a) annealed cast FeCrAl billets, (b) extruded master tubes by using a mandrel, and (c) the master tubes after cleaning both outer and inner surfaces

The C35M3, C36M2, and C37M alloys were also selected for the second trial tube fabrication at Rhenium Alloys, Inc. The VIM ingots were homogenized at $1200^{\circ} \mathrm{C}$, and then extruded at $800^{\circ} \mathrm{C}$ to make bar samples as shown in Figure 6. The bars were straightened, gun-drilled to make 1.0” OD x 0.1 ” WT, cleaned, and then annealed at the Rhenium Alloys, Inc., and then warm-drawn by using a mandrel and a steel die, similar to the C35MN6 alloy. 


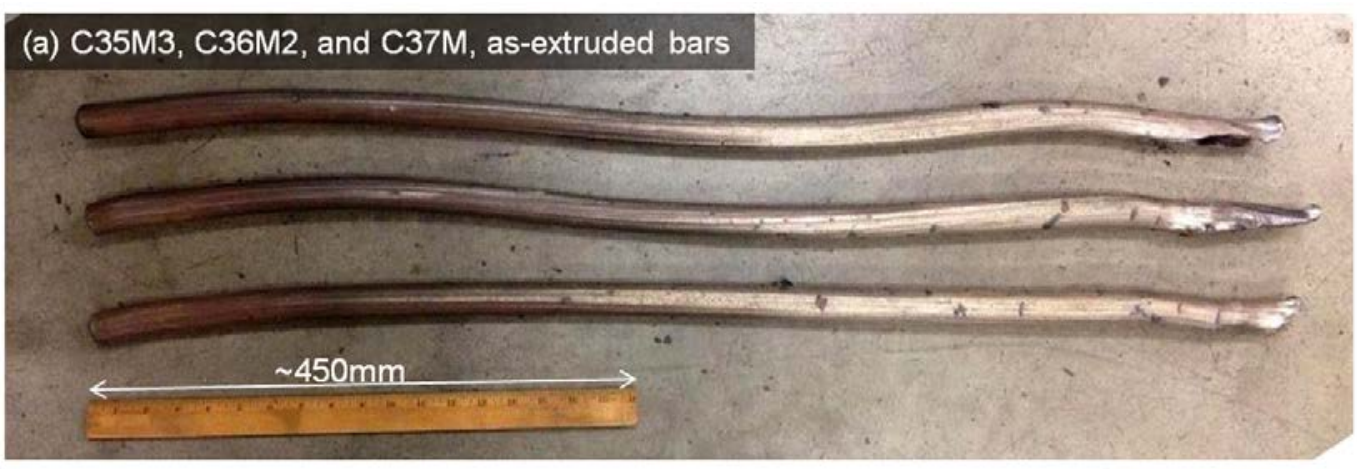

(b) Machined and gun-drilled tubes to be drawn (at Rhenium Alloys, Inc.)

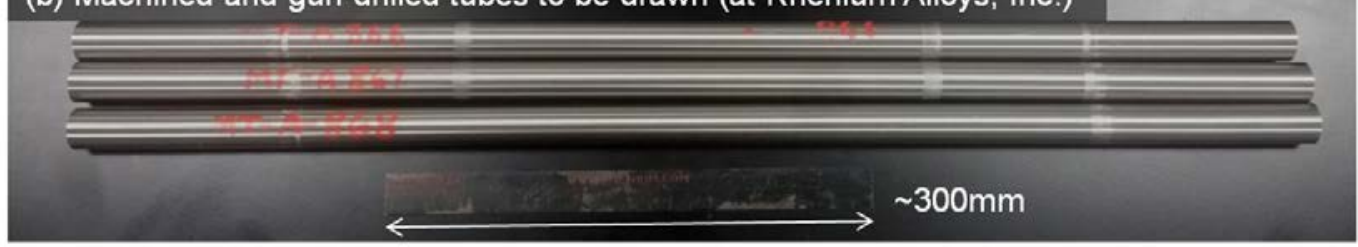

Figure 6. Preparation steps of C35M3, C36M2, and C37M master tubes to be tube-drawn; (a) extruded master bars, and (c) the master tubes after gun-drilling and cleaning

\subsection{Tube Burst Testing}

The tube burst testing of pre-pressurized FeCrAl tubular specimens were conducted. Two different tubes were newly provided; a drawn C35M3 provided by Rhenium Alloys, Inc., and a seamed and drawn Kanthal AF tube, as shown in Figure 7. The as-drawn tubes were annealed at $600^{\circ} \mathrm{C}$ for $1 \mathrm{~h}$, followed by air-cooling, in order to relieve potential residual stress due to the warm drawing process. The tubes with $~ 50 \mathrm{~mm}$ length and two end caps made of C35M3 bulk piece (one end has a small hole) were e-beam welded in a vacuum, followed by laser beam welding inside a chamber with He gas atmosphere pressurized at $0.3 \mathrm{ksi}$ (2.07 MPa). The detailed experimental procedure of the testing followed the previous report [11], and described in Chapter 5.
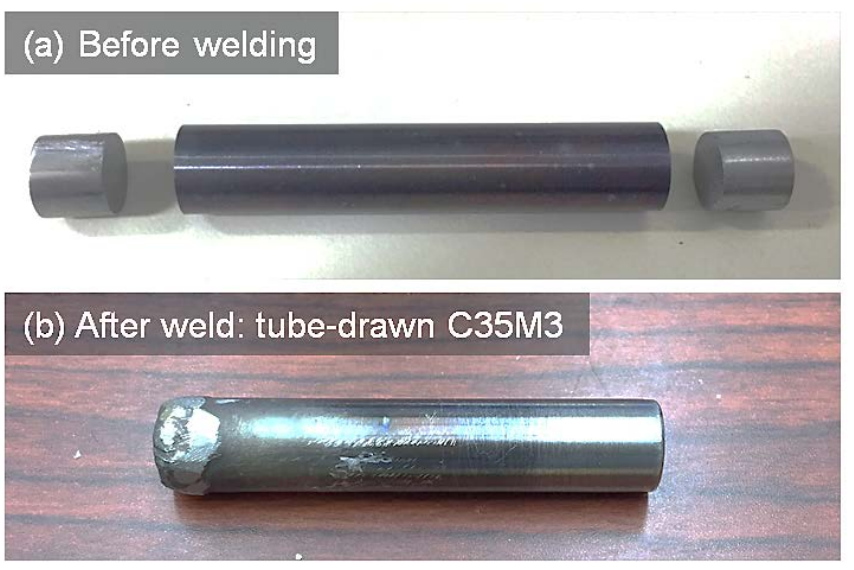

Figure 7. Tube burst test specimen made of the drawn C35M3, before (a) and after weld (b) 


\section{BASE ALLOY PROPERTIES AND THIN-WALL TUBE FABRICATIONS}

\subsection{Effect of Alloying Additions on Tensile Properties}

\subsubsection{Effect of $\mathrm{Cr}$ and Al additions on Phase I alloys}

Table 3 and Figure 8 summarize all room temperature tensile test results of Phase I alloys. The tensile data were sorted with the $\mathrm{Cr}$ or $\mathrm{Al}$ contents, and then plotted as a function of the $\mathrm{Al}$ or $\mathrm{Cr}$ contents, respectively. In Figure 8a and b, it clearly shows that the yield and the ultimate tensile strength increase with increasing the $\mathrm{Al}$ content at any given $\mathrm{Cr}$ levels. It seems no significant effect of the $\mathrm{Cr}$ additions on the strengths between 5 to $13 \mathrm{wt} . \% \mathrm{Cr}$ alloys, but the $\mathrm{Al}$ dependence on the strength are similar to each other, with a rate of $\sim 35 \mathrm{MPa} / \mathrm{wt} . \% \mathrm{Al}$ in the range studied. The alloys with 15 and 17.5 wt.\% Cr show significant increase of the strength compared to the low-range $\mathrm{Cr}$ alloys, as well as the large $\mathrm{Al}$ dependence with a rate of $\sim 100 \mathrm{MPa} / \mathrm{wt} . \% \mathrm{Al}$. The ductility shows the opposite tendency for both the $\mathrm{Al}$ and $\mathrm{Cr}$ additions, namely the lower the $\mathrm{Al}$ or $\mathrm{Cr}$ the better for RT ductility.

Table 3. RT tensile properties of Phase I alloys

\begin{tabular}{ccccc}
\hline \multirow{2}{*}{ ID } & \multicolumn{2}{c}{ Strength (MPa) } & \multicolumn{2}{c}{ Plastic } \\
\cline { 2 - 5 } & Yield & Ultimate & Uniform & Total \\
\hline B055Y & 362 & 480 & 26.9 & 40.1 \\
\hline B058Y & 507 & 616 & 12.3 & 26.5 \\
\hline B085Y & 392 & 518 & 23.4 & 35.6 \\
\hline B086Y & 421 & 528 & 14.5 & 28.9 \\
\hline B087Y & 472 & 574 & 13.1 & 26.8 \\
\hline B088Y & 493 & 610 & 13.8 & 29.6 \\
\hline B106Y & 426 & 536 & 17.2 & 32.0 \\
\hline B107Y & 534 & 646 & 12.8 & 23.7 \\
\hline B108Y & 503 & 665 & 14.1 & 23.4 \\
\hline T35Y2 & 384 & 536 & 21.8 & 37.5 \\
\hline B136Y & 442 & 580 & 15.7 & 33.3 \\
\hline B137Y & 474 & 646 & 12.9 & 31.0 \\
\hline B154Y-a & 428 & 541 & 15.1 & 28.3 \\
\hline B155Y-a & 505 & 618 & 13.5 & 26.3 \\
\hline B183Y-a & 354 & 459 & 19.5 & 35.4 \\
\hline B184Y-a & 462 & 568 & 14.1 & 26.7 \\
\hline
\end{tabular}

On the other hand, the effect of the $\mathrm{Cr}$ additions on the tensile properties is not so significant compared to the $\mathrm{Al}$ addition, as can be seen in Figure 8c and d. The $\mathrm{Cr}$ dependence of the yield and ultimate tensile strengths exhibits a rate of $\sim 13 \mathrm{MPa} / \mathrm{wt} . \% \mathrm{Cr}$ in the case of the $5 \% \mathrm{Al}$ alloys, and much lower than that in the other Al levels, indicating that the effect of the $\mathrm{Cr}$ addition would be only less than one third of the $\mathrm{Al}$ addition. 
It should be noted that in the previous report the $\mathrm{Al}$ and $\mathrm{Cr}$ dependences on the tensile properties were not so significant $[7,16]$, because the range of $\mathrm{Al}$ and $\mathrm{Cr}$ contents were narrower than the current study.
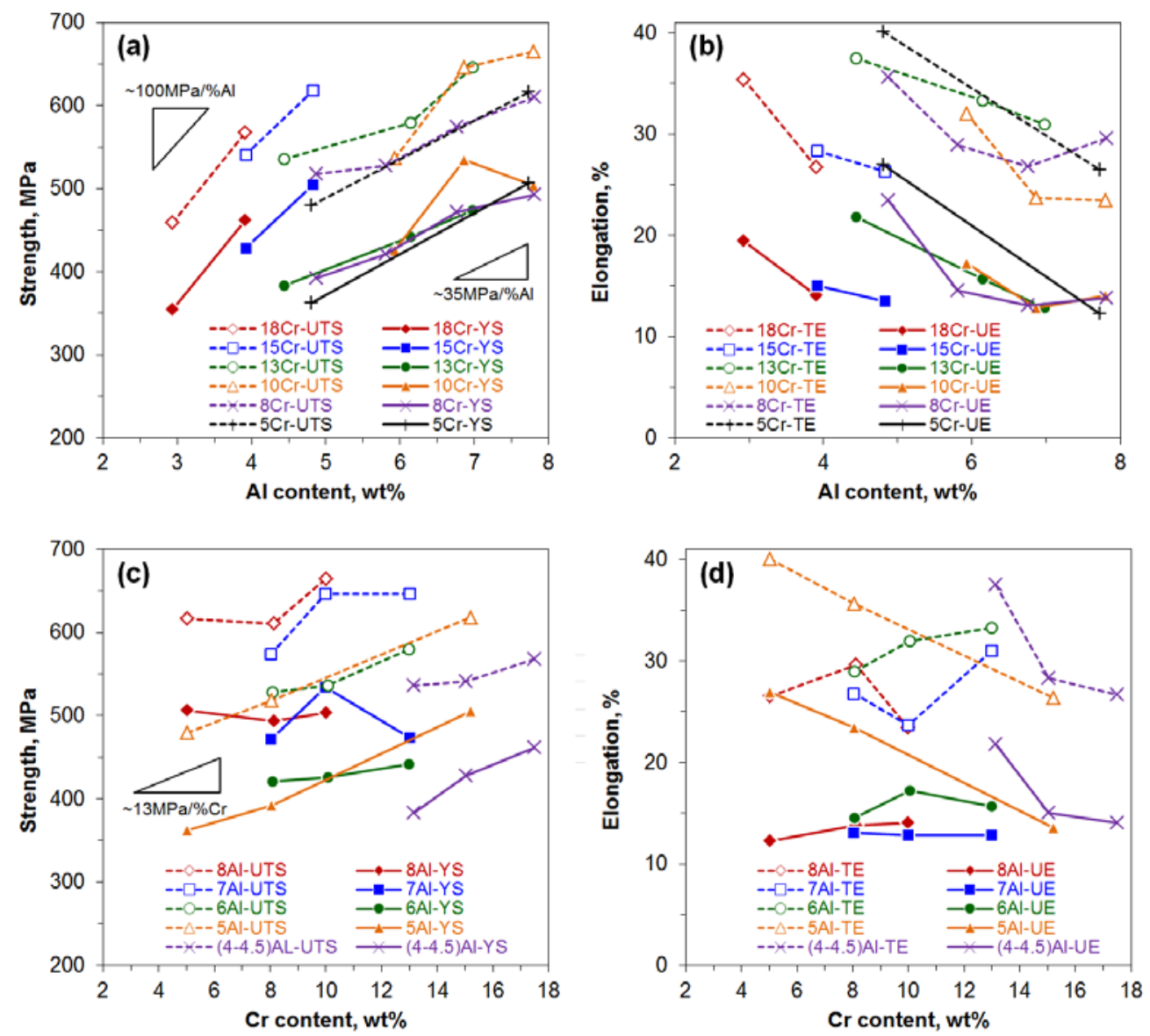

Figure 8. RT tensile properties of Phase I alloys plotted as a function of $\mathrm{Al}(\mathrm{a}, \mathrm{b})$ and $\mathrm{Cr}$ (c, d).

\subsubsection{Effect of $\mathrm{Al}, \mathrm{Mo}$, and $\mathrm{Nb}$ additions on Phase I and Phase II alloys}

Figure 9a compares the stress-strain curves of the alloys containing 13wt.\% Cr, and shows the effects of the $\mathrm{Al}$ and $\mathrm{Cr}$ additions on the curves. The $\mathrm{Al}$ addition increases not only the yield and ultimate tensile strength as described in the previous section but also the work hardenability (the slope after yielding), and the changes look significant even with only $1 \mathrm{wt} . \%$ increment of the $\mathrm{Al}$ addition (from 6 to $7 \mathrm{wt} . \%$ ). This indicates that the $\mathrm{Al}$ addition increases the deformation resistance significantly, and it is very sensitive to the amount of $\mathrm{Al}$. It is not preferable when considering the processbility needed to fabricate thin-walled tubing from FeCrAl alloys. On the other hand, the work hardening is less sensitive to $\mathrm{Cr}$ additions, as seen when comparing the curves of B166Y (16Cr-6.1Al) and B136Y (13Cr-6.1Al). Figure 9b represents the effect of the Mo and $\mathrm{Nb}$ additions on the curves of 13Cr-(4.2-4.4)Al alloys. The addition of 2 wt.\% Mo appears to have nearly the same net effect of the Al addition (+1.7 wt.\%) on increasing the strength, and the further addition of $0.8 \mathrm{wt} . \% \mathrm{Nb}$ results in increasing $150 \mathrm{MPa}$ more yield strength, indicating that the material becomes stronger but it is more difficult to deform. All 
materials were tested in a solution heat-treated condition, so that the strengthening effect comes from the solution hardening. Since the $\mathrm{Nb}$ addition is effective for improving the high temperature microstructure stability [15], it requires proper optimization to balance the beneficial and detrimental effects of its addition in the FeCrAl based matrix. The optimization effort is currently in progress.
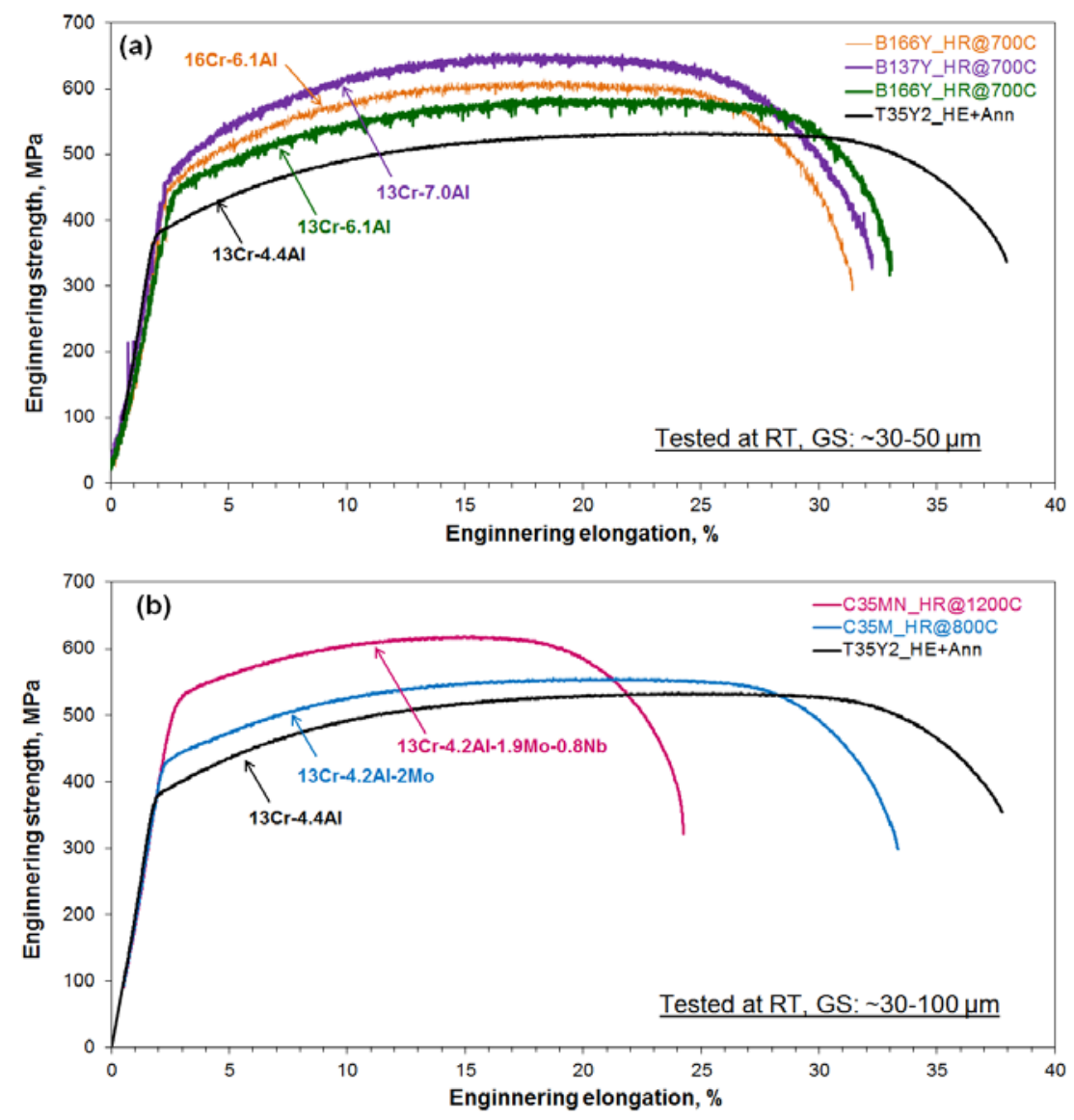

Figure 9. Stress-strain curves of Phase I and Phase II alloys tested at RT, showing the effect of (a) the $\mathrm{Al}$ and $\mathrm{Cr}$ additions and (b) the Mo and $\mathrm{Nb}$ additions on the properties

Figure 10 summarizes the temperature dependence of the tensile properties of the forged FeCrAl alloys, compared with previously reported tensile data (T35Y2, C35M, C35MN, and C35MN5 [15]). The yield strength of C35M2 (5.2Al-2Mo) and C36M (5.9Al-2Mo) alloys at RT or up to $\sim 300-400^{\circ} \mathrm{C}$ are more than $200 \mathrm{MPa}$ higher than the C35M (4.2Al-2Mo) which exceeds the effect of $\mathrm{Al}$ additions discussed in the previous section. This was due to the deformed microstructure of the forged alloy which could easily increase the strength at relatively low temperature range. The effect of deformed microstructure on the strength was minimized at temperatures above $700^{\circ} \mathrm{C}$ due to recovery and recrystallization, so that no significant difference can be expected in the alloys with different $\mathrm{Al}$ levels. On the other hand, the $\mathrm{Zr}$ addition is beneficial for improving the tensile properties at RT and high temperatures. The C35MZ exhibited the highest yield and tensile strengths among the all the alloys studied over a wide range of temperatures. The highest strength at RT could appear with the combination of the 
deformed microstructure effect, and the best properties can also be observed even above 600$700^{\circ} \mathrm{C}$. On the other hand, the $\mathrm{Nb}$ addition (C35MN5) shows the highest strength at $\sim 400-500^{\circ} \mathrm{C}$ range, but no significant difference from the C35M2 above $600^{\circ} \mathrm{C}$. Although the detailed microstructure characterization of C35MZ has not been conducted yet, it is speculated that high thermal stability of the deformed microstructural is expected at elevated temperature similar to the $\mathrm{Nb}$ addition by the formation of Laves-phase precipitates [15]. Since the C35MZ contains only 0.3 wt.\% of Zr which is lower than the amount of $\mathrm{Nb}$ in C35MN (1 wt.\%), the Zr addition could be another candidate for improvement of high temperature mechanical properties.
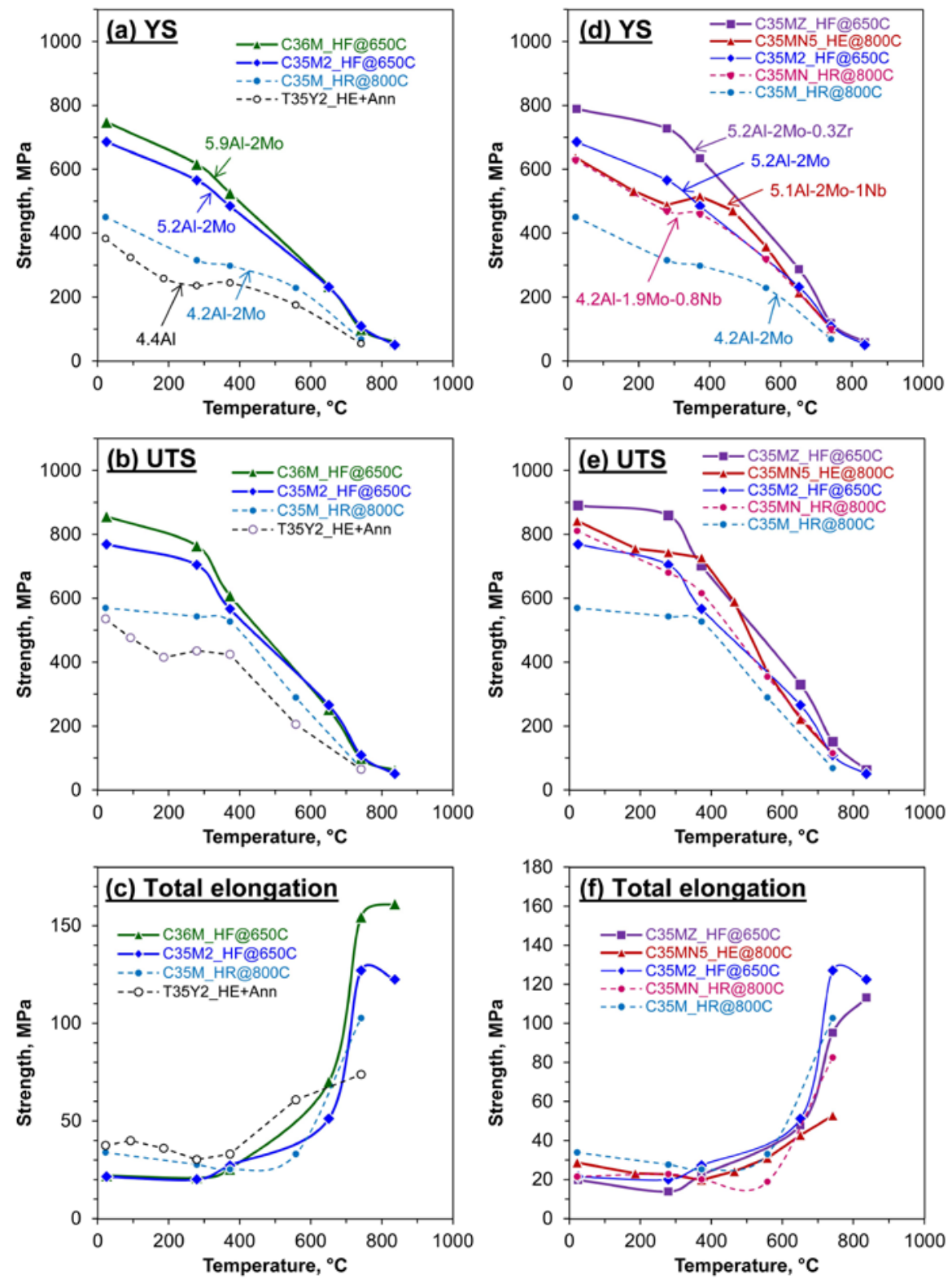

Figure 10. Temperature dependence of tensile properties of Phase II alloys, showing the effect of (a-c) the $\mathrm{Al}$ addition and (d-f) the $\mathrm{Nb}$ and $\mathrm{Zr}$ additions on the properties 


\subsection{Tube Manufacturing with Commercial Manufacturers}

The first trial tube-drawing was initiated in November 2014 with two C35MN6 master tubes. The initial size was 1.25 " OD and 0.125 " WT, and the tube-drawing with the area reduction of $\sim 10 \%$ per pass was scheduled. The drawn tube was heated up at $\sim 320^{\circ} \mathrm{C}$ by using a gas burner just before being drawn at the die. Unfortunately, both tubes were failed during drawing after several passes. One of the tubes was ruptured at the middle of the length, just after passing the die, as shown in Figure 11. The rupture occurs when the drawn resistance at the die (the work hardening + the friction between the tube and the die/mandrel) exceeds the rupture strength of the deformed tube, and it depends on the amount of area reduction. The accumulated area reduction from 2-3 drawing passes led to the material critical state where the drawn resistance at the die exceeded the rupture strength. To overcome such effect, an intermediate annealing step was applied at each drawing pass for the second C35MN6 tube, but it failed with similar rupture indicating the select annealing step did not provide sufficient recovery of processbility. Detailed characterization of the cross-sectional ruptured tube indicated that the failure might occur because of not only the work hardening (measured from the hardness analysis) but also preexisting defects such as an internally distribute hairline crack in the master tube. Such defect might form during the tube extrusion process, or even in the as-cast ingot. Based on these results, the tube drawing of C35MN6 was discontinued, and efforts were refocused on other potential candidate alloys.
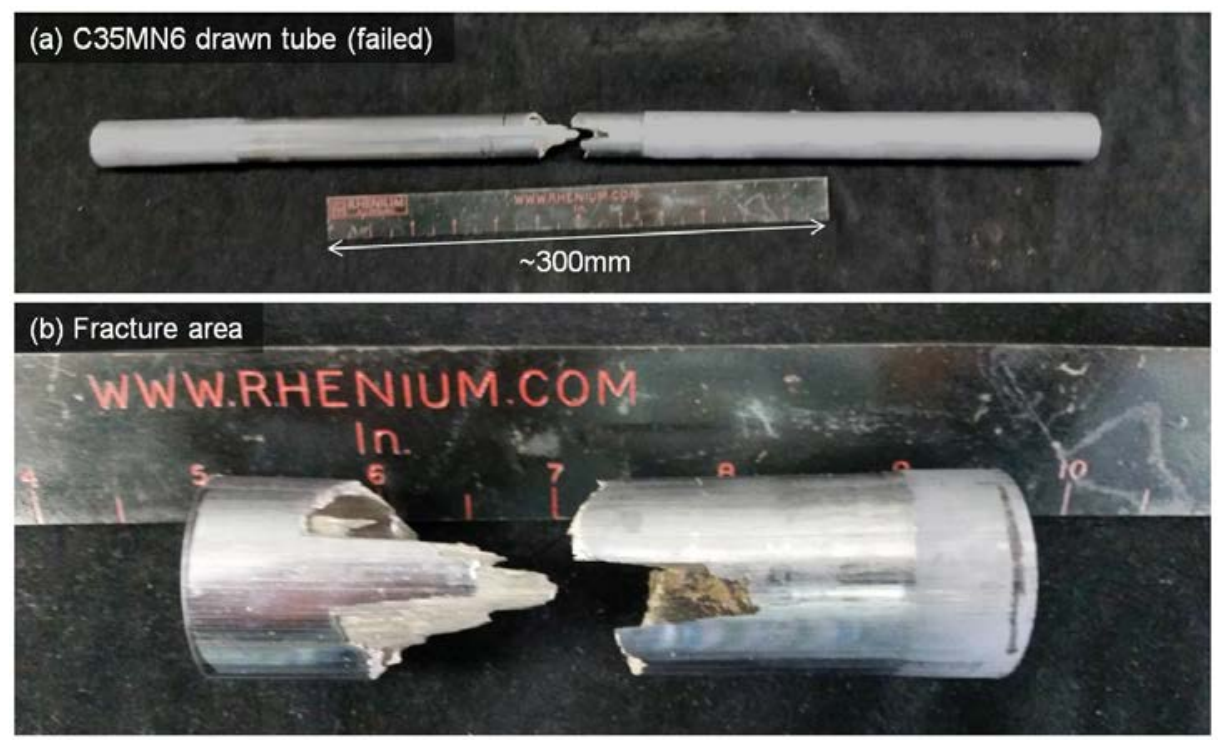

Figure 11. A C35MN6 drawn tube failed during drawing process

The second trial tube drawing was conducted with no Nb containing Phase II alloys in order to avoid the observed work hardening problem. At the same time, the high Al containing alloys such as C36M2 and C37M were also selected to be drawn in order to see the effect of $\mathrm{Al}$ on the tube processbility. The results of the drawing process are summarized in Figure 12. There was no problem after the second drawing pass in all alloys. However, the C36M2 tube ruptured three times at the pointed tip before beginning the third pass, as shown in Figure 12b. In case of the C37M, the mandrel support inside the tube was broken during the third pass which caused severe crack formation of the rest of the tube, as can be seen in Figure 12a. Based on the results, the 
intermediate annealing was applied to the C35M3 after each drawing pass, and it resulted in making further tube-drawing of the C35M3 compared to the other alloys. Several different intermediate annealing conditions were attempted in the course of the reduction process, and it caused the failure for some cases due to either insufficient for recovery or over-annealing to reduce ductility. However, it was successfully fabricated the thin-wall C35M3 tube with 9.5mm OD and $<0.4 \mathrm{~mm}$ WT, as shown in Figure 13. There were two tubes delivered with $400 \mathrm{~mm}$ and $520 \mathrm{~mm}$ length so far. A part of one was sectioned and used for the tube burst test specimen preparation. Microstructure characterization of the drawn tube is currently in progress.

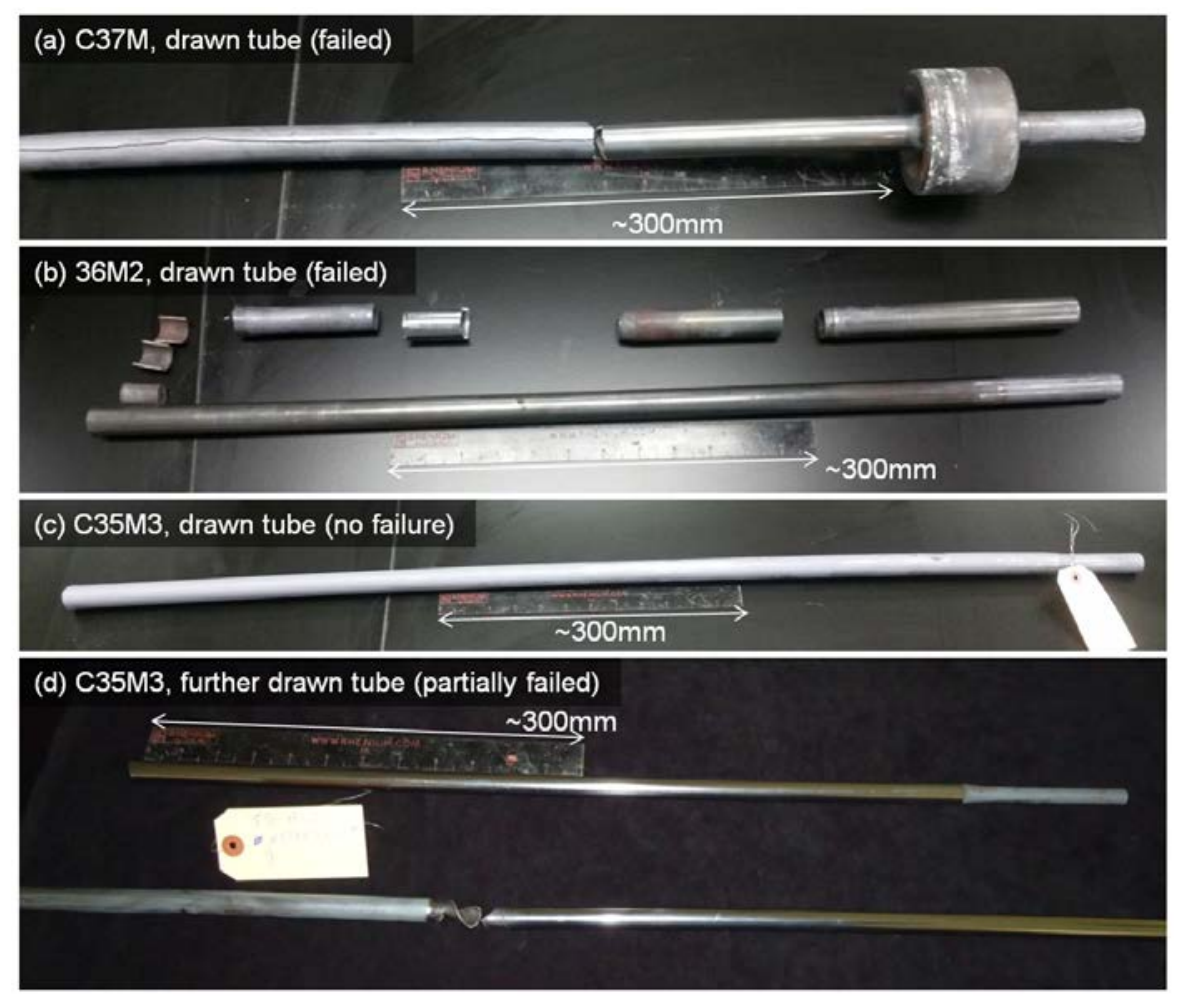

Figure 12. Drawn tubes after several passes; (a) C37M, failed, (b) C36M2, failed, (c) C35M3, no failure, and (d) C35M3 after further drawing, partially failed

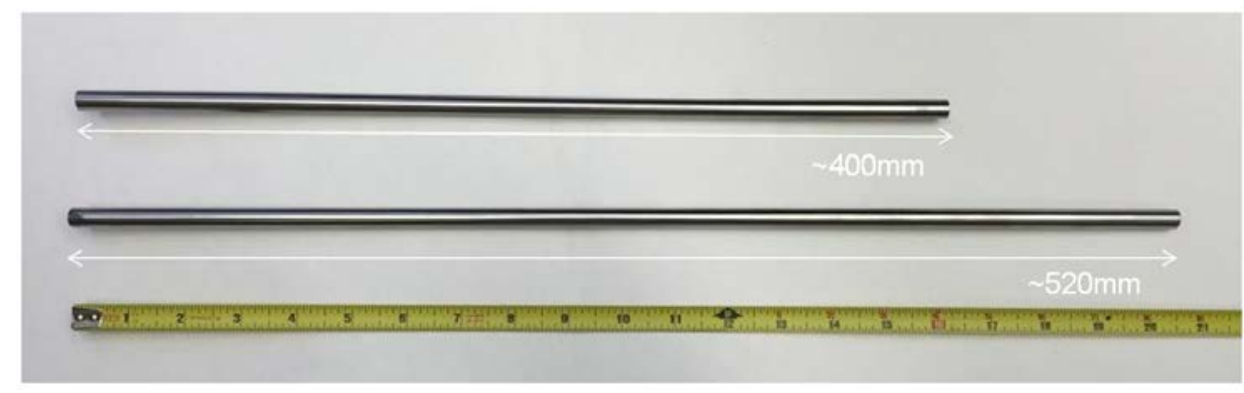

Figure 13. As-received C35M3 drawn tubes with 9.5mm diameter and $<0.40 \mathrm{~mm}$ wall thickness 


\section{TUBE BURST TESTING WITH IN SITU MEASUREMENTS}

As discussed above, in both normal operation and accident conditions, the fuel cladding is the most critical core structure in fission reactors as it is subjected to the most extreme conditions but has to function as the first safety barrier. In general, the fuel cladding material is selected considering a variety of aspects such as neutron absorption cross section, mechanical performance, irradiation and thermal creep resistance, resistance to embrittlement, thermal expansion and conductivity, and chemical compatibility to name a few. One of the key benchmarking properties for demonstrating fuel cladding performance and accident tolerance should be the deformation to burst behavior of tubular form specimens.

Traditionally, the tube burst testing is performed using high-pressure gas to measure the burst temperature versus internal tube pressure. Typically a $30 \mathrm{~cm}$ long tubular specimen is employed in such tube burst testing to measure the structural behavior data of burst temperature and internal pressure. However, this kind of testing provides very limited data, actually, only one "temperature-pressure" point per specimen. To experimentally simulate the cladding behavior, including severe accidents, one needs more efficient testing and evaluation methodology to obtain more data on material properties. The present chapter describes a new testing and evaluation method for simulating cladding behavior in accident conditions. To demonstrate the advantages of the method, a number of materials have been tested including few modified alloys developed in the framework of the present project.

\subsection{Materials and Specimen geometry}

Twelve (12) new candidate cladding materials have been acquired and tested in this investigation as listed in Table 4. In addition to the materials from the original work scope (see Chapters 2 and 3 ), few more potentially useful alloys were included in the test program. The first seven alloys belong to the group of FeCrAl alloy, which usually have excellent oxidation resistance at high temperatures and considered as primary candidate cladding materials for the accident tolerant fuels (ATFs). The next two materials, D115 series alloys, are advanced oxide dispersion strengthened (ODS) alloys with base FeCrAl alloy compositions. The last three alloys are also advanced ODS alloys but belong to the traditional nanostructured FeCr ferritic alloy (NFA) group, without measurable $\mathrm{Al}$ content.

The tubes were produced through either traditional tube process (pilgering) or machining (gun drilling) (see Chapter 4 for detail). Since no tube processing technology is available for the advanced ODS alloys and strengthened $\mathrm{FeCrAl}$ alloys, the tubular specimens for these hard alloys were machined from thick plates or coupons. Table 1 summarizes the chemical composition and final treatment of the test materials. 
Table 4. Chemistry and final processes for candidate cladding materials; the highlighted materials were prepared under the current program via machining (blue) or tube processing (red)

\begin{tabular}{|c|c|c|}
\hline Materials Code & Composition (wt.\%) & Final Processes \\
\hline Kanthal-AF & $\begin{array}{l}\text { Fe-21.2C-5.2Al-0.15Mn-0.19Si- } \\
0.028 \mathrm{C}\end{array}$ & $\begin{array}{l}\text { Processed for tubing, seam welding } \\
\text { followed by tube processing }\end{array}$ \\
\hline T35Y & Fe-13.2Cr-4.4Al-0.07Y & $\begin{array}{l}\text { Extruded at } 950^{\circ} \mathrm{C}+\text { annealed at } \\
700^{\circ} \mathrm{C} \text {, machined from rod }\end{array}$ \\
\hline С35М3 & Fe-13Cr-5.3Al-2Mo-0.13Si-0.05Y & $\begin{array}{l}\text { Extruded at } 800^{\circ} \mathrm{C}+\text { tube processing }+ \\
\text { annealed at } 600^{\circ} \mathrm{C}\end{array}$ \\
\hline C35MN5 (lot C) & $\begin{array}{l}\text { Fe-13Cr-5.1Al-2Mo-1Nb-0.2Si- } \\
0.03 \mathrm{Y}\end{array}$ & $\begin{array}{l}\text { Extruded at } 800^{\circ} \mathrm{C}+\text { annealed at } \\
800^{\circ} \mathrm{C} \text {, machined from rod }\end{array}$ \\
\hline C35MN6 (lot A-1) & $\begin{array}{l}\text { Fe-13Cr-5.1Al-2Mo-1Nb-0.2Si- } \\
0.04 \mathrm{Y}\end{array}$ & $\begin{array}{l}\text { Extruded at } 1200^{\circ} \mathrm{C}+\text { annealed at } \\
800^{\circ} \mathrm{C} \text {, machined from rod }\end{array}$ \\
\hline A-T35Y2 & Fe-13.2Cr-4.4Al-0.12Y & $\begin{array}{l}\text { Extruded at } 1050^{\circ} \mathrm{C}+\text { annealed at } \\
700^{\circ} \mathrm{C} \text {, tube processing }\end{array}$ \\
\hline B-T35Y2 & Fe-15.1Cr-3.9Al-0.12Y & $\begin{array}{l}\text { Extruded at } 1050^{\circ} \mathrm{C}+\text { annealed at } \\
700^{\circ} \mathrm{C} \text {, tube processing }\end{array}$ \\
\hline D155YT & Fe-14.57Cr-4.7Al-0.44Ti-0.3Y ${ }_{2} \mathrm{O}_{3}$ & $\begin{array}{l}\text { Consolidation-extruded at } 850^{\circ} \mathrm{C} \text {, hot- } \\
\text { rolled at } 1000^{\circ} \mathrm{C} \text {, machined from plate }\end{array}$ \\
\hline D155YMT & $\begin{array}{l}\text { Fe-14.55Cr-4.75Al-0.44Ti- } \\
0.88 \mathrm{Mo}-0.3 \mathrm{Y}_{2} \mathrm{O}_{3}\end{array}$ & $\begin{array}{l}\text { Consolidation-extruded at } 850^{\circ} \mathrm{C} \text {, hot- } \\
\text { rolled at } 1000^{\circ} \mathrm{C} \text {, machined from plate }\end{array}$ \\
\hline 9YWTV-PM1 & $\begin{array}{l}\text { Fe-8.9Cr-2W-0.35Ti-0.18V-0.11C- } \\
0.3 \mathrm{Y}_{2} \mathrm{O}_{3}\end{array}$ & $\begin{array}{l}\text { Consolidation-extruded at } 850^{\circ} \mathrm{C} \\
\text { machined from coupon }\end{array}$ \\
\hline 9YWTV-PM2 & $\begin{array}{l}\text { Fe-9.9Cr-2W-0.37Ti-0.18V-0.06C- } \\
0.3 \mathrm{Y}_{2} \mathrm{O}_{3}\end{array}$ & $\begin{array}{l}\text { Consolidation-extruded at } 850^{\circ} \mathrm{C} \\
\text { machined from coupon }\end{array}$ \\
\hline 14YWT-CRT & Fe-14Cr-2W-0.4Ti-0.3Y $\mathrm{Y}_{2} \mathrm{O}_{3}$ & $\begin{array}{l}\text { Consolidation-extruded at } 850^{\circ} \mathrm{C} \text {, hot- } \\
\text { rolled at } 1000^{\circ} \mathrm{C} \text {, machined from plate }\end{array}$ \\
\hline
\end{tabular}

A pre-pressurized tubular specimen was used for efficient in situ deformation and burst testing in furnace. The advantages of using a small pre-pressurized specimen in tube burst testing are the simplified test facility which does not need gas control system and the fact that a small size tubular specimen is tested in a small furnace but can provide detailed creep deformation data. Short tubes were fabricated from candidate specimens with a length of $50 \mathrm{~mm}$ by sectioning from long mother tubes, or machined from blocks of candidate cladding materials when tube drawing technology was not available. Endcaps were fabricated from the same materials and welded to the both ends of those tubes in the pressurized chamber of laser-beam welding machine. One of the two endcaps used for each specimen had $<0.5 \mathrm{~mm}$ diameter hole and was sealed at target pressure in the welding chamber. All specimens were pressurized to $2.07 \mathrm{MPa}$ $(0.3 \mathrm{ksi})$ at room temperature. Note that this internal pressure will increase with temperature obeying the gas law but will not be linearly proportional to the furnace temperature since the tube balloons by deformation. After pressurization and welding, leak test in water was performed for all welded specimens. Pictures of a set of pressurized specimens are shown in Figure 7 (Chapter 3). 


\subsection{Optics Principle Used for High temperature Measurements}

The main goal of imaging technology based experiment is to pursue an in situ observation and recording of high temperature deformation and burst in simulated accident conditions. The images of deforming tubes can then be converted into dimensional data and then hoop strain values. The resulting data enables key data such as creep rate and failure strain and stress to be calculated. The image recording will also enable a precise detection of deformation initiation as the dimensional resolution based on monochromatic light exists within the micron range.

Another merit of using image recording system is that simultaneous dimensional measurements at multiple positions can be pursued with affordable programing effort. Contact measurement via a mechanical extensometer was considered initially to measure specimen diameter in situ; however, it was rejected mainly because of the limited number of measuring points and general instability and unreliability of sensor devices at high temperatures, which can be well above $1000^{\circ} \mathrm{C}$. In the past few decades video cameras have become affordable for dimensional measurements, even with high resolution and data transfer rate. The most common method for optic measurement is the digital image correlation (DIC) providing precise strain analysis and displacement measurements. In the present experiment, therefore, an algorithm based on the DIC technology was developed so that the PC can simultaneously perform the video streaming and on-fly data processing on multiple points during temperature ramping.

In detail, however, there found a few difficulties associated with the testing at very high temperatures and with the continuous temperature ramping. The first issue was the steep gradient of temperature that may lead to severe air convection, in particular, near the observatory windows where lenses are closely installed. Since the index of light reflection is sensitive to the temperature of matter, it could affect image stability and thus decrease the precision of the dimensional measurement. It was not possible to completely eliminate air convection and temperature gradients with the definite distance between lenses and furnace windows and rapidly increasing temperature; however, the influence was effectively suppressed by running small fans at the outer protective glass of view windows and by installing multiple protective glasses to form many air layers.

The second issue was the intense thermal radiation at elevated temperature, which usually causes faint and blurry images. As temperature increases, the maximum intensity of thermal emission shifts from infrared range to visible light area. It can overwhelm useful light signal and drastically decrease image quality starting at $\sim 800^{\circ} \mathrm{C}$, and therefore the image of an object from the furnace at such high temperature is usually faint and blurry. The technique we pursued to enhance the image quality was to replace the thermal radiation of broad wavelength with a light beam of near-single wavelength. The unwanted lights can be removed nearly completely by combining special filters and monochromatic blue light sources. Then an external light source was used to illuminate the object in furnace providing sufficient brightness level for precise dimensional measurements.

\subsection{Equipment and Software}

A Prosilica GX 6600 digital CCD camera chosen for the project as it has a very high sensor resolution and acceptable frame rate at the maximum resolution. It has common F-type lens mount that can accommodate a wide range of different lenses to be used. The key component of 
the camera is the high sensitivity low-noise Truesense KAI-29050 sensor, which is a 29megapixel charge-coupled device (CCD) in a $35 \mathrm{~mm}$ optical format with relatively wide operating temperature range. With its 5.5 micron interline transfer CCD platform, the sensor can feature broad dynamic range and excellent imaging performance with a flexible readout up to 4 frames per second at full resolution. In this system the high resolution camera has high heat resistance (up to $60^{\circ} \mathrm{C}$ ) as it needs to face the hot quartz window of furnace, and the heat from the furnace is shielded by a glass panel installed in front of the furnace. Practically, the majority of the heat imposed to camera is absorbed by the filter package as it is installed at the camera lens and screens most of the red and infrared lights generated in furnace. The Macro-Symmar 5.6/120 lens used in this system provided high-quality imaging with uniform brightness and minimal distortion.

Assembled to the lens were light filters designed for a narrow and specific transmitting wavelength band: a Schneider Kreuznach light filter (40.5 BP 465 70) with 37-mm thread was used to block red and infrared lights from heated furnace and transmit selected visible lights with relatively narrow range of wavelengths. The BP470-37 band pass filter, which passes lights with 450-470 nm wavelengths (blue light range) only, was selected because the CCD camera used has a maximum sensitivity at a wavelength of $\sim 470 \mathrm{~nm}$ (blue light) and light sources at this specific wave length are readily assessable. Also considered was that thermal emission is negligibly small at this wavelength below $\sim 1100^{\circ} \mathrm{C}$. High brightness LED spotlights with $470 \mathrm{~nm}$ wavelength (blue color) were used to provide clear object visibility. It was shown that good imaging condition was achieved at least up to $1100^{\circ} \mathrm{C}$, the higher temperature limit of the furnace.

Laboratory-made software was used to control the camera and to record video stream data. Software allows for camera setting control and provides the capability to measure the specimen diameter in situ during the experiment. Additional details are given in our previous report [11].

\subsection{Custom-built Furnace and specimen holder}

A special furnace with windows for viewing and light sources was designed and produced by ThermCraft Inc. The furnace design was based on a standard laboratory furnace; however, the front door was re-designed to provide the specimen optic observation capability and good lighting conditions. The front door had three through channels (windows): one for the camera and two for the lights. The camera channel has an opening with a diameter of $50 \mathrm{~mm}$ and five high-quality quartz glasses, each of $0.8 \mathrm{~mm}$ thick, thereby reducing heat loss and air convection. The spacing between the glasses was about $8 \mathrm{~mm}$. The light channels had four protective glass plates and additionally a special temperature-resistant lens providing a required divergence and scattering of the light.

In addition, a set of special shutters was attached to the view channel. This aimed to decrease the size of camera channel for less thermal emission though it and thus to minimize thermal impact on camera and other components.

Specimen holder was designed by taking into account the specimen geometry, specimen-tospecimen dimensional variation, and the dimensional change during heating. The specimen holder consisted of base plate, two supporting rods, and movable top beam compensating the specimen thermal expansion (Figure 14). The base plate and top beam have cone-shaped holes to accept specimens with different diameters and hold them vertically straight. These also have a 
set of holes for thermocouples. The first holder set was machined from special MACOR ceramic, which has a good machinability and could work up to $\sim 1050^{\circ} \mathrm{C}$.

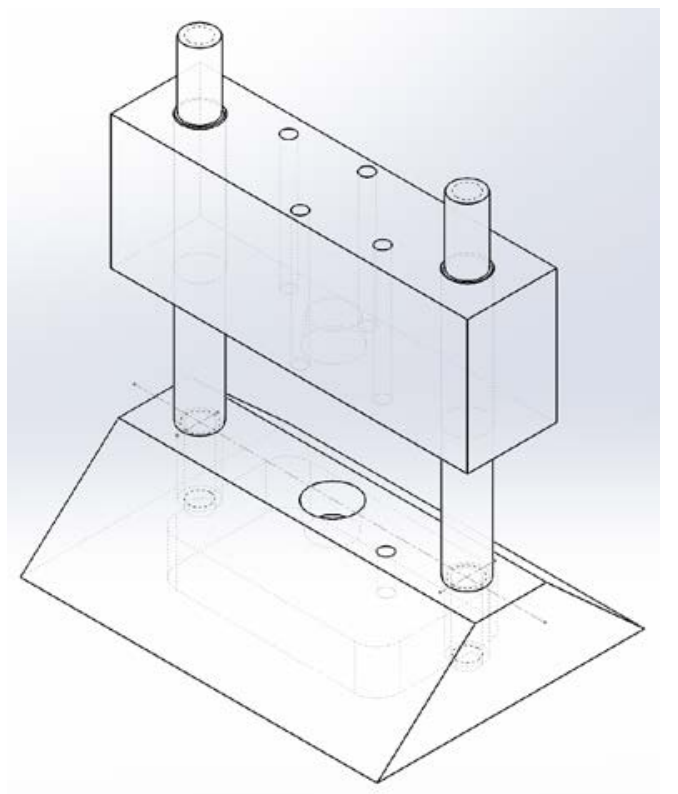

Figure 14. A drawing of tube specimen holder

\subsection{Temperature Measurement details}

Recording temperature on heating was one of the key issues in the setup of the present experiment since the temperature ramping was not near the steady state heating and it generated large differences between control temperature and local specimen temperature and within the specimen-holder assembly. To reduce errors in temperature data, temperature readings from multiple locations were recorded using a multichannel temperature controller/processing unit. NI cDAQ-9171 temperature controller (National Instruments) was selected to measure the specimen temperature. This controller processed signals from up to four thermocouples, and the temperature readings were sent to the controlling PC through a USB port.

In addition to the furnace control and safety thermocouples, four K-type thermocouples were employed to measure temperatures from various positions at the specimen-holder assembly. Those four thermocouple positions are marked in Figure 15: the two thermocouples marked as TC1 and TC3 were used to monitor the temperatures of specimen holder and the other two (TC2 and TC4) to monitor specimen temperature. Final configuration of the tube deformation and burst test system is shown in Figure 15 for internals and in Figure 16 for front door portion. 


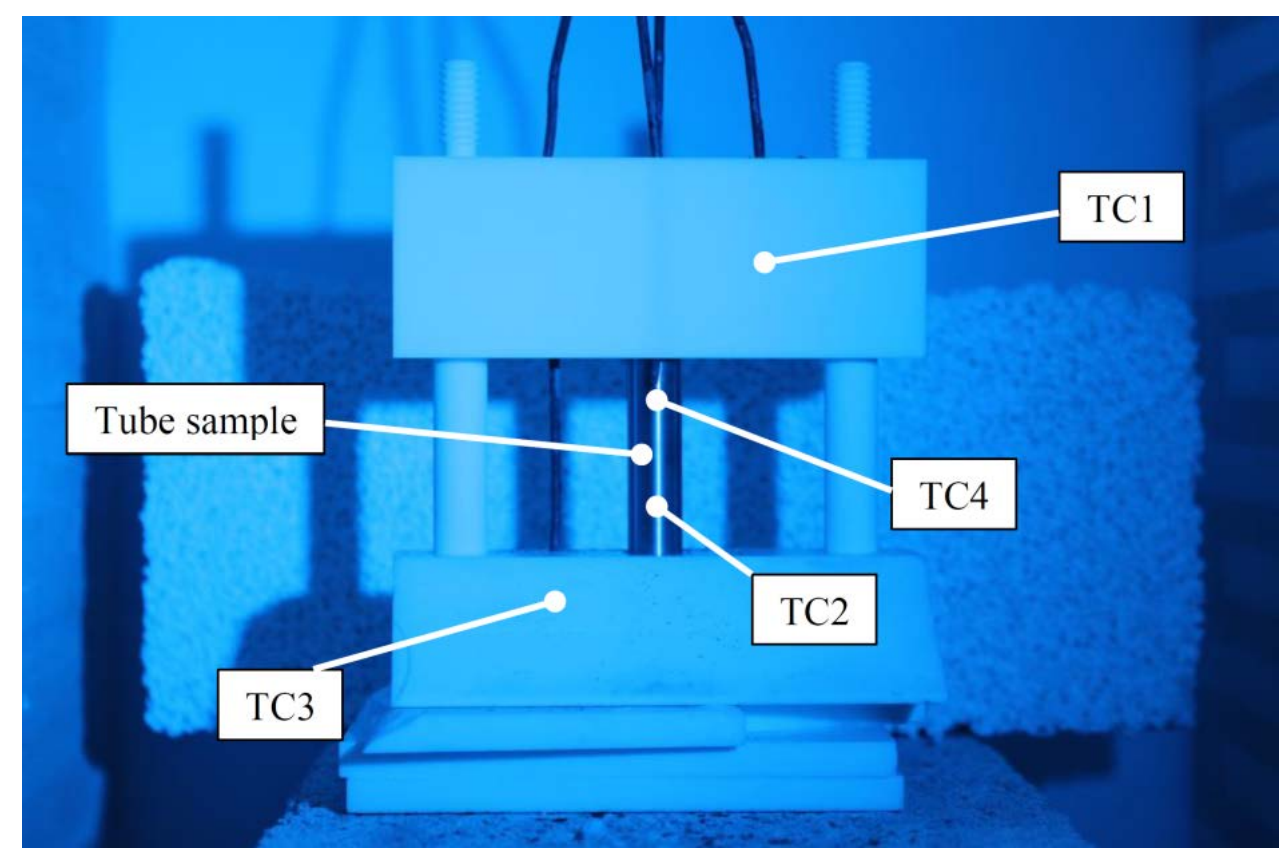

Figure 15. Setup of specimen and holder in the furnace, in which four thermocouples are installed: TC2 and TC4 touching at specimen surface and TC1 and TC3 embedded in holder top and bottom bars (the width of the horizontal support plate is $60 \mathrm{~mm}$ ).

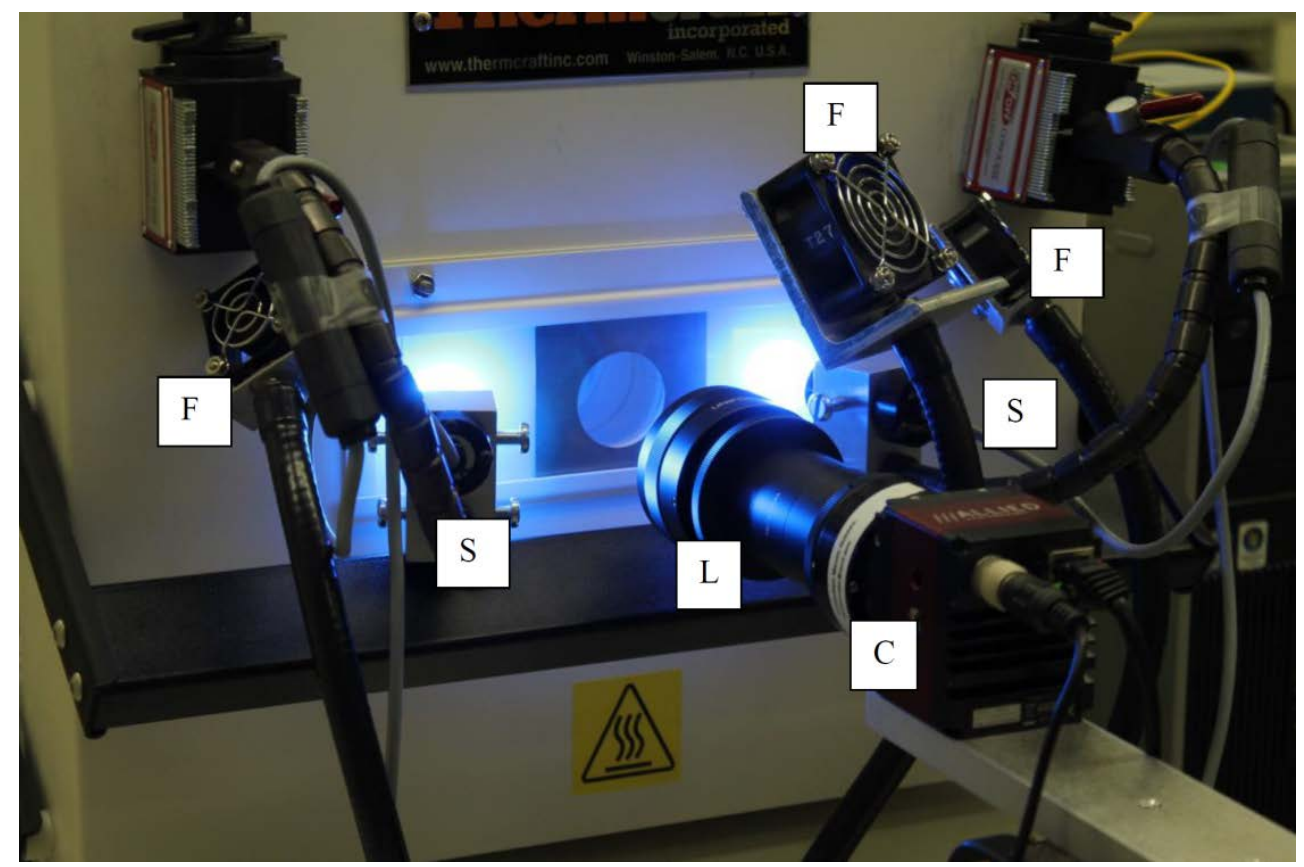

Figure 16. The configuration of camera-light source unit. Main components are one camera (C), one lens (L), two light sources (L), and two fans (F) 


\subsection{Results and Discussion}

\subsubsection{Deformation and burst behavior of candidate alloys}

A list of alloys and tests is given in Table 5, which shows, in total, 13 specimens of 12 different alloys were successfully tested. Heating durations in the tests were spread over the range of $\sim 2.5$ to 5 hours, which depended on whether the test specimen could fail by deformation in the course of heating or not. Such a wide range of test duration with the same initial internal pressure was because the new high strength materials did not initiate plastic deformation on heating up to the limit of furnace capacity $\left(\sim 1100^{\circ} \mathrm{C}\right)$ with the initial pressure $2.07 \mathrm{MPa}$. After either specimen failed or the temperature reached the furnace limit, the system was stopped and allowed to cool down to replace the next test specimen.

Only four specimens demonstrated significant plastic deformation followed by burst during heating (Figure 17, Figure 18, Table 5). For these burst specimens, the swelling-start temperatures could be determined using images recorded during the tests, and then the burst temperature determined soon after. In the pressurized specimens the initial room temperature gas pressure was set at 2.07 MPa ( 20 atm), and the internal pressure might increase by 3-4 times at the burst temperatures according to the gas law. At the time of burst, which usually made by a small opening, the discharging gas can expand its volume drastically and lower its temperature. This can generate a jet flow or turbulence around the nearby thermocouples and a small drop of temperature can be detected. Another indication of burst is that the diameter of specimen will stop as the stress in the tube wall is released. Therefore, there are two ways to detect the burst and determine tube failure temperature using the recorded data: by observing the small temperature drop at the burst and/or termination of diametral change with further temperature increase.

Table 5. Summary on the dimensional changes and temperature parameters

\begin{tabular}{|l|c|c|c|c|c|c|}
\hline Material code & $\begin{array}{c}\text { Final } \\
\text { Temp., } \\
{ }^{\circ} \mathrm{C}\end{array}$ & $\begin{array}{c}\text { Initial } \\
\text { Diameter, } \\
\mathrm{mm}\end{array}$ & $\begin{array}{c}\text { Maximum } \\
\text { Post-test } \\
\text { Diameter, mm }\end{array}$ & $\begin{array}{c}\text { Swelling } \\
\text { Start } \\
\text { Temp., }\end{array}{ }^{\circ} \mathrm{C}$ & $\begin{array}{c}\text { Failure } \\
\text { (Burst) } \\
\text { Temp., }\end{array}$ & $\begin{array}{c}\text { Endcap } \\
\text { Deformation }\end{array}$ \\
\hline \hline T35Y* & 809 & 9.53 & 11.51 & $\mathbf{6 5 0}$ & $\mathbf{7 9 0}$ & Yes \\
\hline T35Y* & 847 & 9.52 & 10.65 & $\mathbf{6 6 0}$ & $\mathbf{7 7 5}$ & Yes \\
\hline KT-AF & 757 & 10.34 & 11.03 & $\mathbf{5 8 0}$ & $\mathbf{7 4 6}$ & No \\
\hline C35M3 & 1007 & 9.48 & 9.48 & $>1007$ & n/a & No \\
\hline C35MNSC & 975 & 9.51 & 9.51 & $>975$ & n/a & No \\
\hline C35MN6A1 & 1038 & 9.54 & 9.54 & $>1038$ & n/a & No \\
\hline B-T35Y2 & 1054 & 9.51 & 9.54 & $>1054$ & n/a & No \\
\hline 14YWT-CRT & 1070 & 10.2 & 10.2 & $>1070$ & n/a & No \\
\hline A-T35Y2 & 836 & 9.51 & 13.14 & $\mathbf{6 2 7}$ & $\mathbf{7 4 5}$ & No \\
\hline 9YWTV-PM2 & 1085 & 10.21 & 10.25 & $>1085$ & n/a & No \\
\hline 9YWTV-PM1 & 1030 & 10.21 & 10.22 & $>1030$ & n/a & No \\
\hline D155YT & 1030 & 9.53 & 9.54 & $>1030$ & n/a & No \\
\hline D155YMT & 1050 & 9.52 & 9.55 & $>1050$ & n/a & No \\
\hline
\end{tabular}

*Two specimens were tested at the same conditions. 
In the case that the specimen experienced ballooning and then a burst was detected, heating was stopped soon after the burst. Otherwise, test was stopped just below $1100^{\circ} \mathrm{C}$ for safety (see Table 5). Diametral change was measured after each test to have final dimension data by physical contact. Since plastic strain and diametral change were strongly inhomogeneous along the length direction as well as in the hoop direction (see Figure 17, Figure 18), the largest diameter value was recorded to estimate the maximum hoop strain. In the two T35Y specimens after burst failure, multiple cracks with (or without) openings were observed in the middle of specimen or in the highest diameter area, Figure 18. The surface cracks are formed by strain localization after some plasticity and at least one of them in each specimen should have developed to a local failure or opening as the specimen was depressurized. It is not known which opening has been made first. Both specimens show a few cracks (white arrows) oriented approximately along the specimen axis.

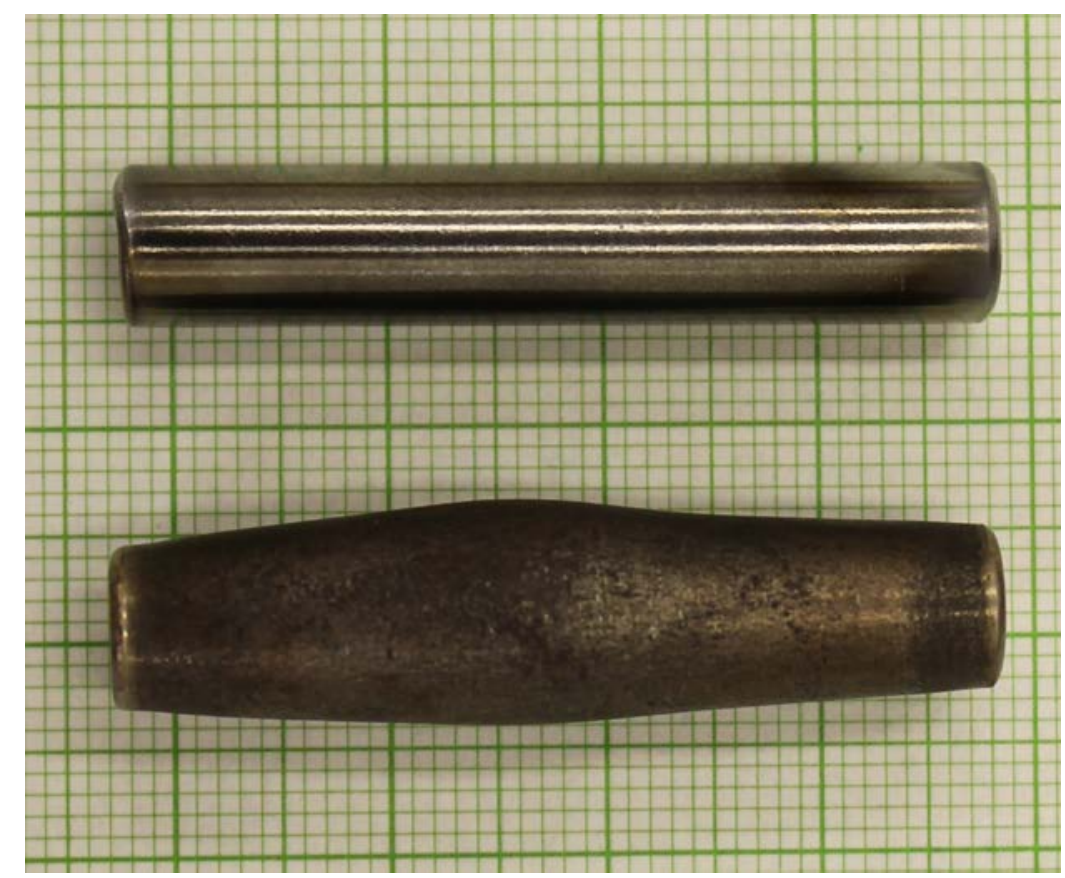

Figure 17. An alloy A-T35Y2 specimen prior (top) and after (bottom) burst test. 

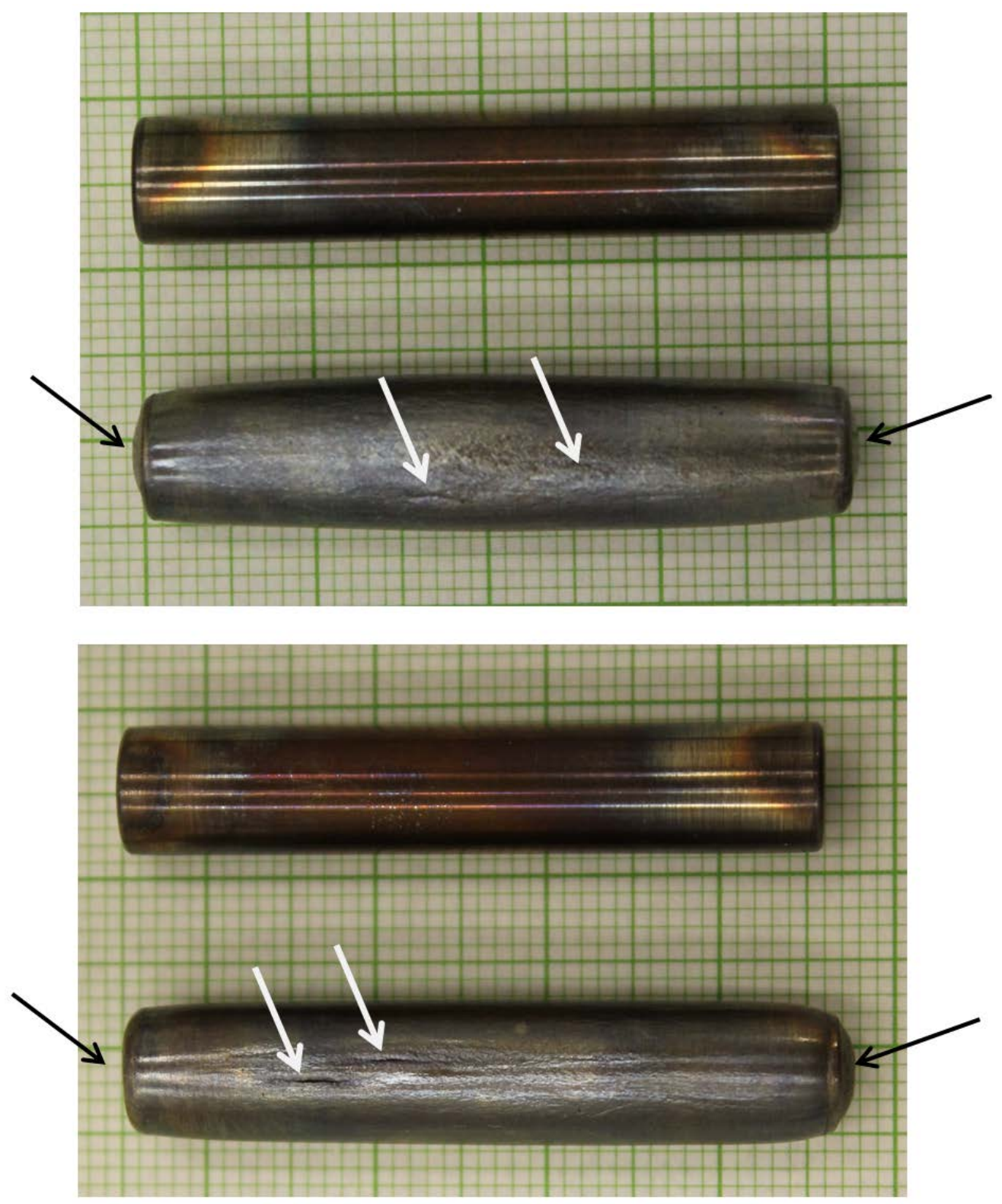

Figure 18. Two alloy T35Y specimens showing deformation and burst. Note that the cracks with openings (or holes) are marked by white arrows and the deformation of endcaps by black arrows.

For the other specimens that did not fail by heating (Figure 19), average diameters were measured to evaluate the amount of permanent deformation, if any. Indeed, some specimens without showing apparent plastic strain, slight increase in the average diameter (0.01-0.04 mm), which is most probably due to plastic deformation plus oxidation.

The endcaps of the T35 specimens displayed strong deformation in the endcaps; these showed a ballooned or round endcap portions. Such endcap deformation was not observed for other alloys. 

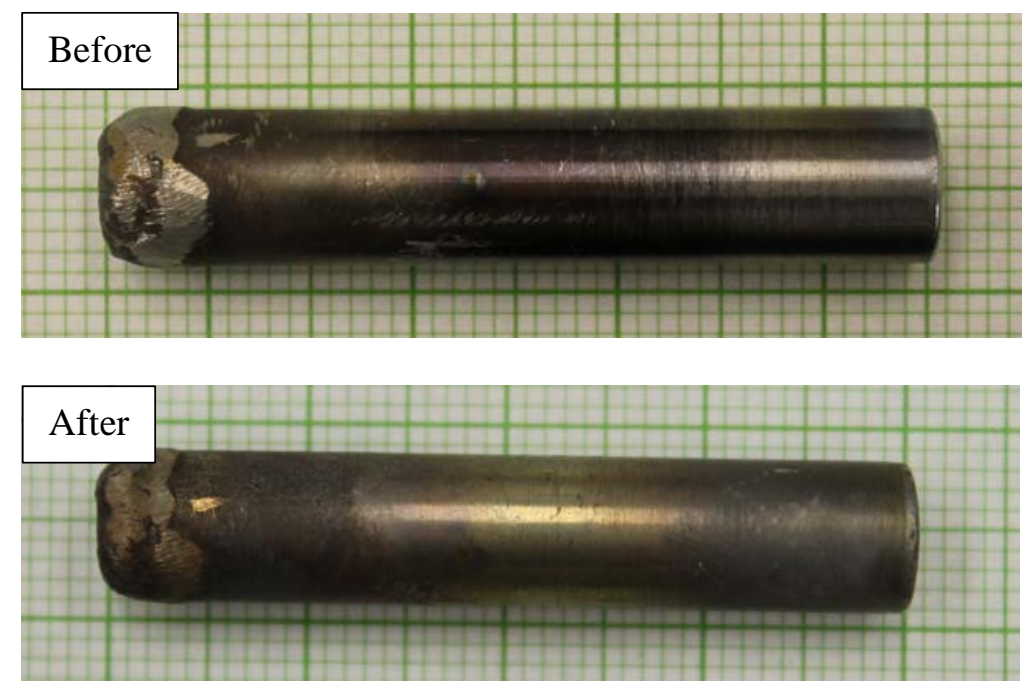

Figure 19. C35M3 alloy specimen before and after the test. Top temperature $\sim 1007^{\circ} \mathrm{C}$.

Figure 20 displays diametral change vs. temperature curves for the specimens without visible plastic deformation. These curves demonstrate nearly monotonous increase in diameter up to the furnace limit temperature. Most of the diameter increase may be explained by thermal expansion of specimen ( $<1 \%$ at highest temperature if a typical value of $11 \mathrm{ppm} /{ }^{\circ} \mathrm{C}$ is used for thermal expansion coefficient) and smaller contribution made by elastic strain. The elastic deformation of the tube due to gas pressure contributes to the diametral increase, but this value should be smaller $(<0.2 \%)$. Another contributor would be inelastic strain due to stress relaxation and, in fact, can be the second largest strain contributor for those non-burst specimens. An accurate evaluation of this component is, however, remained beyond the means in this research. The diametral increases were similar for all specimens in Figure 20, for example, reached $\sim 1.5 \%$ at $\sim 900^{\circ} \mathrm{C}$.

It is worth noting that the noise level for all curves is estimated to be $\sim 0.1-0.15 \%$ of the measured diameter (or $\sim 1$ pixel in the raw image). This noise was caused by the constant temperature increase and air convection in the furnace and the space between the protective glasses. Noise level should decrease significantly at stable temperature, but the nature of the present experiment required the temperature increase that generated the unstable environment. 


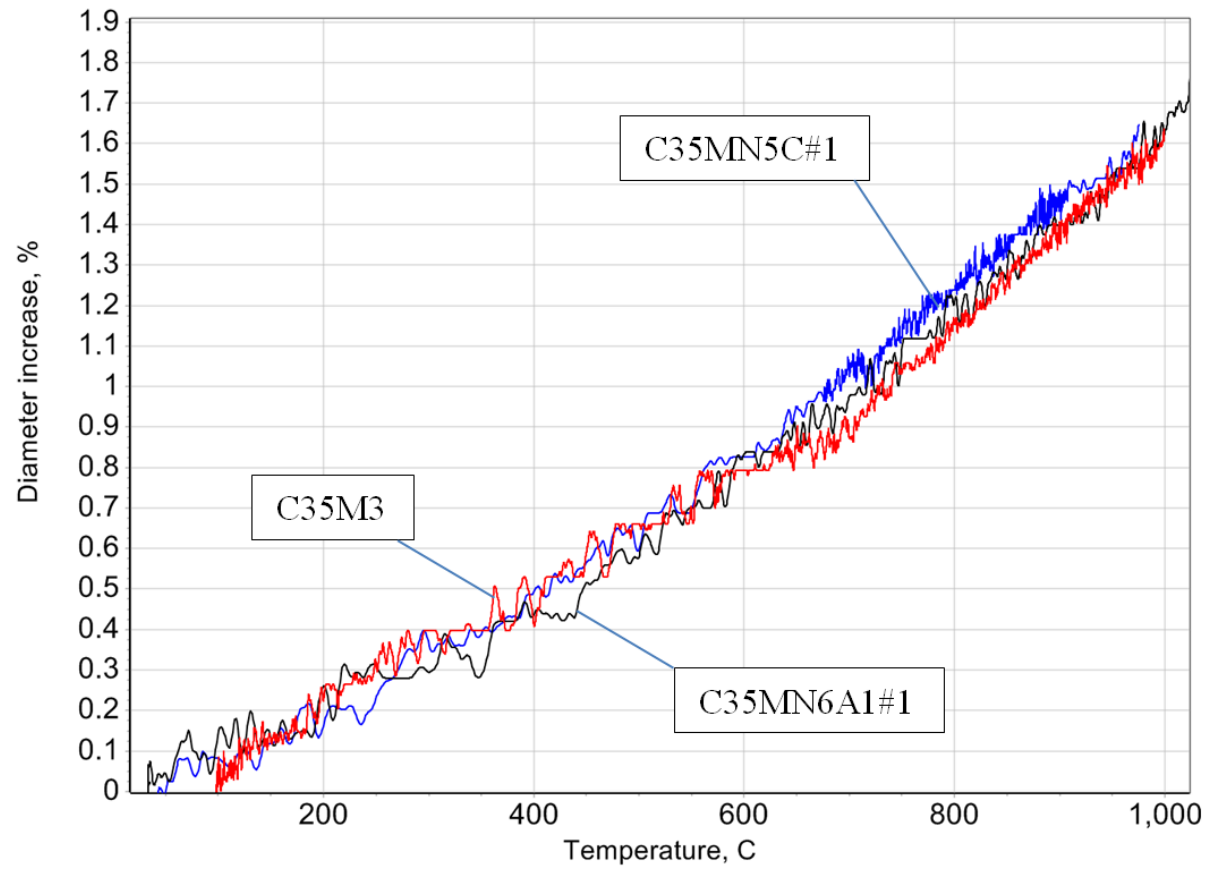

Figure 20. Diametral change versus temperature curves in the specimens without significant deformation. Note that all of these materials are $2^{\text {nd }}$ generation FeCrAl alloys.

The in situ strain data obtained for the specimens with significant plastic strain are compared in the low-temperature range $\left(<600^{\circ} \mathrm{C}\right)$ their straining behaviors were very similar, above which the diameter increase smoothly up to $\sim 8$ to $30 \%$ with the rate depending on material. The burst failure temperature in all cases can be seen very clear by the sharp bend in the curve and also in the temperature data.

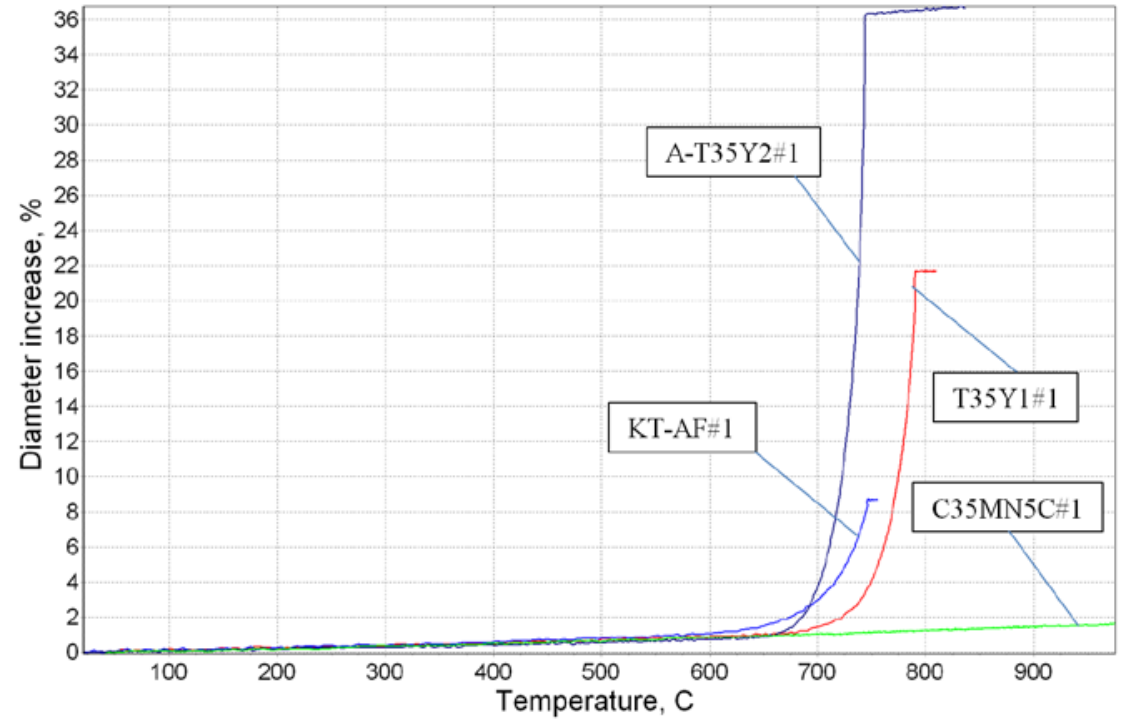

Figure 21. Materials with pronounced (>2\%) diameter change. Alloy C35MN5C (which did not demonstrate plastic deformation) is given for comparison. The curves are given for the area with the largest diameter increase. 
To correctly explain the deformation and burst behavior of individual specimens, actual hoop stress applied to the cladding wall needs to be considered. Although argon gas was charged into tubular specimens at the same initial pressure of 2.07 MPa, the hoop stress in the wall of specimens on testing would become vastly different because of the different wall thicknesses and of the volume expansion by ballooning. As listed in Table 4, indeed, significantly different initial hoop stresses, 15 - $29 \mathrm{MPa}$, are calculated for specimens, and the hoop stresses increase 4 to 7 folds at the terminal temperature due to the thermal expansion of gas and reduction of wall thickness.

The relatively higher initial pressure resulted in burst in the Kanthal (KT)-AF specimen. However, such a higher pressure is not considered to be a common cause for failure since we can observe burst failure in T35Y with relatively lower initial and final hoop stresses. Overall mechanical properties, strength in particular, seem to be the key factor for having burst failure in a relatively low temperature. Once the plastic deformation is started, the wall thickness itself exacerbates the load sustainability because it is reduced nearly proportionally by the deformation. It was observed that all of those with burst failure showed the final failure occurring within $110-170{ }^{\circ} \mathrm{C}$ from the initiation of plastic deformation. To provide a real mechanical resistance of fuel cladding to a rapid heating accident, therefore, avoiding or delaying the initiation of creep deformation during the heating will be a key measure. This again indicates that the development of high strength materials is essential for accident tolerant fuel cladding.

Table 6. Hoop stress data at initial and final moments in deformation-burst tests

\begin{tabular}{|l|c|c|c|c|c|c|c|}
\hline $\begin{array}{l}\text { Material } \\
\text { code }\end{array}$ & $\begin{array}{c}\text { Final } \\
\text { Temp., } \\
{ }^{\circ} \mathrm{C}\end{array}$ & $\begin{array}{c}\text { Initial } \\
\text { Diameter, } \\
\mathrm{mm}\end{array}$ & $\begin{array}{c}\text { Maximum } \\
\text { Post-test } \\
\text { Diameter, } \\
\mathrm{mm}\end{array}$ & $\begin{array}{c}\text { Initial } \\
\text { Nominal Wall } \\
\text { Thickness, } \\
\mathrm{mm}\end{array}$ & $\begin{array}{c}\text { Failure } \\
\text { (Burst) } \\
\text { Temp., } \\
{ }^{\circ} \mathrm{C}\end{array}$ & $\begin{array}{c}\text { Initial } \\
\text { Hoop } \\
\text { Stress, } \\
\text { MPa }\end{array}$ & $\begin{array}{c}\text { Final } \\
\text { Hoop } \\
\text { Stress, } \\
\text { MPa }\end{array}$ \\
\hline T35Y & 809 & 9.53 & 11.51 & 0.5 & $790^{*}$ & $\mathbf{1 9 . 7}$ & $\mathbf{1 0 3 . 7}$ \\
\hline T35Y & 847 & 9.52 & 10.65 & 0.5 & $775^{*}$ & $\mathbf{1 9 . 7}$ & $\mathbf{8 7 . 6}$ \\
\hline KT-AF & 757 & 10.34 & 11.03 & 0.37 & $746^{*}$ & $\mathbf{2 8 . 9}$ & $\mathbf{1 1 3 . 6}$ \\
\hline C35MNSC & 975 & 9.51 & 9.51 & 0.5 & n/a & $\mathbf{1 9 . 7}$ & $\mathbf{8 3 . 2}$ \\
\hline C35MN6A1 & 1038 & 9.54 & 9.54 & 0.5 & n/a & $\mathbf{1 9 . 7}$ & $\mathbf{8 7 . 7}$ \\
\hline B-T35Y2 & 1054 & 9.51 & 9.54 & 0.37 & n/a & $\mathbf{2 6 . 6}$ & $\mathbf{1 2 0 . 4}$ \\
\hline $\begin{array}{l}\text { 14YWT- } \\
\text { CRT }\end{array}$ & 1070 & 10.2 & 10.2 & 0.63 & n/a & $\mathbf{1 6 . 8}$ & $\mathbf{7 6 . 3}$ \\
\hline A-T35Y2 & 836 & 9.51 & 13.14 & 0.37 & $745^{*}$ & $\mathbf{2 6 . 6}$ & $\mathbf{1 7 5 . 2}$ \\
\hline $\begin{array}{l}\text { 9YWTV- } \\
\text { PM2 }\end{array}$ & 1085 & 10.21 & 10.25 & 0.69 & n/a & $\mathbf{1 5 . 3}$ & $\mathbf{7 1 . 0}$ \\
\hline $\begin{array}{l}\text { 9YWTV- } \\
\text { PM1 }\end{array}$ & 1030 & 10.21 & 10.22 & 0.59 & n/a & $\mathbf{1 7 . 9}$ & $\mathbf{7 9 . 2}$ \\
\hline D155YT & 1030 & 9.53 & 9.54 & 0.5 & n/a & $\mathbf{1 9 . 7}$ & $\mathbf{8 7 . 3}$ \\
\hline D155YMT & 1050 & 9.52 & 9.55 & 0.52 & n/a & $\mathbf{1 8 . 9}$ & $\mathbf{8 5 . 5}$ \\
\hline
\end{tabular}

*Burst failure occurred in these specimens only; the other tests were stopped before failure.

Finally, the change of specimen weight was measured to check the possibility of excessive oxidation during testing. Table 5 compares the weight data measured before and after tests. Most of failed specimens demonstrated some weight decrease ( -5 to $-7 \mathrm{mg}$ ) except the alloy A-T35Y2 specimen (+7 mg), while all non-failed specimens had pronounced weight increase (up to 20-34 
mg). The weight change was the result of two competing processes: weight increase due to oxidation and weight loss because of specimen depressurization. Although the small gains in the latter specimen group ( $<\sim 35 \mathrm{mg}$ ) can be realized as the result of surface oxidation, the oxidized surface layers in most cases were colored in light yellow or blue and are considered thin enough to not significantly impact bulk mechanical properties. Generally speaking, all alloys tested demonstrated good oxidation resistance which is comparable to ordinary austenitic steels like AISI 304 and AISI 316.

Table 7. Specimen weight changes before and after deformation-burst test

\begin{tabular}{|l|c|c|c|}
\hline Materials Code & Weight before Test, $\mathbf{g}$ & Weight after Test, $\mathbf{g}$ & Weight Change $\left.\boldsymbol{~}_{\mathbf{m}}\right), \mathbf{g}$ \\
\hline T35Y & 6.65086 & 6.64503 & $\mathbf{- 0 . 0 0 5 8 3}$ \\
\hline T35Y & 7.05913 & 7.05627 & $\mathbf{- 0 . 0 0 2 8 6} *$ \\
\hline KT-AF & 8.52316 & 8.51647 & $\mathbf{- 0 . 0 0 6 6 9 *}$ \\
\hline C35MN6A1 & 8.65557 & 8.65816 & $\mathbf{0 . 0 0 2 5 9}$ \\
\hline B-T35Y2 & 7.40628 & 7.44107 & $\mathbf{0 . 0 3 4 7 9 *}$ \\
\hline 14YWT-CRT & 10.71597 & 10.73055 & $\mathbf{0 . 0 1 4 5 8}$ \\
\hline A-T35Y2 & 7.52281 & 7.53028 & $\mathbf{0 . 0 0 7 4 7}$ \\
\hline 9YWTV-PM2 & 10.74273 & 10.76713 & $\mathbf{0 . 0 2 4 4}$ \\
\hline 9YWTV-PM1 & 10.79929 & 10.82021 & $\mathbf{0 . 0 2 0 9 2}$ \\
\hline D155YT & 6.42781 & 6.4616 & $\mathbf{0 . 0 3 3 7 9}$ \\
\hline D155YMT & 6.95458 & 6.95673 & $\mathbf{0 . 0 0 2 1 5}$ \\
\hline
\end{tabular}

*Specimens failed and degassed.

\subsection{Calculation of Hoop Strain Values}

\subsubsection{Maximum diameter and hoop strain}

The outer diameter data, which were converted from the numbers of pixels in the middle of tubular specimens, are compared in Figure 22. Although the pixels over diameter were counted at equally spaced 10 to12 longitudinal locations in each tubular specimen, the stress and strain analyses were focused on the behavior in the middle (i.e., maximum diameter) position. Note that the overall resolution limit in the dimensional measurement is 12 to $15 \mu \mathrm{m}$ for the present optical procedure. In Figure 22 the burst and intact specimens demonstrate starkly different curves: the outer diameters of all tested specimens are nearly flat up to about $650^{\circ} \mathrm{C}$, the four curves of T35Y-1 \& 2, A-T35Y2, and Kanthal-AF start to deviate from their linear portions and rapidly increase in $600-800^{\circ} \mathrm{C}$ range until failure, while the curves of other specimens remain nearly flat up to the maximum test temperature near $1100{ }^{\circ} \mathrm{C}$.

The ballooned and burst specimens were made of relatively soft materials and relatively thin walled tubes. The highest maximum diametral expansion, $3.5 \mathrm{~mm}$, was observed from the specimen A-T45Y2, and no other displays more than a few millimeters. The diameters remain unchanged after burst as no further deformation can be induced after the deflation. A high reproducibility in the diameter-temperature data is notable as the two T35Y specimen curves are 
nearly identical up to the final burst of T35Y-2. Regardless of such high reproducibility, the formation of through-the-thickness crack may be highly subjected to the local microstructure and surface morphology around the middle section of specimen, and therefore the rupture diameters should show large scattering and could be significantly different for the same alloy. It is also a notable observation that the tube burst, i.e., ballooning and failure, occurs in a short range of temperature. Once the plastic (creep) deformation is initiated, the final failure occurs within $<100{ }^{\circ} \mathrm{C}$ increase.

The true hoop strains could be easily calculated from the diametral change and are compared in Figure 23 for all test alloys. Again, the maximum strain, 0.32, was obtained for A-T35Y2 alloy, and the other three ballooned specimens showed true strains less than 0.2 . The other specimens showing straight lines only are relatively higher strength and/or thicker specimens. The total strain for these cases comprises thermal expansion strain and pressure-induced elastic strain only, and hence the slopes of the curves for these nil-plasticity specimens are nearly negligible when compared to those of crept specimen.

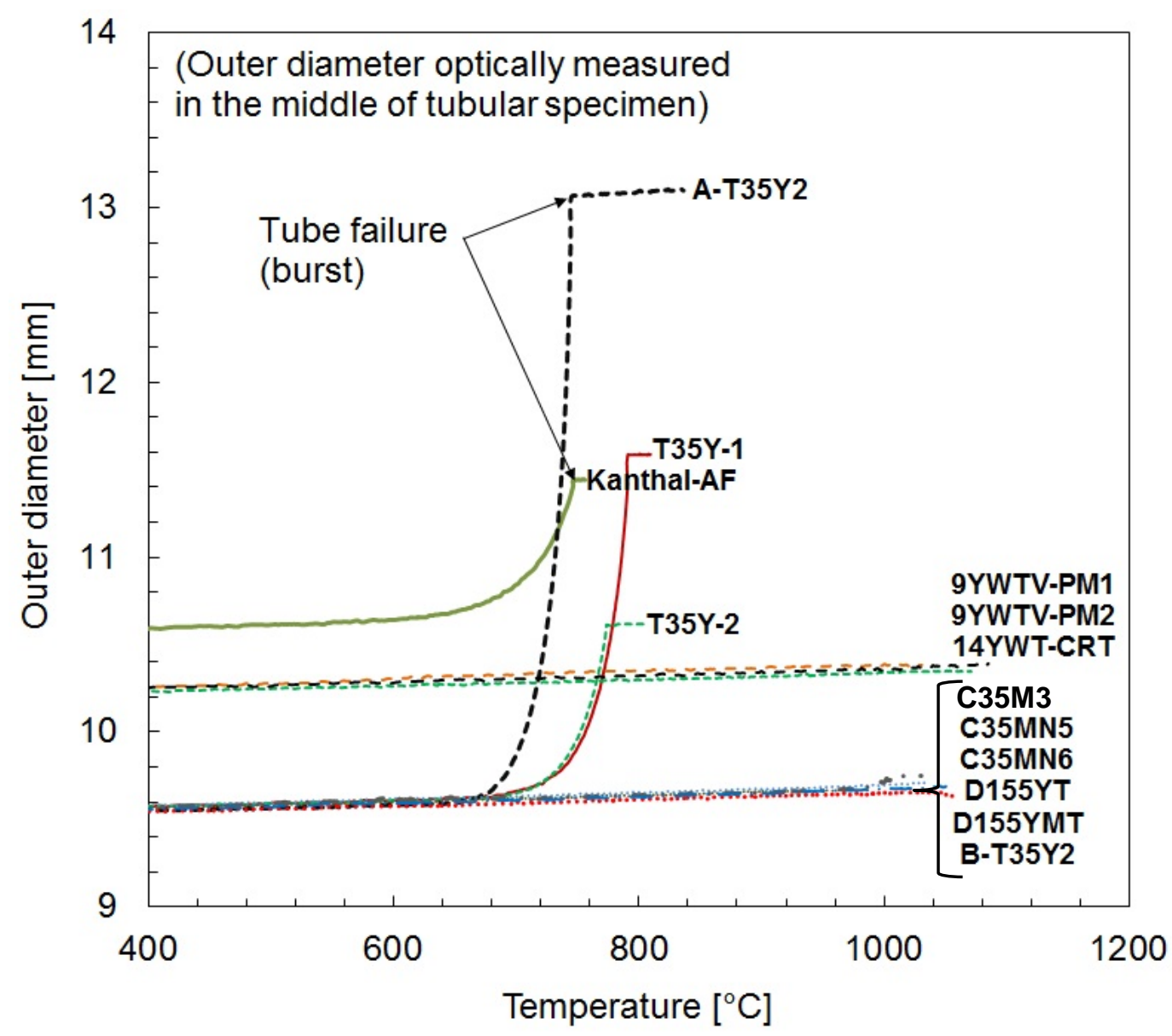

Figure 22. Temperature dependence of outer diameter converted from optical measurements, i.e., the number of pixels through the specimen diameter. 


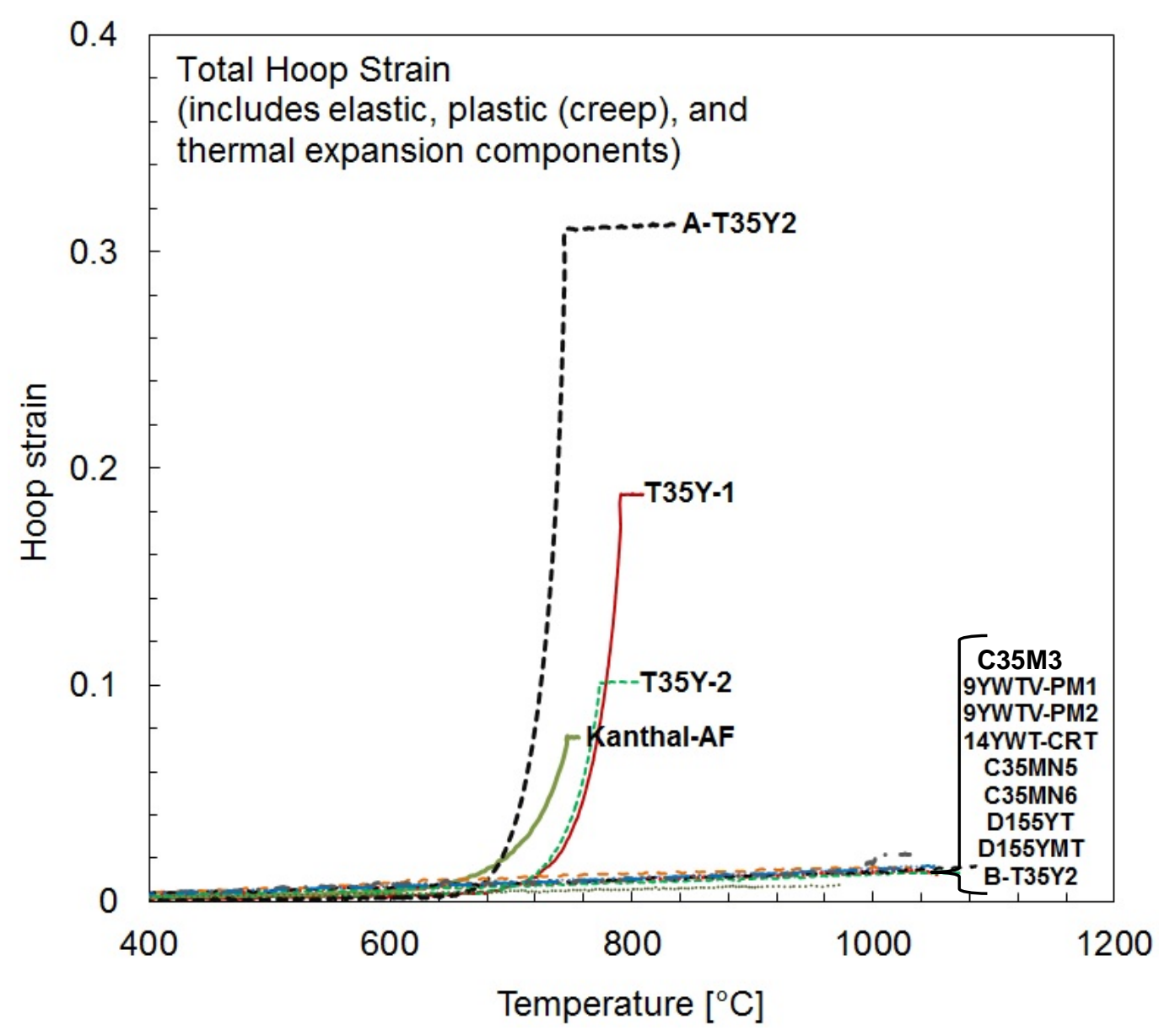

Figure 23. Temperature dependence of hoop strain. The true strain values were calculated from the outer diameters of specimens.

\subsubsection{Internal pressure and true hoop stress}

The internal pressure versus temperature curves are displayed in Figure 24. The internal pressure during heating was calculated using the gas law (Boyle's law). The volume of a heated tubular specimen was calculated from the average of diametral measurements on the 11 equally spaced points over the length of the specimen. Since the initial gas pressures were set at the same pressure of $2.07 \mathrm{MPa}$ and the pressure increase is caused mostly by gas expansion, the internal pressure during heating was linearly proportional to the gas temperature until plastic deformation becomes significant. In Figure 24, the closely spaced linear lines indicate that the thermal expansion and elastic deformation of specimens have yielded very minor differences among these specimens.

As in the diameter and strain versus temperature curves, in Figure 22, Figure 23, and Figure 24 indicates that the internal pressure curves of the $4 \mathrm{FeCrAl}$ alloy tubes start to deviate from their linear portions above $600^{\circ} \mathrm{C}$, while the thicker and/or stronger specimens experienced no plastic deformation within the test temperature range $<1100^{\circ} \mathrm{C}$. It should be a notable observation that the tube burst, i.e., ballooning and failure, occurs in a short range of temperature: once the plastic 
(creep) deformation is initiated in the range $600-680{ }^{\circ} \mathrm{C}$, the final failure occurs within $<100{ }^{\circ} \mathrm{C}$ increase.

Although the internal gas pressure that increases with temperature is the main force for inducing plastic deformation, the initiation and rate of plastic straining is determined by actual stress in the wall of tubular specimens. The internal pressure data in Figure 24 were converted to the true hoop stress at maximum diameter location and compared in Figure 25, using the wall thickness data calculated with the constant volume assumption in plastic deformation. Due mostly to the difference in initial wall thickness, the hoop stresses were significantly different among the material groups: all of the FeCrAl, Fe-9Cr, and Fe-14Cr ODS alloys were subjected to relatively low hoop stress, and consequently no creep deformation was induced for those alloys. The hoop strain and stress for these alloys behavior in the opposite ways: the hoop stress decreases as the strain increases. In an actual LOCA accident, the internal gas pressure and hoop stress in cladding wall should behave similarly.

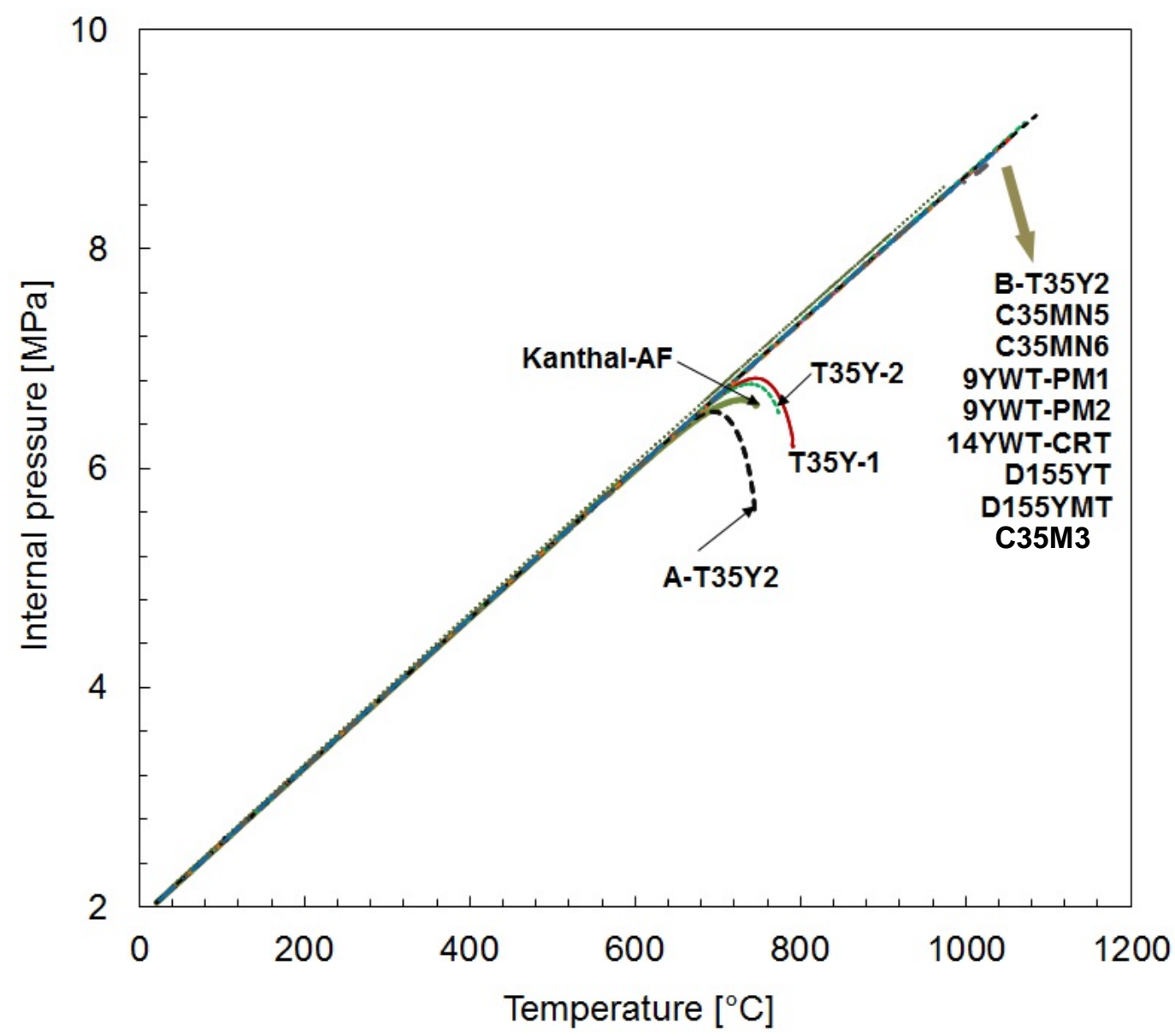

Figure 24. Internal pressure versus temperature curves. The internal pressure is almost purely dependent on the thermal expansion of helium gas filled in the tubular specimen. The curves deviating from linear lines are because of the ballooning or internal volume expansion of the pressurized tubular specimens. 


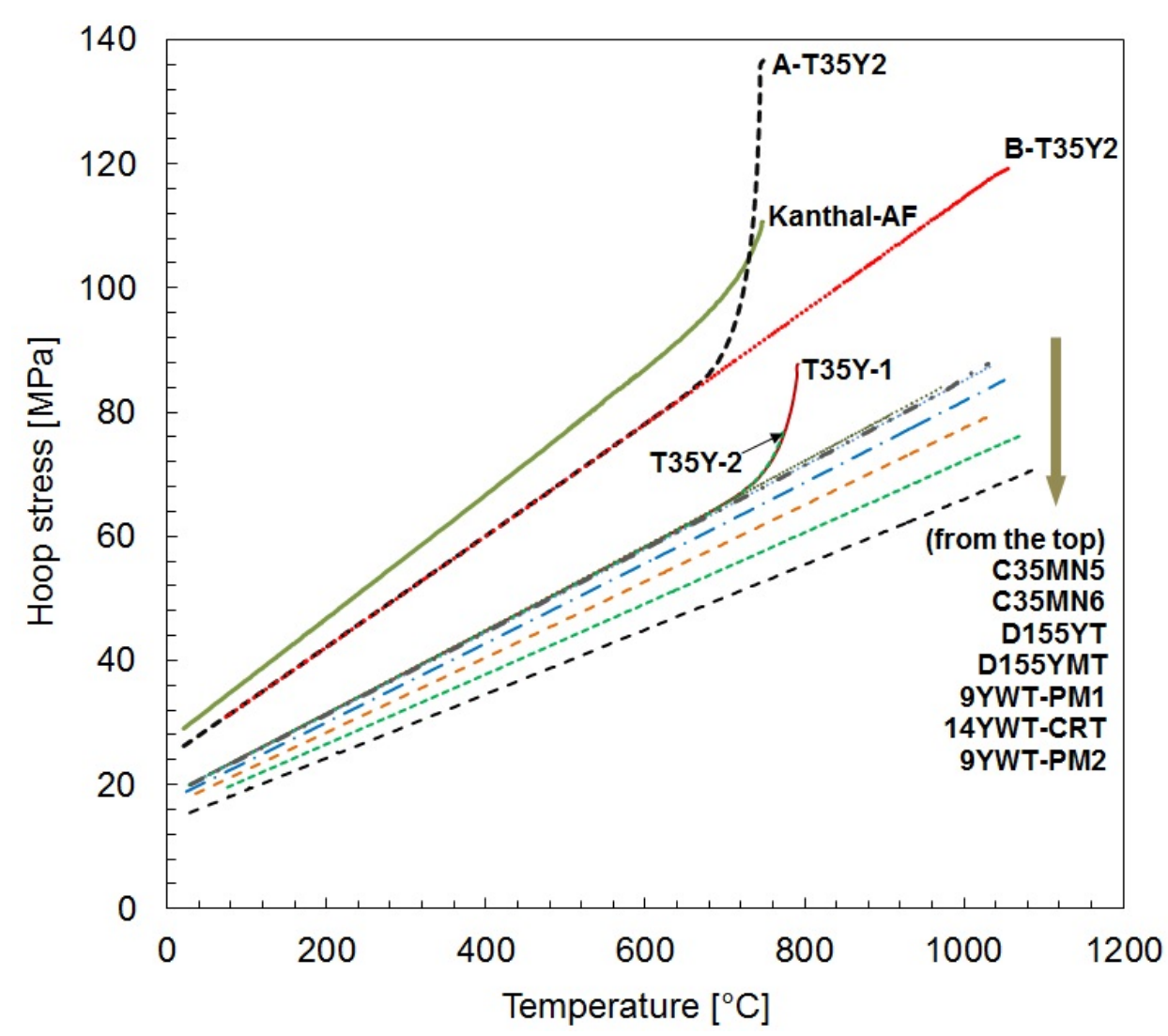

Figure 25. Temperature dependence of hoop stress in the wall of tubular specimen. The differences in wall thickness and diameter resulted in significantly different hoop stresses.

\subsubsection{High-temperature plastic (creep) deformation behavior}

The most unique output of the present in situ testing method should be the in situ creep rate data from the ballooning tube specimens. In the fuel behavior analysis under accident conditions, the creep test data, which are usually obtained through multiple static creep or tensile tests, have been used as input for the constitutive equation of high temperature deformation [17]. Such an approach of using static test data, however, may not correctly simulate the actual 'dynamic' cladding deformation under biaxial loading as the most important controlling parameters for deformation, i.e., temperature and true stress, keep increasing during a LOCA. The typical primary-steady-tertiary creep stages cannot be defined but the creep curve may be described by a transition from consecutive primary creep stages in relatively low temperature region to near 'instant' plastic deformation just before rupture. As it is aimed, the present in situ testing method can provide the strain rate data under such constantly changing condition. For the specimens ballooned and ruptured, the hoop strain rate was calculated and displayed in Figure 26. Note that the non-permanent deformation such as thermal expansion and elastic deformation is much smaller than the permanent (plastic) deformation: at a heating rate of $\sim 10^{\circ} \mathrm{C} / \mathrm{s}$, for example, the non-permanent strain increased at a rate of $\sim 1 \times 10^{-6} \mathrm{~s}^{-1}$.

A few unique behaviors can be found from these strain (creep) rate data, which might originate from the transitional deformation in a simulated accident condition differs significantly from those of static creep or tensile testing at fixed conditions: First, the strain rate in logarithmic scale 
increases almost linearly with test temperature. This indicates that the creep or plastic deformation is rapidly accelerated with temperature, which is because the increasing temperature lowers the strength of materials but increases internal gas pressure. Further, the thickness being thinned with deformation should significantly contribute to the strain rate being accelerated. Second, the strain rate measurements range from $10^{-6} \mathrm{~s}^{-1}$ to $10^{-3} \mathrm{~s}^{-1}$. Such a significant increase in strain rate confirms that the plastic deformation during heating at a nominal heating rate of $\sim 10$ ${ }^{\circ} \mathrm{C} / \mathrm{s}$ has started at a rate of slow (creep) deformation but ended at a typical rate of static tensile testing at burst temperature. The majority of plastic strain to burst should result from the quasistatic plastic deformation as in a low strain rate tensile testing.

Third, a lower slope of strain rate in the semi-log curve is found for the Kanthal-AF tube compared to those of the other three specimens (K35Y-1, -2, and A-K35Y2), which all show similar slopes. It is also noted that the creep strain in Kanthal-AF starts to increase at a relatively low temperature of $\sim 610^{\circ} \mathrm{C}$ but the creep deformation ends at the lowest value of $6.7 \%$ among the burst FeCrAl specimens, Figure 23. A cause for these differences in creep rates could be the difference in their chemistries: the Kanthal-AF has 21wt.\% chromium in it and the others have $\sim 13 \mathrm{wt} . \%$. It has been shown that in $\mathrm{Fe}-\mathrm{Cr}$ steels the resistance to creep rupture decreases from the peak at $10 \%$ chromium, although the effect of chromium on the creep rupture strength becomes complex in commercial steels as it forms various carbides, which is influenced by other alloy elements [18].

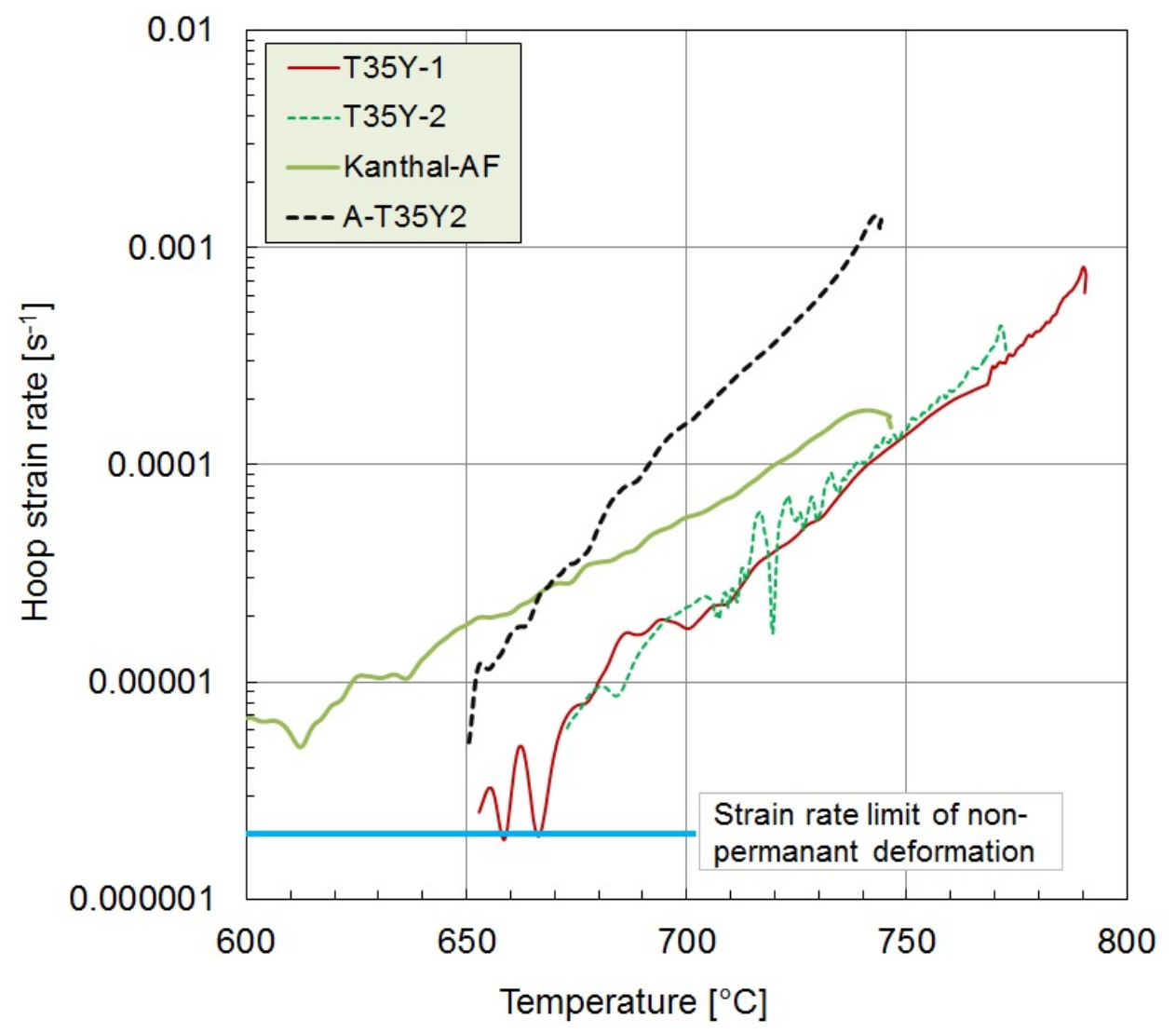

Figure 26. Creep rate versus temperature curves for relatively soft FeCrAl alloys: T35Y, Kanthal-AF, and A-T35Y2. 
The significant difference in strain rate $(\dot{\varepsilon})$ behaviors should be reflected in the creep parameters such as activation energy (Q) and stress exponent (n) when the creep rate data are fitted into a general form of creep equation [19,20]:

$$
\dot{\varepsilon}=A \sigma^{n} \exp \left(\frac{-Q}{R T}\right), \quad \text { (Eq. 1) }
$$

where $A$ is a coefficient determined by diffusion coefficient $\left(D_{0}\right)$ and elastic modulus $(G)$ and $R$ the gas constant $(8.314 \mathrm{~J} /(\mathrm{K} \cdot \mathrm{mole}))$. Table 8 lists the coefficients for the four ruptured specimens obtained by iterative curve fitting process. The values of stress exponent (n) are in a relatively narrow range of 2.9-4.5, which are relatively low values but well in the range of n-values for the dislocation creep in metallic materials (i.e., 3-8) [20]. The activation energy (Q) obtained for the $13 \mathrm{Cr}$ alloys are commonly about $250 \mathrm{~kJ} / \mathrm{mole}$, while the $21 \mathrm{Cr}$ alloy shows much lower value, $143 \mathrm{~kJ} /$ mole. For this Kanthal-AF case, the earlier start of deformation during heating can be explained by such low activation energy. It is also noted that the highest stress exponent is found for the Kanthal-AF and the highest stress sensitivity has resulted in relatively low rupture strain $(<10 \%)$.

Table 8. Summary of creep parameters

\begin{tabular}{|l|c|c|c|}
\hline Alloy & Strength Exponent $\mathrm{n}$ & Activation Energy $[\mathrm{kJ} / \mathrm{mole}]$ & Coefficient ${\mathrm{A}\left[\mathrm{s}^{-1}\right]}^{1}$ \\
\hline T35Y-1 & 3.7 & 248 & 82 \\
\hline T35Y-2 & 3.9 & 254 & 84 \\
\hline Kanthal-AF & 4.5 & 143 & $2.9 \times 10^{-6}$ \\
\hline A-T35Y2 & 2.9 & 258 & $2.2 \times 10^{+4}$ \\
\hline
\end{tabular}

Lastly, as shown in the above discussion, the traditional dislocation creep model (Eq. 1) could successfully describe the creep deformation behavior of tubular specimens during the simulated accident conditions. Elucidating the difference in those coefficients between the present tube testing, where the stress and temperature keep changing, and the traditional steady state creep testing should be interesting but beyond the scope of this study.

\subsubsection{Rupture temperature versus hoop stress with database}

The traditional tube burst testing to measure rupture stress and temperature is a well-established method that has helped accumulate a sizable database for fuel claddings [21]. In Figure 27 the rupture (burst) temperature versus hoop stress data of new alloys are compared to the database for Zircaloy, which are a collection of cladding rupture data in a variety of materials and pressurization conditions [21]. The comparison shows that the four data of relatively soft FeCrAl alloys, i.e., T35Y, Kanthal AF, and A-T35Y2, fall within the band of Zircaloy data. The tubular specimens of the other alloys with higher strength, including newly procured C35M3 tube, experienced little plastic deformation and no rupture until heating was stopped and, as indicated in Figure 27, their rupture temperatures are expected to be higher than $1100^{\circ} \mathrm{C}$.

During a postulated LOCA, the reactor coolant pressure may drop below the internal fuel rod gas pressure and cause the fuel cladding to swell and rupture in some conditions [17,21]. The severity of the accident would determine the core structure behavior such as the time at which swelling and rupture occur, the magnitude of swelling, the resulting coolant flow blockage, and eventually release of fuel fragments and fission product. Although having many specimens 
without bursting is one shortcoming in the present burst experiment, the data can be still used to demonstrate that a fuel cladding with higher strength can suppress plastic deformation and delay rupture during accident. This can lead to maintaining fuel channel cooling capability for longer time and to a lesser fuel material release. The high strength itself offers more accident tolerance.

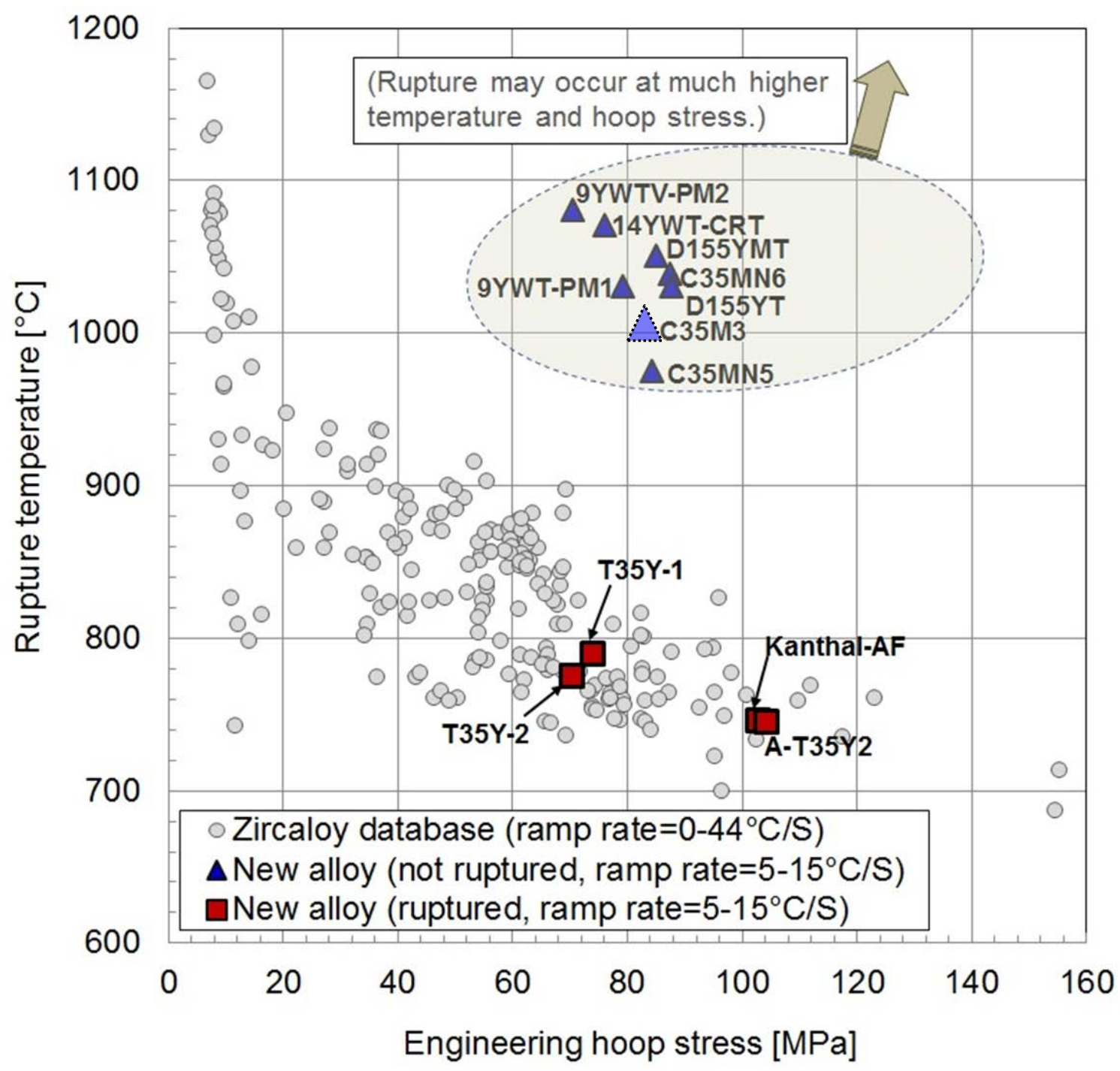

Figure 27. Comparison of rupture temperature versus hoop stress data. The Zircaloy database is from the reference [21] which integrates the results of tube burst tests by international institutes. 


\section{POST-TEST STRUCTURE CHARACTERIZATION}

\subsection{Specimens to Be Characterized}

As discussed in Chapter 5, three different materials demonstrated deformation and fracture during the tube burst testing in the present study. Two burst-tested specimens, T35Y\#1 and AT35Y2, were selected to conduct microstructure characterization because of the largest diameter change (see Table 6). More apparent microstructural change is expected compared to the asreceived materials, which would help describing the ballooning or the bursting sequence.

\subsection{Experimental Methods}

Each specimen was cut into five pieces for the transverse direction analysis and 2 pieces for the longitudinal cross-section analysis, as shown in Figure 28. The cross-sectional samples were mounted in an epoxy resin, ground and polished in conventional technique, and then etched for microstructure observation. The mounted and polished specimens are also shown in Figure 29. Optical microscope (OM) and scanning electron microscope (SEM) equipped with energy dispersive spectroscopy (EDS) were used for microstructure characterization and compositional analysis of the second-phase particles.

(a) T35Y,\#1

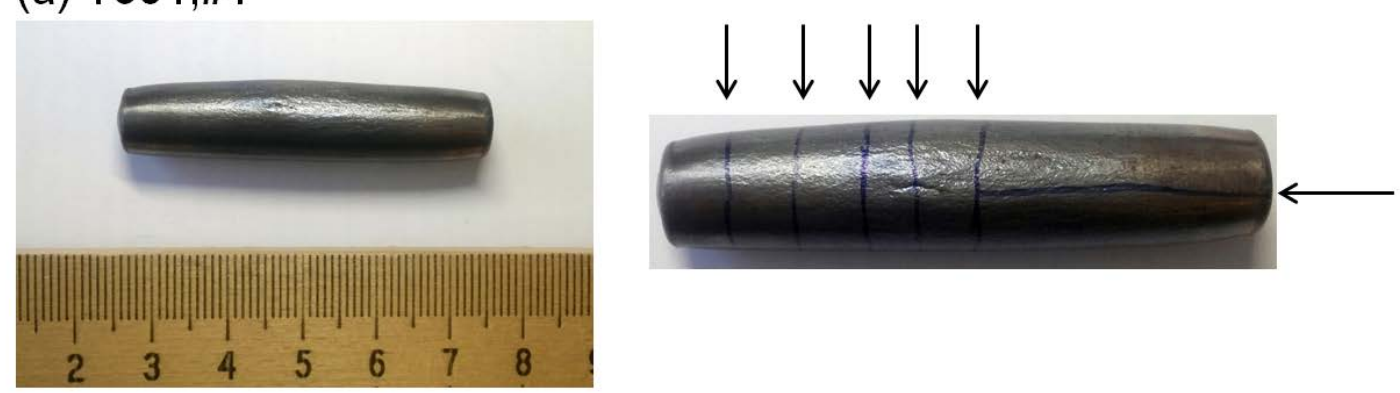

(b) A-T35Y2,\#1

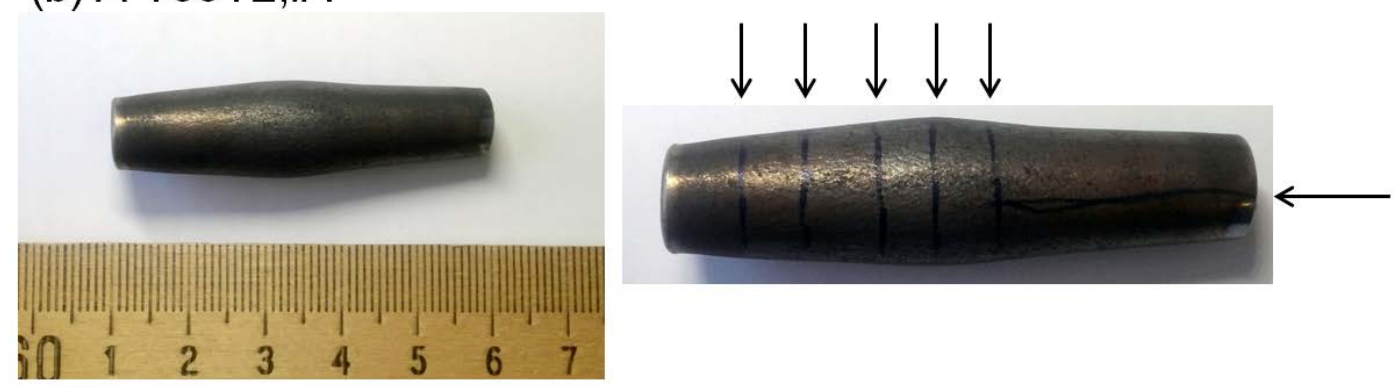

Figure 28. Tested specimens and the scheme of their cutting; (a) T35Y, \#1, and (b) A-T35Y2, \#1 


\section{(a) T35Y,\#1}
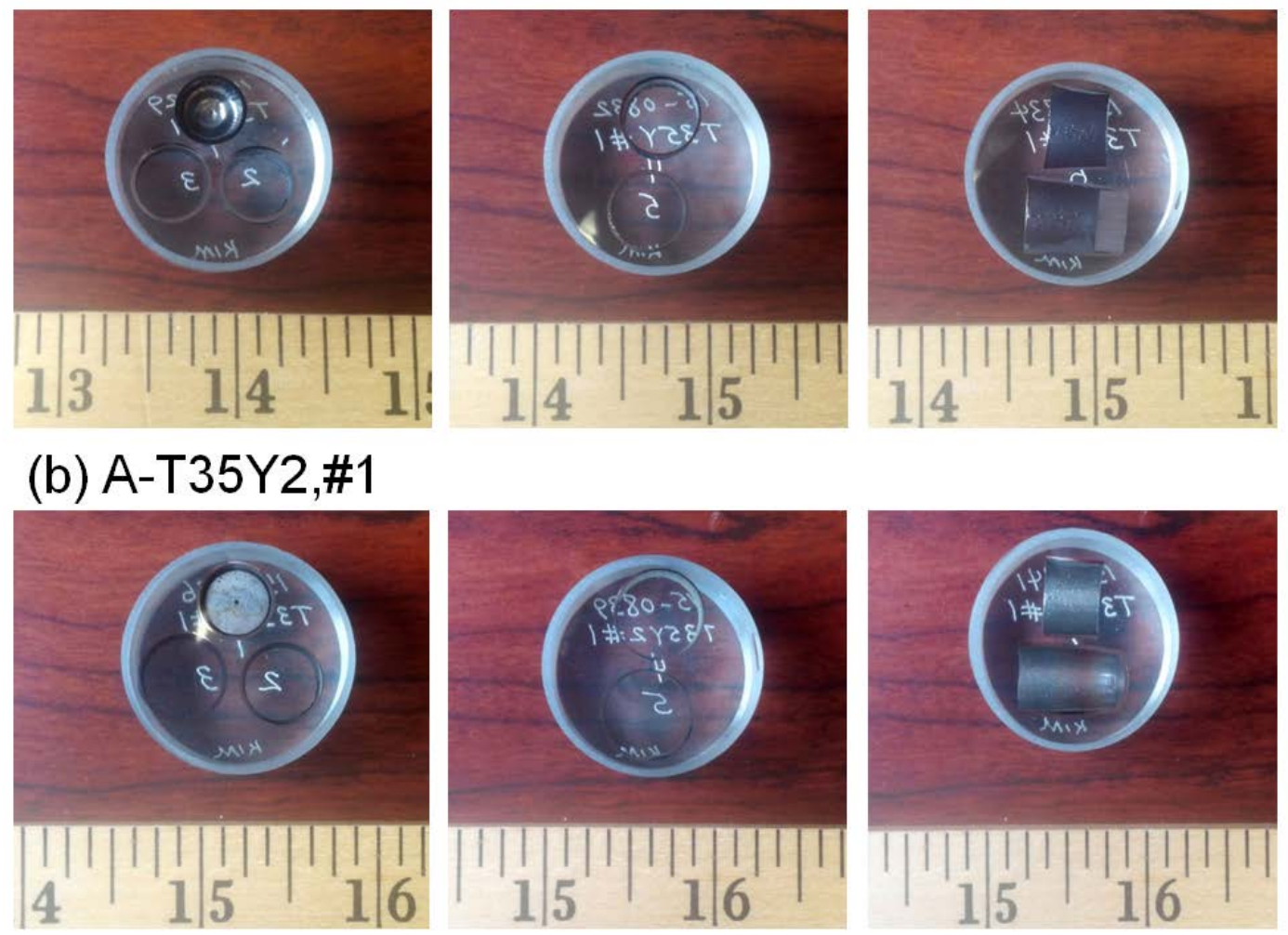

Figure 29. Mounted and polished samples of (a) T35Y, \#1, and (b) A-T35Y2, \#1;. Left, middle: transverse direction; right: longitudinal direction.

\subsection{Structure Evolution during High-Temperature Test}

\subsubsection{Optical microscope analysis}

The prepared cross-sectional samples were investigated in terms of the wall thickness, grain size, as well as dispersion of the second phase particles. In the T35Y \#1 specimen, the wall thickness became thin at the burst side (corresponding to "thin side" in Figure 30a), suggesting strong gradients in plastic strain from the other side ("Thick side”). The grain size of the sample ends near " 1 " showed no significant changes in the grain size compared to the as-received material (not shown in the figure). Grain growth was observed at the necking area "4", and the coarser grain could also be seen in the areas “ 3 ” and “5”. The A-T35Y2 \#1 specimen showed gradual thickness thinning as go to the burst location. Both the burst side and the other side were thinned in a similar manner, which could be due to thinner starting wall-thickness than that of T35Y \#1 (= larger hoop stress). Pronounced grain growth was observed for the whole specimen, and the final grain size was larger compared to the T35Y \#1 specimen. The average wall-thickness of each location of both specimens is summarized in Table 9.

High magnification OM pictures are shown in Figure 31. Globular shape particles with less than $100 \mu \mathrm{m}$ size were observed in the T35Y \#1 specimen, and their morphology was close to the particles observed in the as-received material. The particles in T35Y \#1 seem smaller than that of A-T35Y2 (no quantitative analysis was made). The particle shape and morphology in the 
materials before and after testing did not show a significant difference, indicating that the burst test conditions scarcely affected the second phase particle dispersions.
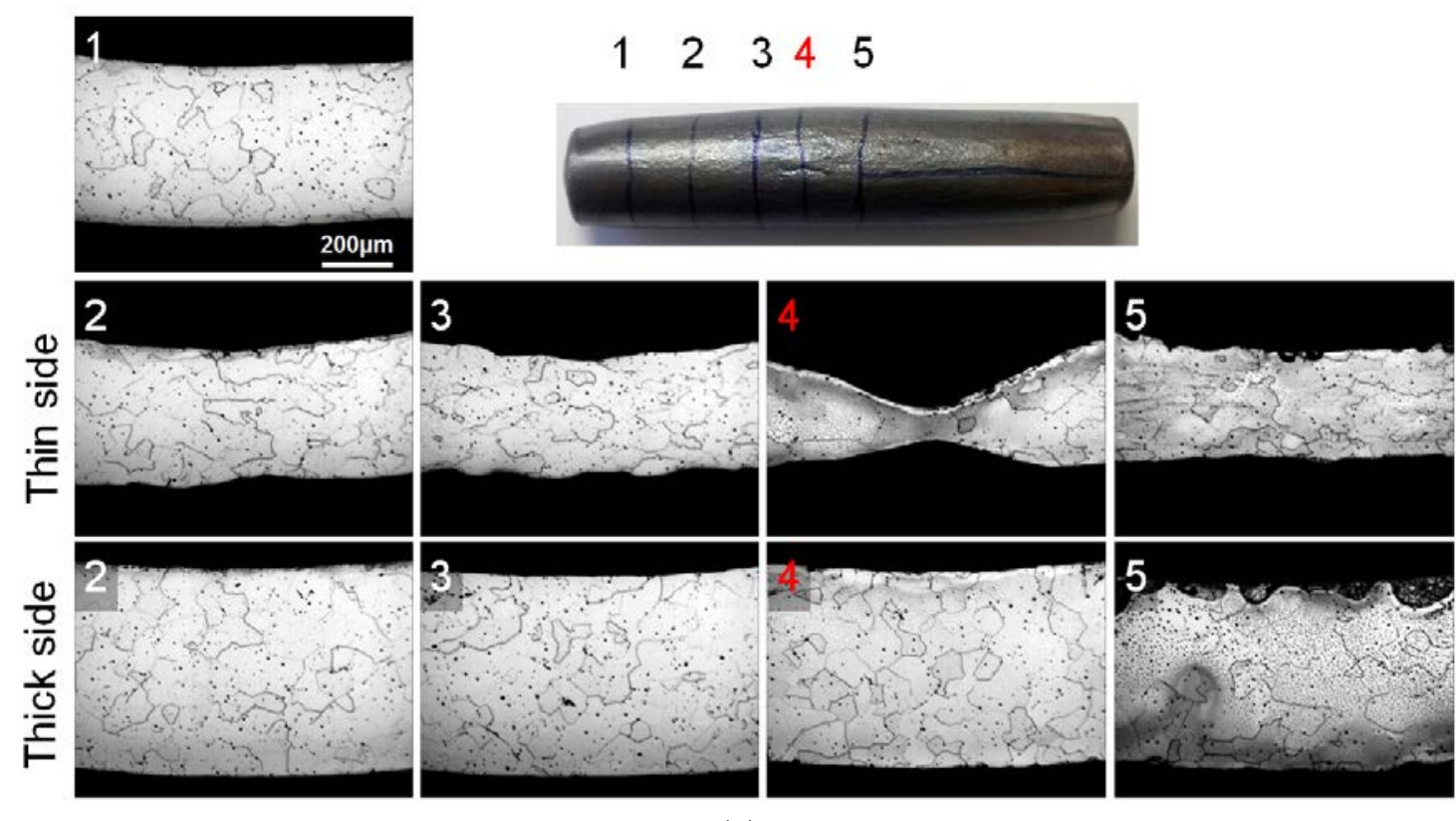

(a)
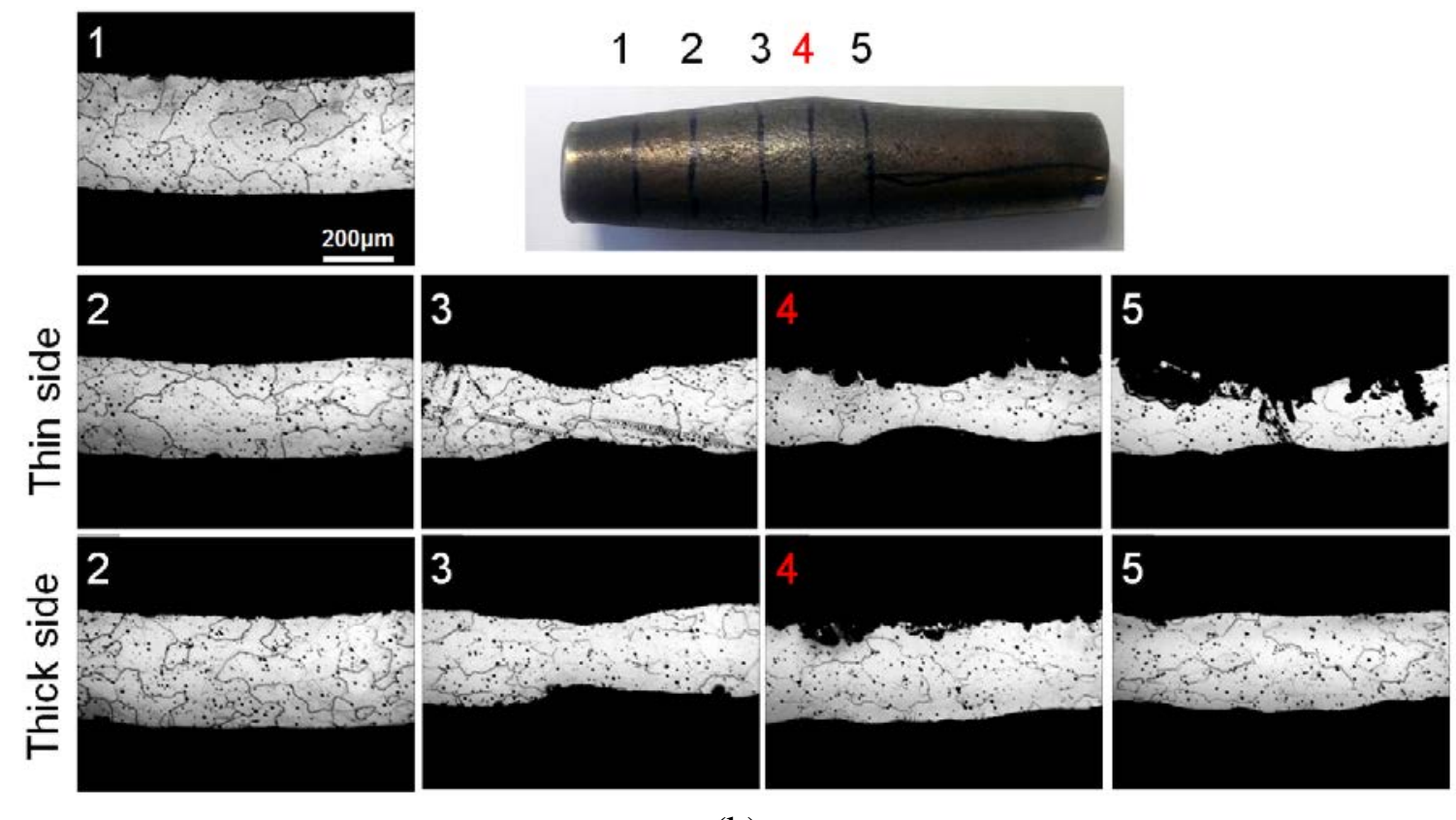

(b)

Figure 30. Optic images of the specimen microstructure. 1-5: different locations along the tube specimen length. (a) T35Y\#1 and (b) A-T35Y2,\#1. 
Table 9. Average wall thickness of the tubes before and after testing (in micrometer)

\begin{tabular}{|c|c|c|c|c|c|c|}
\hline \multirow{2}{*}{ Sample } & \multirow{2}{*}{ As-received tube } & \multicolumn{5}{|c|}{ After burst testing } \\
\cline { 3 - 7 } & & $\# 1$ & $\# 2$ & $\# 3$ & $\# 4$ (necking) & $\# 5$ \\
\hline T35Y, \#1 & n.a. & 467 & 357 & 319 & 81 & 276 \\
\hline A T35Y2, \#1 & 357 & 324 & 276 & 157 & 119 & 157 \\
\hline
\end{tabular}

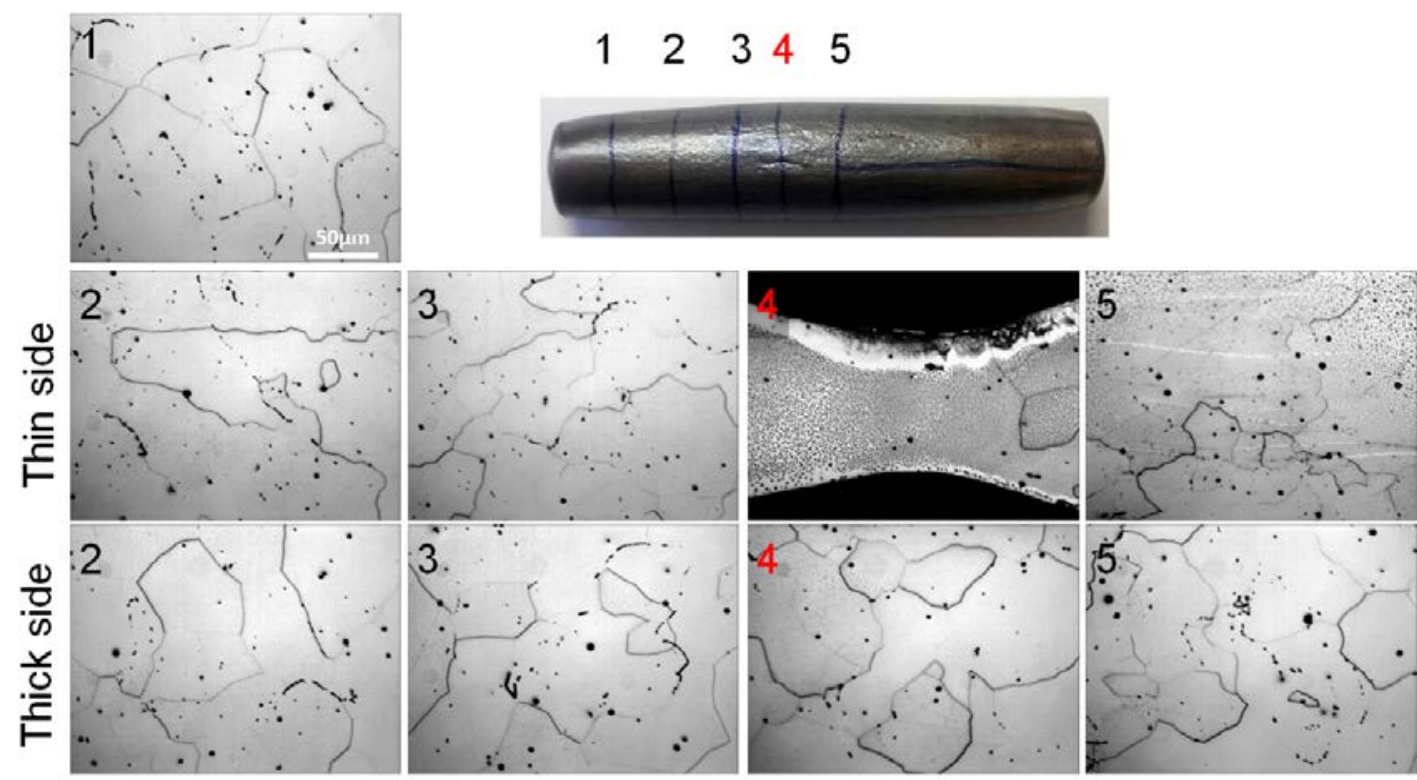

(a)

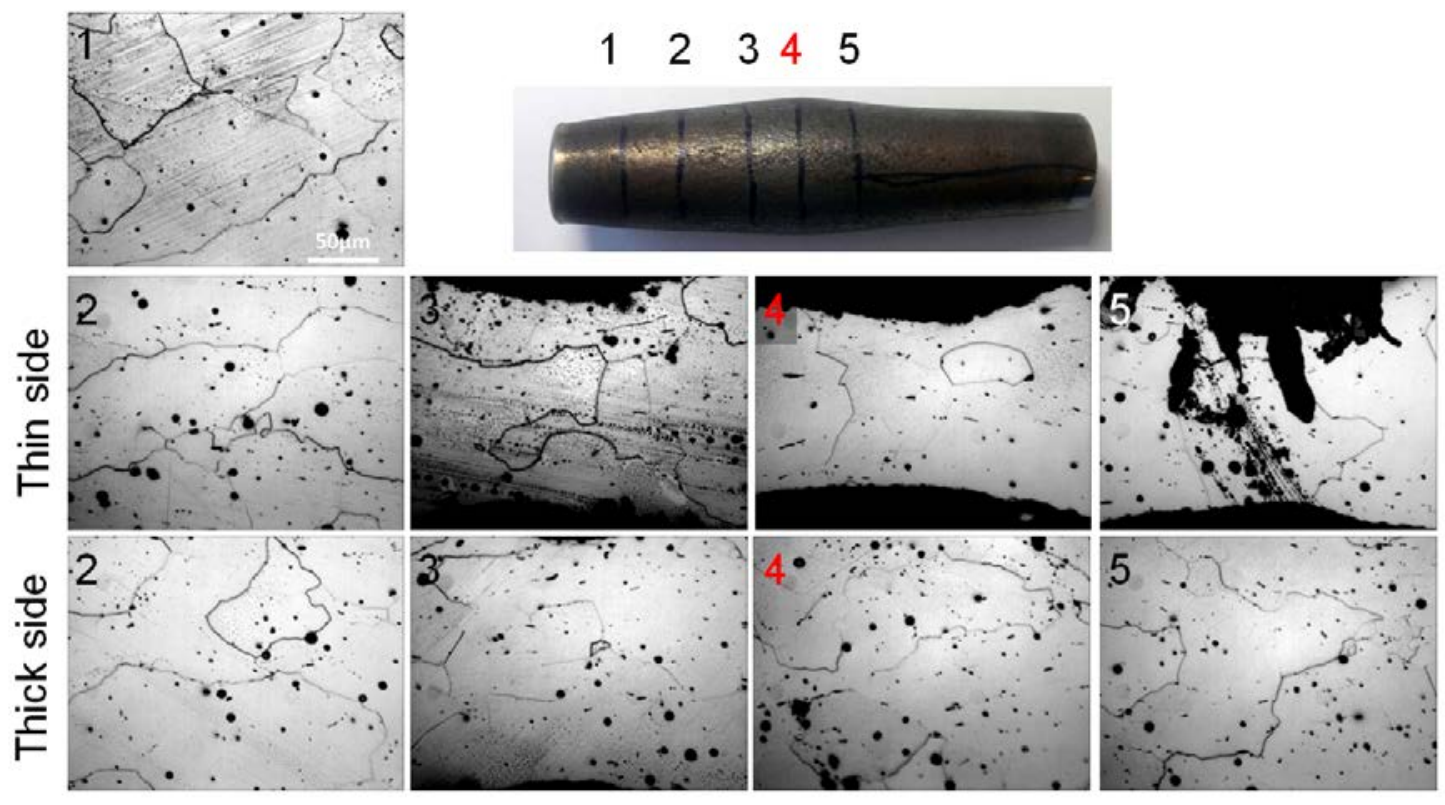

(b)

Figure 31 Microstructure at different locations. Position \#4 corresponds to the neck location. (a) T35Y, \#1, and (b) A-T35Y2, \#1 


\subsubsection{Electron microscope analysis}

SEM analysis was conducted to characterize sub-micron-scale microstructures, including cracks, particles, and sub-grains. Figure 32 shows the secondary electron images taking from various sections of the tested specimens.

In the T35Y\#1 specimens, cracks were frequently observed in the area " 1 ” and " 2 ” along the grain boundary, but the number decreased close to the necking position and become zero at the necking area. Each grain consisted of fine equi-axial sub-grains, and the size became smaller as one moved closer to necking area. Such sub-grain structure formation indicated that strong deformation was introduced and dynamically recovered. The heavy plastic deformation and high temperature might also cause dynamic recrystallization as well.

Globular shaped particles were evenly dispersed in a matrix of the burst-tested sample. Similar particle distribution was also found in A-T35Y2 \#1. SEM-EDS analysis indicated that they are yttrium-rich oxide particles which formed during solidification process of the materials. The particles were aligned along the rolling direction, which was typically observed in any of the wrought FeCrAl alloys in the present study. It should be noted that many holes with a morphology similar to the particles was observed in the T35Y1 \#1 specimens, which should correspond to the yttrium-rich oxide particles but they might be dissolved or removed during the etching process.

Figure 32b indicated that the cracks were rarely observed in A-T35Y2 \#1 specimen. The measured grain and sub-grain sizes, summarized in Table 10, indicated that recrystallization and grain growth were evenly occurred everywhere in A-T35Y2,\#1, which was quite different features observed at the necking area in T35Y1\#1 specimens. Since the chemistry or the initial microstructures are not so different between T35Y and A-T35Y2, the observed difference in the grain structure represented the effect of hoop stress. The mechanism is still not clear, and it requires further investigation.

Although the stress dependence of microstructure evolution is not clear, the whole result suggested that the microstructure stability at elevated temperature would be key for preventing the deformation concentration. Since the Nb additions improved not only the high temperature strength but also the thermal stability of the deformed microstructure [15], it is more important to design the alloy with stable microstructure. The optimization effort of the alloy composition is currently in progress. 


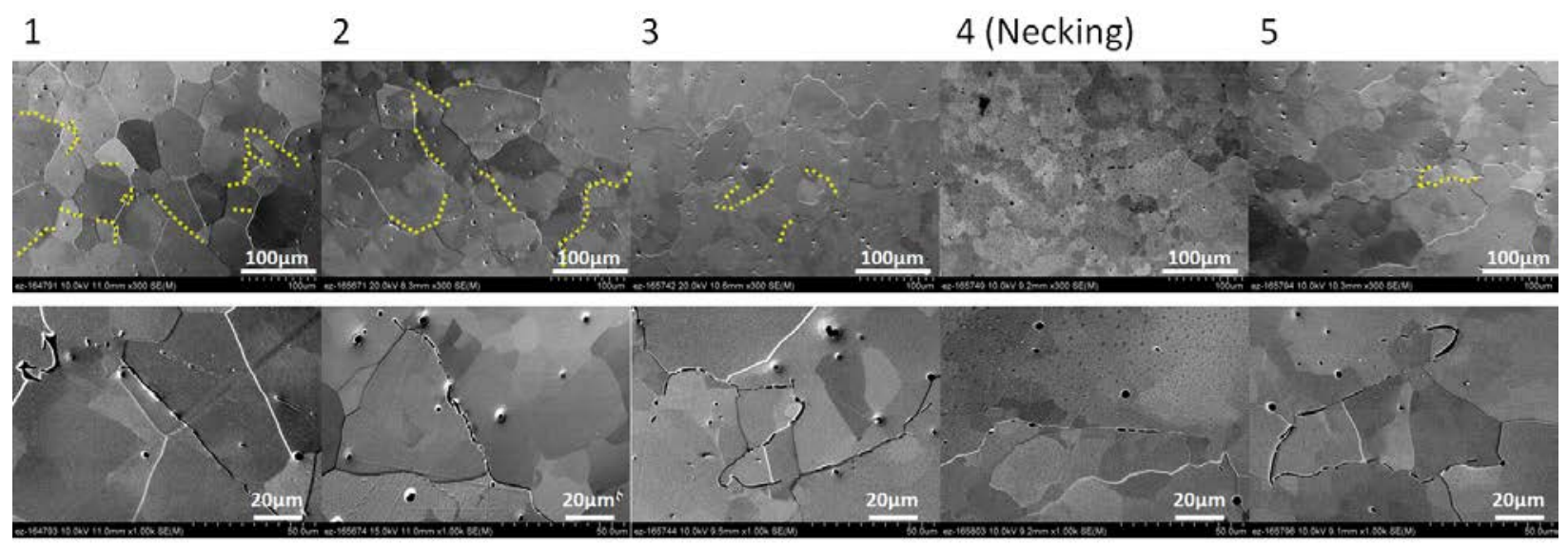

(a)

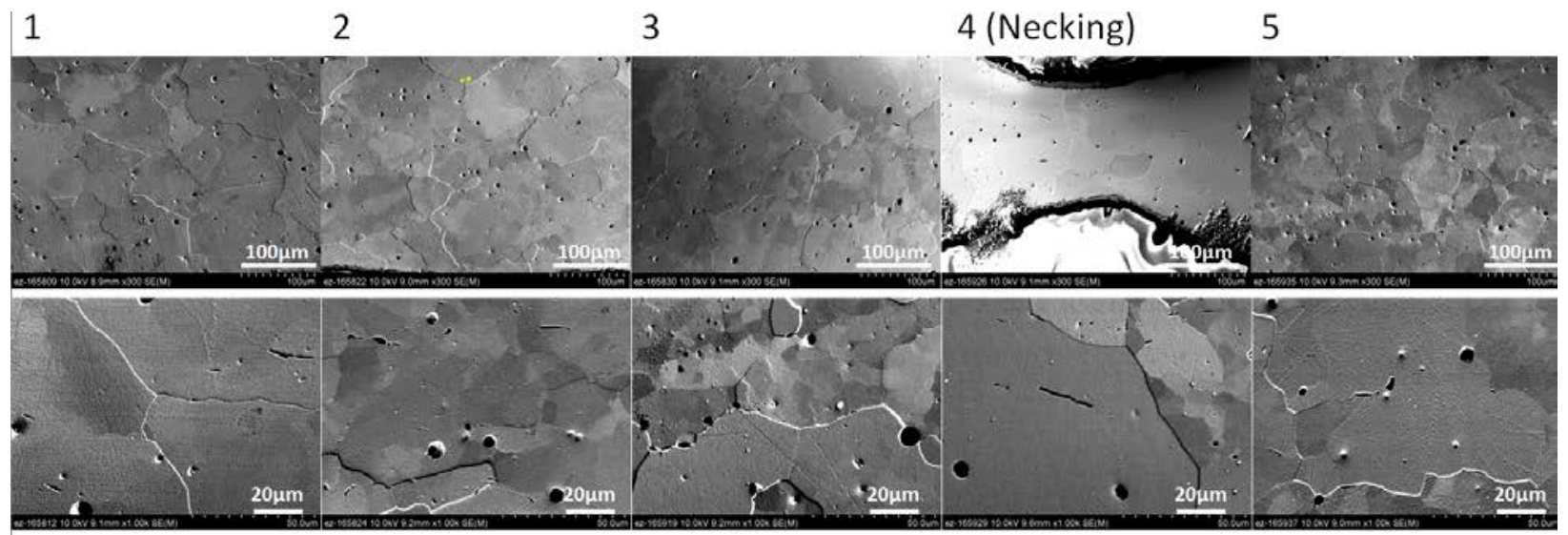

(b)

Figure 32 SEM image depending on distance from necking location, (a) T35Y\#1 and (b) AT35Y2,\#1.

Table 10. Average grain size of the tubes before and after testing (in micrometer)

\begin{tabular}{|c|c|c|c|c|c|c|}
\hline \multirow{2}{*}{ Sample } & \multirow{2}{*}{ As-received } & \multicolumn{6}{|c|}{ After burst testing } \\
\cline { 3 - 7 } & & $\# 1$ & $\# 2$ & $\# 3$ & $\# 4$ (necking) & $\# 5$ \\
\hline T35Y, \#1, Major grain & n.a. & 63 & 80 & 112 & 81 & 207 \\
\hline T35Y, \#1, Sub-grain & n.a. & 47 & 30 & 28 & 19 & 21 \\
\hline A T35Y2, \#1, Major grain & 54 & 108 & 115 & 65 & 60 & 79 \\
\hline A T35Y2, \#1, Sub-grain & 47 & 35 & 25 & 31 & 31 & 26 \\
\hline
\end{tabular}




\section{THE CONCEPT AND DESIGN OF THE ADVANCED IN SITU TESTING}

\subsection{Limitation of Existing Test Method}

Early in this project, a thin-walled tube testing technology based on a computer-controlled highresolution camera was designed and built to obtain in situ deformation and burst data for the cladding materials. This testing method allowed for producing the detailed in situ mechanical property data for the candidate accident tolerant fuel (ATF) claddings in simulated accident conditions (see Chapters 3 and 4). The newly built tube testing system was able to record and analyze the burst images of pressurized tube specimens as well as temperatures at multiple places during heating. It allowed for the detailed post-test strain distribution (Chapter 5) and microstructure analysis (Chapter 6).

However, some principal limitations were recognized. The first limitation was the narrow range of heating (ramp) rates, leading to difficulties with real LOCA simulations. The second limitation was the fixed internal pressure (2.07 MPa was used). The fixed (and relatively low) internal pressure limited the range of materials; modern high-strength alloys could not be tested to burst. Additionally, there was no possibility to use a controlled environment like hot steam. The temperature ramp rate was limited by the furnace design and heating method; conduction heating did not allow for ramp rates more than 10-20 degree per minute. Producing specimens with the internal pressure higher than $2.07 \mathrm{MPa}$ also might be an issue leading to price increment and potential safety concerns with keeping the pressurized objects. Also, it was difficult to combine the electric resistance furnace with the hot steam environment.

\subsection{Concept and Design of Advanced Test System}

To overcome the limitations discussed above, it was decided to design a new furnace combining the advantages of both systems: a possibility of fast heating under controlled pressure in a controlled environment (the existing LOCA testing station) with the direct observation and in situ measurements of the specimen geometry via optic methods proven in the previous configuration.

The use of optic non-contact measurements at high temperatures is a quickly growing research field with a number of approaches offered recently. Optic ports, band-pass filters, and special lighting conditions are widely used in the thermal expansion coefficient measurements, analysis of high-temperature deformation, etc. Recently, an extended high-temperature DIC method employing ultraviolet (UV) lights and special UV optics was offered [22]; this method almost completely eliminates the radiating light emitted by high-temperature specimens. Sometimes even more complicated solutions, based on X-ray imaging, are being employed for hightemperature measurements.

In the present project, it was decided to exclude any potential safety concerns and cost increase by staying away from ultraviolet or X-rays. The measurement in visible light was chosen as a main method. The brightness level may be controlled by neutral-density filters. As believed, the acceptable level of object visibility may be provided by contrast back screen. 
In current furnace configuration, the object is being heated with four light sources. Special parabolic-shape mirrors provide uniform temperature field. Thus, the minimally required modification is an optic port (through hole) in the furnace body. The port diameter should provide the observation of the object taking into account the increase in the object size during deformation. Also, a possibility to install additional glass windows should be considered.

Based on the design scheme (Figure 33, left) and budget limitations, the possible solution was discussed with potential vendors. One of the offered variants is shown in Figure 33, right. In this design, the light sources should be used "as is", without mirrors, and the internal furnace geometry allowed for free observation of the tube specimen. The design was analyzed and rejected since it was difficult to provide the uniform temperature field at the specimen surface.
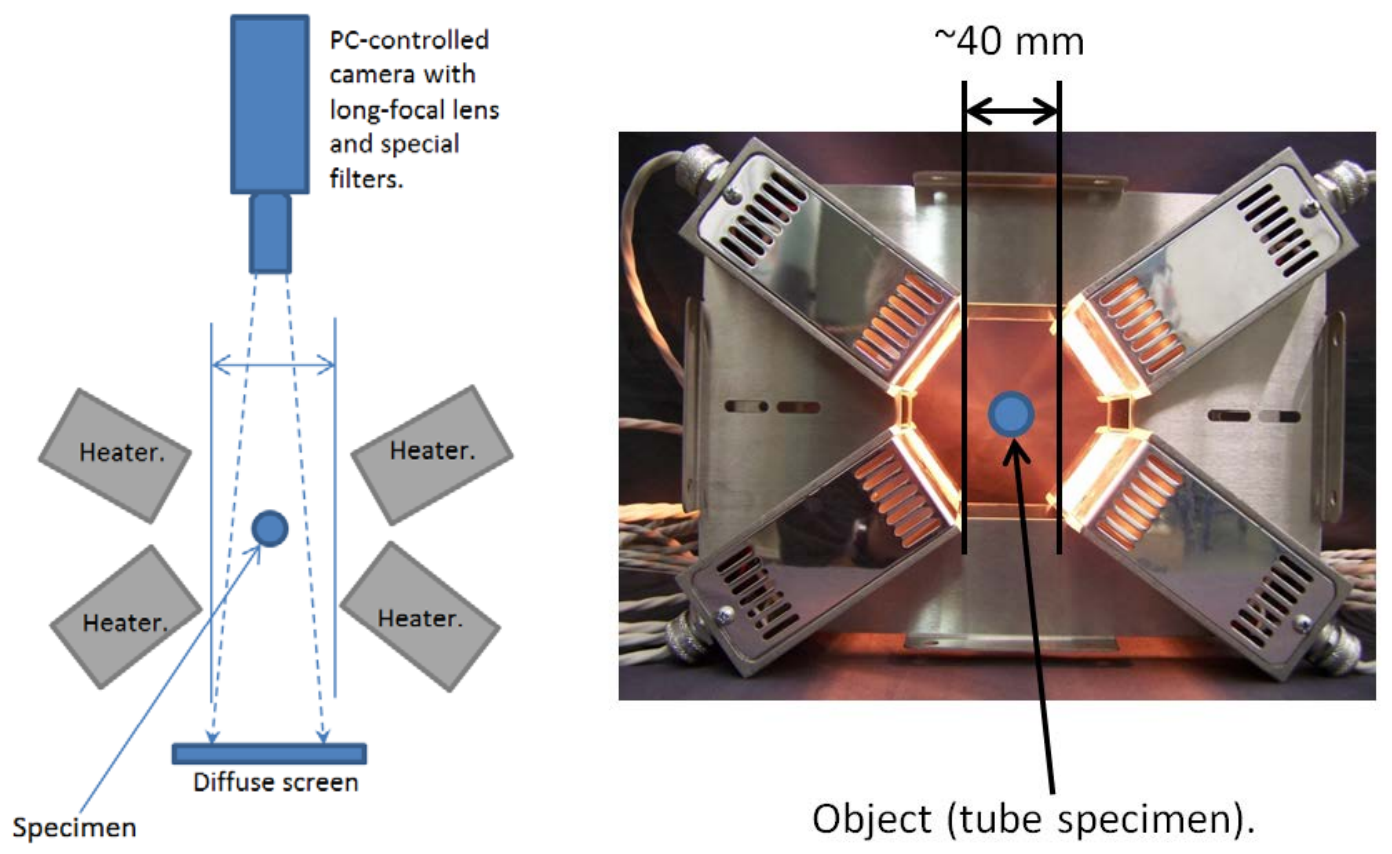

Figure 33. The scheme (at the left) and a general view of the first furnace offered by the vendor.

After additional discussion with the vendor, the mirrors were returned in the design scheme, and the furnace with the optic port was ordered, as shown in Figure 34 and Figure 35. The nonstandard design required additional changes in the water cooling system, geometry of water flow channels, etc. Finally, the modified furnace (Figure 36) kept full compatibility with the existing power sources and temperature measurement and control systems. 


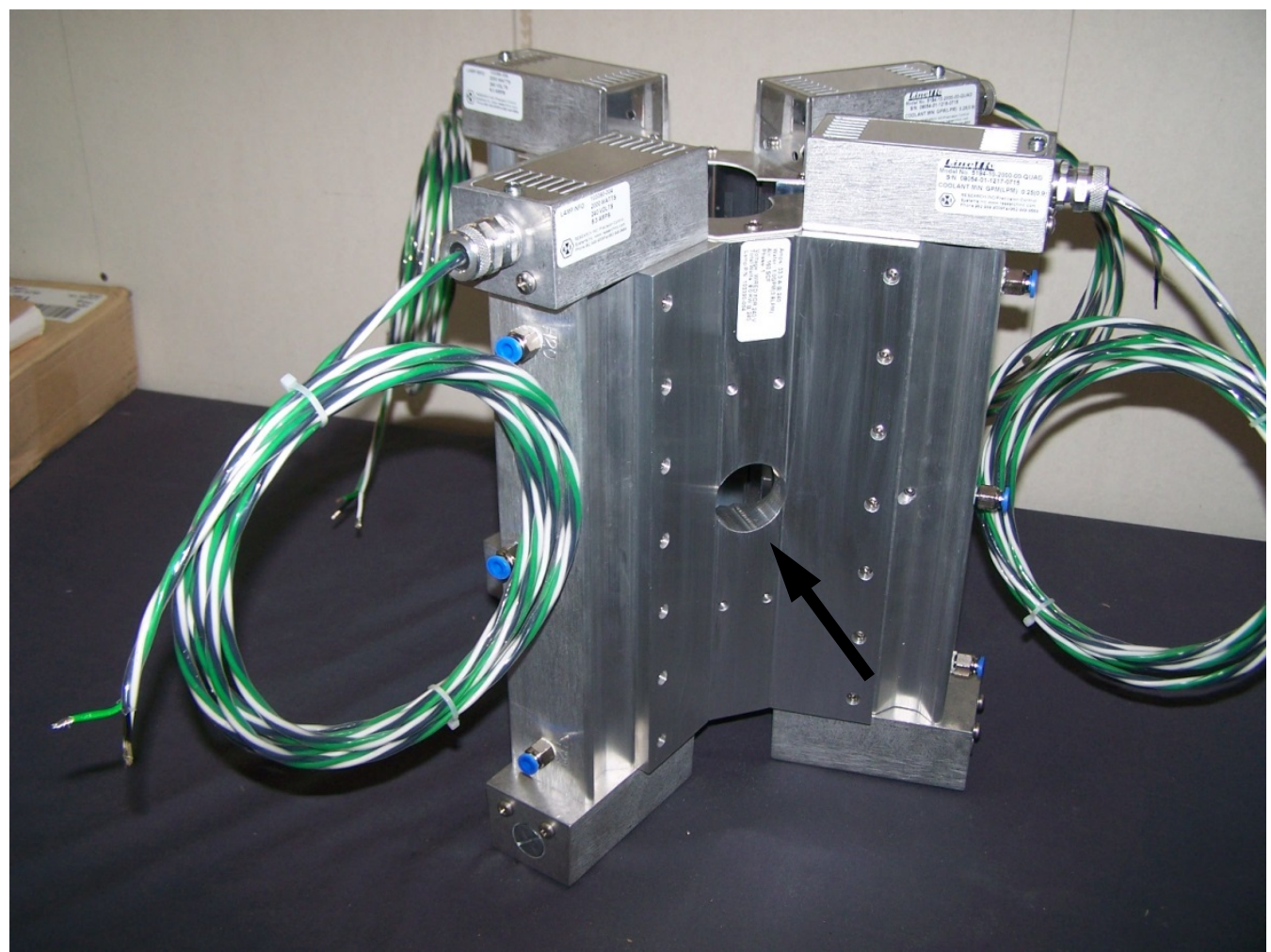

Figure 34. The general view of the modified furnace. The black arrow points the optic port. The design and geometry followed the light furnace used in the current test station.

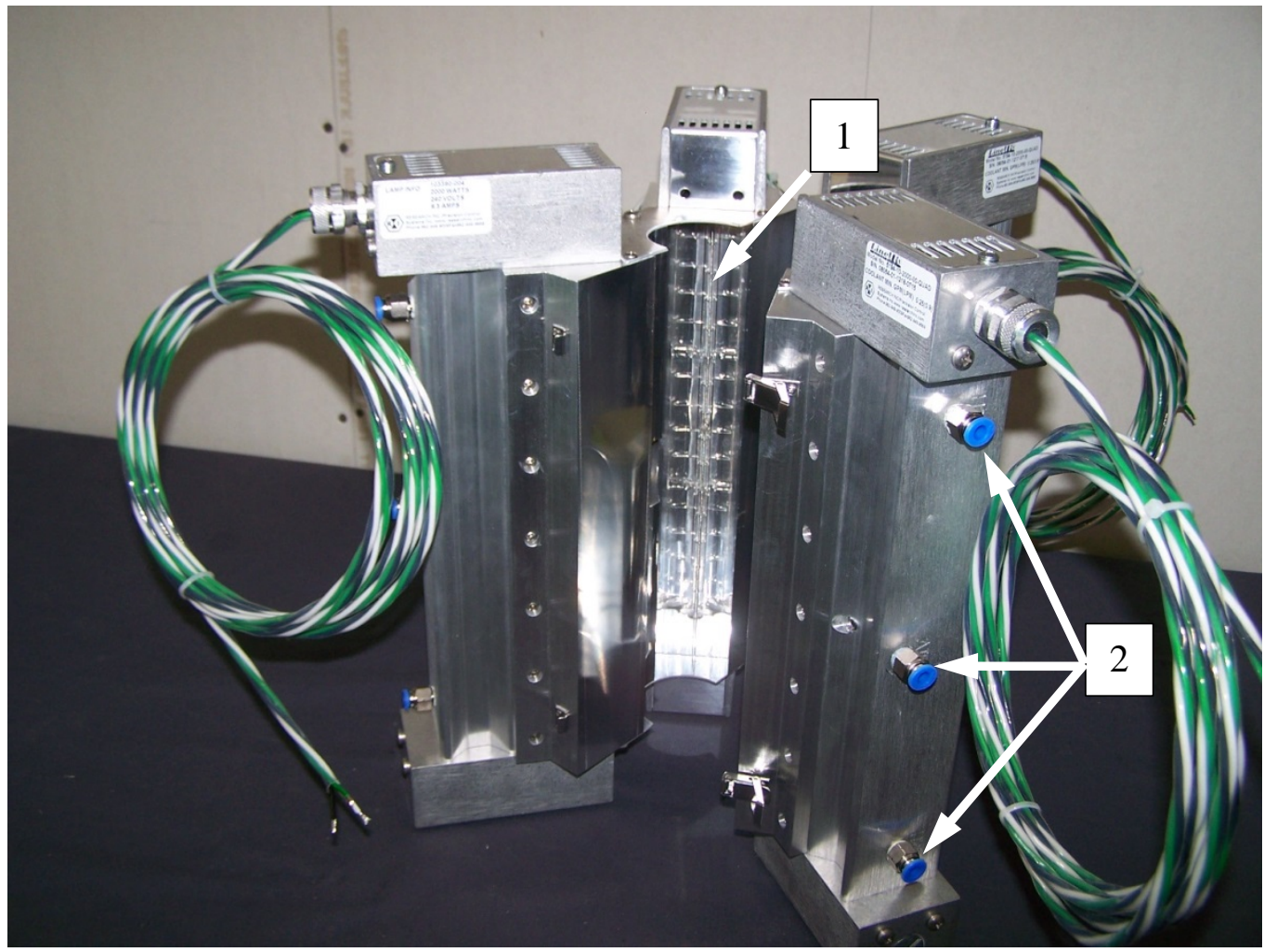

Figure 35. Modified furnace. 1 - light optic heater. 2 - water cooling channels. 


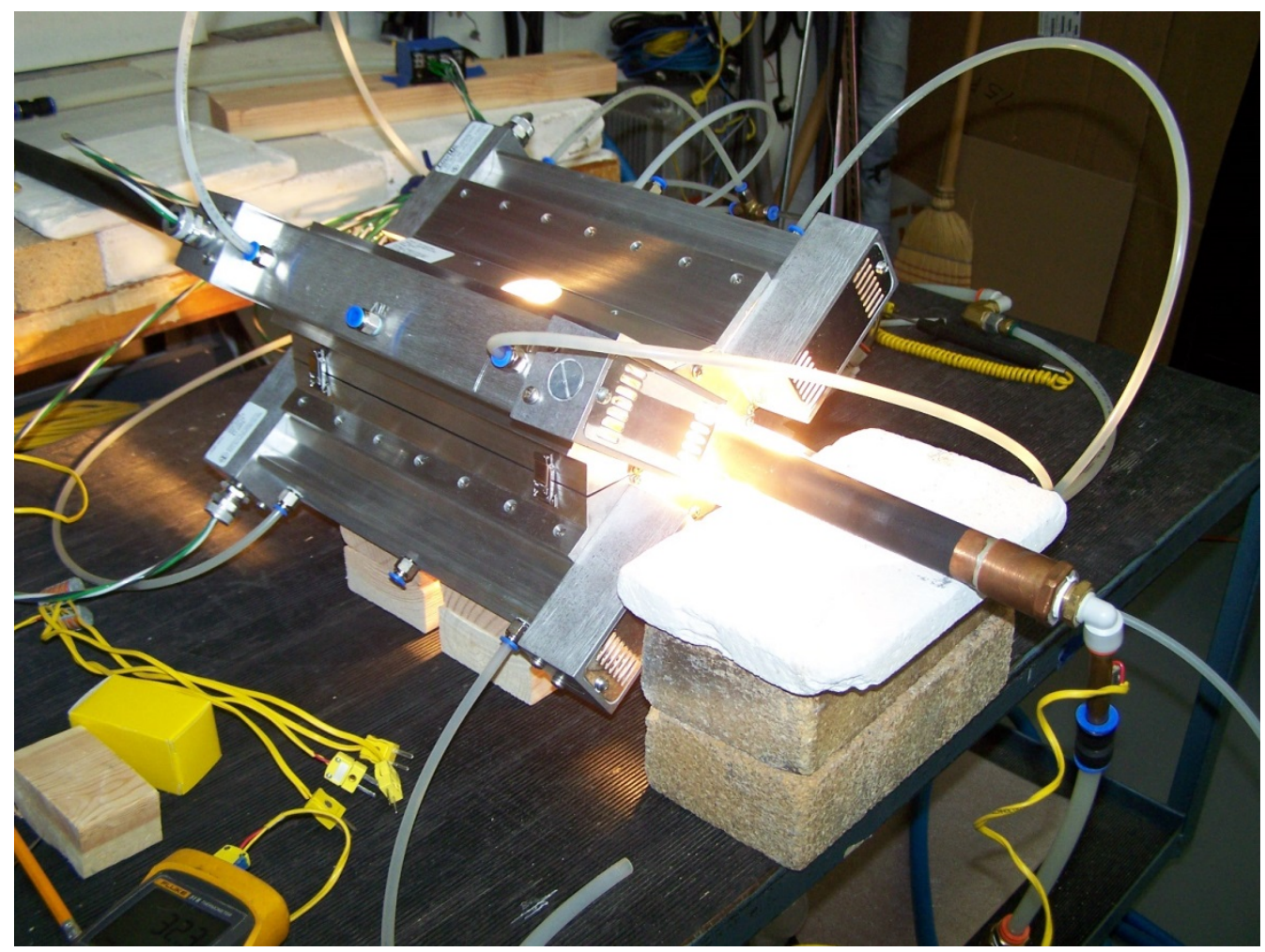

Figure 36. The final inspection of the furnace body (the image provided by the vendor).

The installation of the furnace and testing has been completed. A picture of the test run is shown in Figure 37. Due to modifications, safety inspection, paperwork, and getting approvals may take additional time before initiating the actual testing. As believed, the system will allow for testing tube specimens in a wide range of temperature ramp rates with the possibility to measure the specimen diameter change in situ. Pressure also may be varied in wide range providing a possibility to test modern high-strength materials like advanced ODS steels. 


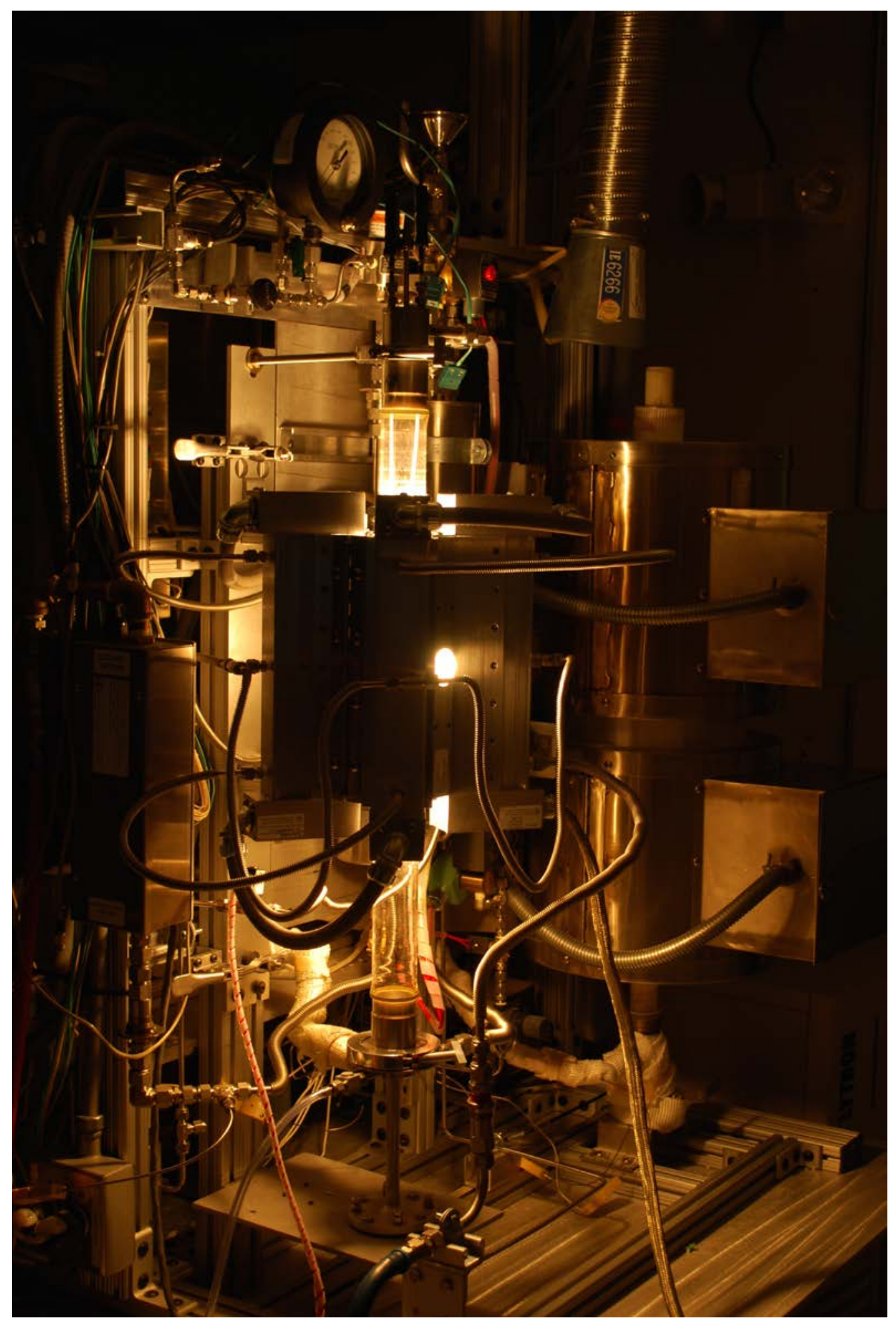

Figure 37. A picture showing the test run of new furnace installed in the test station 


\section{SUMMARY AND CONCLUSIONS}

This milestone report discussed two major topics; one is the optimization effort of the 2nd generation ATF FeCrAl alloys to date, especially focusing on the mechanical properties of both Phase I and Phase II alloys (model alloys and modified alloys, respectively) under the optimization process. It includes actual thin-wall tube fabrication efforts of the selected 2nd generation ATF FeCrAl alloys with a commercial tube-drawing company. The other is the tube burst behavior of various FeCrAl alloys via in situ deformation and burst observation captured by a high-temperature, high-speed digital camera. It contains not only the evaluation of the deformation sequence but also microstructure characterization to investigate the deformation mechanism.

Room temperature tensile properties of hot-rolled Phase I alloys were evaluated, and compared as a function of the $\mathrm{Cr}$ and $\mathrm{Al}$ additions in a composition range of $\mathrm{Fe}-(0-18) \mathrm{Cr}-(3-8) \mathrm{Al}-\mathrm{Y}$, in weight percent. It was found the tensile strength increased with increasing the Al content with a rate of $35-100 \mathrm{MPa} / \% \mathrm{Al}$ at a given $\mathrm{Cr}$ content. The $\mathrm{Cr}$ addition also increased the tensile strength, although the increasing rate was less than one third of the $\mathrm{Al}$ addition. It was also found the effect of the $\mathrm{Al}$ addition on the properties was minimized above $700^{\circ} \mathrm{C}$. Property evaluation of hot-processed Phase II alloys with minor alloying additions of Mo, Nb, and Zr indicated that nearly 50\% improvement of tensile strength compared to the Phase I alloy could be obtained by combining with the proper process condition (e.g. $2 \mathrm{wt} . \% \mathrm{Mo}+0.3 \% \mathrm{Zr}$ additions, hot-forged at $650^{\circ} \mathrm{C}$ ). The key factor for improving high-temperature tensile properties is the thermal stability of the deformed microstructure consisting of sub-grains. It was found that further investigation is required to understand the mechanism of the thermal stability improvement.

Thin-wall tube fabrication has been initiated with support from commercial manufacturers. The C35M3 (Fe-13Cr-5.2Al-2Mo-0.2Si-0.03Y) alloy was successfully drawn to be a thin-wall tube with $9.5 \mathrm{~mm}$ diameter and $<0.4 \mathrm{~mm}$ wall thickness through tube-drawing process with a mandrel at $320^{\circ} \mathrm{C}$. However, it was found that the property improvement from the $\mathrm{Al}$ or $\mathrm{Nb}$ additions actually poisoned the processbility of tube-drawing because the materials became too strong to deform at the process temperature, which limited the range of the alloy compositions that can be drawn.

The advanced in situ deformation and burst testing method has been developed to provide in situ data on material behavior at high temperature under simulated LOCA scenario. The specimen was a reduced length, pressurized tube produced by laser welding. The measurement method was based on visual imaging and allowed for the analysis of plastic strain behavior, creep properties, hoop stress and strain up to $1050^{\circ} \mathrm{C}$. A number of candidate materials were tested including $2^{\text {nd }}$ generation FeCrAl alloys and advanced ODS materials demonstrating the advantages of the in situ analysis.

Detailed microstructure characterization of the tube burst tested specimens (T35Y, \#1 and AT35Y2) was conducted, and compared with the as-received tube samples. As-received tubes consisted of uniform grain structure with around $70 \mu \mathrm{m}$ size, together with globular yttrium-rich oxides $(5 \sim 10 \mu \mathrm{m})$ dispersed in the grain interior and on the grain boundaries. Dynamically recrystallized grains as well as the creep voids were observed near the rupture area in the burst tested specimens. Large plastic deformation was also observed at the necking area. Both intergranular and trans-granular cracks were found at the ends of specimens. From the microstructure 
characterization, the localized plastic deformation seems to be a dominant factor of the tube burst, rather than the brittle fracture.

A decision was made to design a new furnace combining the advantages of both systems: a possibility of fast heating under controlled pressure in a controlled environment (the existing LOCA testing station) with the direct observation and in situ measurements of the specimen geometry via optic methods. The installation of the newly designed optical furnace with windows has been completed, and the test run to heat up to $1000^{\circ} \mathrm{C}$ without tube specimens was successfully conducted. The new system would allow performing the tube burst testing with various pressures and atmospheres, and evaluating the burst sequences directly. 


\section{REFERENCES}

[1] Powers, D.; Meyer, R. Cladding swelling and rupture models for LOCA analysis, NUREG0630; U. S. Nuclear Regulatory Commission: 1980.

[2] B. A. Pint, K. A. Unocic and K. A. Terrani, Materials at High Temperature, 32 (2015) 2835.

[3] M. Moalem, D.R. Olander, Journal of Nuclear Materials 182 (1991) 170.

[4] K. Suzuki, S. Jitsukawa, N. Okubo, F. Takada, J.Nucl.Eng. and Design 240 (2010) 12901305.

[5] M. Steinbrück, M. Große, L. Sepold, J. Stuckert, Nuclear Engineering and Design 240 (7) (2010) 1714-1727.

[6] Y. Yamamoto, Y. Yang, K.G. Field, K. Terrani, B.A. Pint, and L.L. Snead, "Determine viability of commercial heat production of ATF FeCrAl and issue summary report,” M2FT1 5OR0202252, Oak Ridge National Laboratory, to be submitted (2015).

[7] Y. Yamamoto, B.A. Pint, K. Terrani, K.G. Field, L.L. Snead, “Letter report documenting identifying billets and alloys fabricated for distribution to program” M3FT-13OR0202291, ORNL/LTR-2013/322, Oak Ridge National Laboratory (2013).

[8] P. Grobner, Metallurgical and Materials Transactions B, 4 (1973) 251-260.

[9] K.G. Field, X. Hu, K.C. Littrell, Y. Yamamoto, L.L. Snead, "Radiation Tolerance of Neutron-Irradiated Model Fe-Cr-Al Alloys,” Journal of Nuclear Materials, 465 (2015) 746755.

[10] H. Qu, Y. Lang, C. Yao, H. Chen, C. Yang, Materials Science and Engineering: A 562 (2013) 9-16.

[11] T.S. Byun, M.N. Gussev, Y, Yamamoto, “In-situ Tube Burst Testing for Advanced Cladding Materials” M3FT-14OR0202281, Oak Ridge National Laboratorym ORNL.TM2014/671 (2015).

[12] M.N. Gussev, T.S. Byun, Y. Yamamoto, S.A. Maloy, K. Terrani, "In-situ tube burst testing and high temperature deformation behavior of candidate materials for accident tolerant fuel cladding”, submitted to Journal of Nuclear Materials (2015).

[13] C. Massey, K. Terrani, B. Pint, S. Dryepondt, "Burst Behavior of Fe-based Alloy Cladding under LOCA Conditions," Transactions of the American Nuclear Society 112 (2015) 381384.

[14] B. A. Pint, S. Dryepondt, K. A. Unocic, and D. T. Hoelzer, JOM, 66 (2014) 2458-2466

[15] Y. Yamamoto, Y. Yang, K.G. Field, K. Terrani, B.A. Pint, and L.L. Snead, "Letter Report Documenting Progress of Second Generation ATF FeCrAl Alloy Fabrication, FY14 FCRD milestone report,” M3FT-14OR0202232, ORNL/LTR-2014/219, Oak Ridge National Laboratory (2014).

[16] Y. Yamamoto, B.A. Pint, K.A. Terrani, K.G. Field, Y. Yang, L.L. Snead, “Development and Property Evaluation of Nuclear Grade Wrought FeCrAl Fuel Cladding for Light Water Reactors,” submitted to Journal of Nuclear Materials (2015).

[17] T. Manngård, A.R. Massih, Modelling of nuclear fuel cladding under loss-of-coolant accident conditions, Report \# 2013:24 (ISSN: 2000-0456), Swedish Radiation Safety Authority (July 2013) (www.stralsakerhetsmyndigheten.se).

[18] T. Fujita, K. Asakura, H. Miyake, Trans. ISIJ, 22 (1982) 13-21.

[19] S.L. Robertson, O.D. Sherby, Acta Met. 17 (1969) 109-125.

[20] G.E. Dieter, Mechanical Metallurgy, 3rd Eds, McGraw-Hill Book Co., 1986. 
[21] D.A. Powers, R.O. Meyer, Cladding swelling and rupture models for LOCA analysis, NUREG-0630, USNRC, April 1980.

[22] X. Guo, J. Liang, Z. Tang, B. Cao, M. Yu, Optical Eng. 53 (2014) 063101. 